\title{
Assessment of molecular action of direct gating and allosteric modulatory effects of meprobamate (MiltownRTM) on GABA A receptors
}

Manish Kumar

Follow this and additional works at: https://researchrepository.wvu.edu/etd

\section{Recommended Citation}

Kumar, Manish, "Assessment of molecular action of direct gating and allosteric modulatory effects of meprobamate (MiltownRTM) on GABA A receptors" (2016). Graduate Theses, Dissertations, and Problem Reports. 6023.

https://researchrepository.wvu.edu/etd/6023

This Dissertation is protected by copyright and/or related rights. It has been brought to you by the The Research Repository @ WVU with permission from the rights-holder(s). You are free to use this Dissertation in any way that is permitted by the copyright and related rights legislation that applies to your use. For other uses you must obtain permission from the rights-holder(s) directly, unless additional rights are indicated by a Creative Commons license in the record and/ or on the work itself. This Dissertation has been accepted for inclusion in WVU Graduate Theses, Dissertations, and Problem Reports collection by an authorized administrator of The Research Repository @ WVU.

For more information, please contact researchrepository@mail.wvu.edu. 


\title{
ALLOSTERIC MODULATORY EFFECTS OF CARISOPRODOL (SOMA ${ }^{\circledR}$ ) ON
}

\author{
GABAA RECEPTORS
}

By

Manoj Kumar, B.Pharm.

Dissertation submitted to the School of Pharmacy at

West Virginia University in partial fulfillment of

the requirements for degree of

DOCTOR OF PHILOSOPHY

IN

PHARMACEUTICAL AND PHARMACOLOGICAL SCIENCES

COMMITTEE MEMBERS

Glenn H. Dillon, PhD., Chair

Jason D. Huber, PhD

Patrick S. Callery, PhD

Gregory M. Dick, PhD

Robert K Griffith, PhD

Department of Pharmaceutical Sciences

Morgantown, West Virginia

May 2015

Copyright 2015

Keywords: GABAA receptors, GABAA receptor isoforms, Carisoprodol, muscle relaxant, drug abuse 


\section{ABSTRACT \\ ASSESSMENT OF MOLECULAR ACTION OF DIRECT GATING AND ALLOSTERIC MODULATORY EFFECTS OF CARISOPRODOL (SOMA®) ON GABAA RECEPTORS}

Manoj Kumar, B.Pharm.

Carisoprodol is a centrally acting skeletal muscle relaxant frequently prescribed for the treatment of acute musculoskeletal conditions. Recreational use of carisoprodol is an increasing problem. Recent reports highlight the dangers involved in carisoprodol abuse, including severe withdrawal leading to seizures and death. Indeed, carisoprodol has been placed into schedule IV drug at federal level effective January 11, 2012 considering its alarming abuse rate. Until recently, it was widely accepted that the sedative effects of carisoprodol were due predominantly to its metabolite, meprobamate. Our lab recently concluded, that carisoprodol itself, at low concentrations allosterically modulates and at higher concentrations directly activates $\gamma$-aminobutyric acid, type A receptors $\left(\mathrm{GABA}_{\mathrm{A}} \mathrm{Rs}\right)$, the predominant inhibitory neurotransmitter receptor in mammalian brain. This may underlie the capacity of carisoprodol to enhance the sedative effects of CNS depressants, contributing to its potential for abuse.

$\mathrm{GABA}_{\mathrm{A}}$ receptors are member of the cys-loop receptor family that are heteropentameric ligand gated chloride ion channels and play a critical role in mediating fast inhibition in the brain. A diverse number of $\mathrm{GABA}_{\mathrm{A}} \mathrm{R}$ subunits as well as their isoforms have been identified including $\alpha$ (1-6), $\beta$ (1-3), $\gamma(1-3), \rho, \delta, \varepsilon$ and $\theta$. $\alpha \beta \gamma$ and $\alpha \beta \delta$ receptor (2:2:1 stoichiometry) isoforms are the predominant $\mathrm{GABA}_{\mathrm{A}} \mathrm{Rs}$ in the CNS. $\alpha \beta \gamma \mathrm{GABA}_{\mathrm{A}} \mathrm{Rs}$ generally located within the synapses mediating GABAergic phasic inhibition, whereas $\alpha \beta \delta$ receptors are preferentially targeted to extrasynaptic membranes inducing tonic inhibition. Each $\mathrm{GABA}_{\mathrm{A}} \mathrm{R}$ subunit is composed of a large extracellular $\mathrm{N}$ terminus, four transmembrane helices (TM1-TM4), one extracellular TM2-TM3 loop, two intracellular loops (TM1-TM2 and TM3-TM4), and an extracellular C terminus. TM2 from each subunit line the pore of the channel and gate. We hypothesized that carisoprodol modulates $\mathrm{GABA}_{\mathrm{A}} \mathrm{Rs}$ in a subunitdependent manner, possibly through a novel site of action, with different amino acid domains contributing to direct gating and allosteric modulatory actions of carisoprodol. We used HEK293 cells, stably and transiently expressing desired $\mathrm{GABA}_{\mathrm{A}}$ receptor and took advantage of whole cell patch clamp electrophysiology and site directed mutagenesis techniques to address following specific aims: 1) To identify subunit-dependent influence on direct gating and allosteric enhancement effects of carisoprodol on GABA $\left.{ }_{A} R s ; 2\right)$ To identify $\mathrm{GABA}_{\mathrm{A}}$ receptor subunit domains that confer carisoprodol sensitivity.

Our studies demonstrate direct gating and allosteric modulatory effects of carisoprodol are $\mathrm{GABA}_{\mathrm{A}}$ receptor isoforms dependent. Specifically, carisoprodol is most efficacious on $\alpha 1$ containing receptors for allosteric modulatory action and least efficacious on $\alpha 3$ containing receptors for direct gating action. Also, presence or absence of $\gamma$ subunit in 
$\mathrm{GABA}_{\mathrm{A}} \mathrm{R}$ does not affect carisoprodol direct gating and allosteric modulatory efficacy. Regarding $\delta$ containing extrasynaptic receptors, carisoprodol is more efficacious than GABA and potentiated the maximal GABA-gated currents like barbiturates and general anesthetics. Mutagenesis studies showed, transmembrane 4 domains of $\alpha$ subunit are involved in direct gating action of carisoprodol but not in allosteric modulatory action. Mutation of valine at 440 TM 4 domain of $\alpha 3$ subunit to corresponding $\alpha 1$ subunit residue leucine 415 significantly increased the direct gating efficacy of carisoprodol without affecting allosteric modulation properties. In corresponding reverse mutation experiments, mutation of $\alpha 1$ subunit residue leucine 415 to valine 440 residue of $\alpha 3$ subunit significantly reduced direct gating efficacy of carisoprodol but not allosteric effects. In physicochemical analysis of TM4 415 residue, polarity and volume of amino acid influenced the direct gating efficacy of carisoprodol. Taken together, our data indicate that carisoprodol interacts with distinct sites to allosterically modulate and directly gate $\mathrm{GABA}_{\mathrm{A}}$ receptors. Also, the pharmacological profile of carisoprodol at $\mathrm{GABA}_{\mathrm{A}}$ receptors coincide with its therapeutic effects, and carisoprodol's subunit-dependence property may underlie its potential for abuse. 


\section{DEDICATION}

I want to dedicate my work to my parents, Nirmla Devi and Om Prakash, for all the support, who stood by me during ups and downs, supported, inspired and encouraged me to go after my goals. I want to thank you with all my heart for everything. 


\section{ACKNOWLEDGMENTS}

I would like to thank these important people who have helped and guided me in achieving my goals.

Glenn H Dillon: I can't stress it enough, he is a great scientist, an amazing mentor and a very kind person. I am very grateful to you for the way you have groomed, guided and encouraged me during my graduate studies. You are the best mentor and boss one could have and I am blessed to have you as my mentor. I am also very thankful to you for a home like environment in lab away from home and for being like a family.

My committee member: Dr. Patrick Callery, Dr. Jason Huber, Dr. Gregory Dick and Dr. Robert Griffith their guidance, support, critical feedbacks and suggestions that have groomed me as a scientist and a critical thinker. I am very thankful to all of you for making this possible.

Cathy Bell Horner: An exceptional electrophysiology trainer and a down to earth person. I am very grateful to you for training me and for all the fun and friendly time in lab. We missed you here.

My past and current lab colleagues Cathy Bell Horner, Dr. Ren-Qi Huang, Dr. ZhengIan, John Freund and Manish Kumar for their help, constructive discussions and guidance during every step of my graduate studies and for a friendly and healthy lab ambience. Also Dr. Peter Gannet and Dr. Robyn Ayscue for helping me in molecular modeling. I really enjoyed working with you all.

Dawn Dillon: Family away from home. I am so grateful to you for all the love, kindness and blessings. For making me part of each and every festival and celebration. 
My family member; Naresh Kumar, Bharti Kumari, Raj Kumar, Rajesh Kumari, Archana Gaur, Hitakshi Prajapat and Daksha Prajapat for their love, support, inspiration and jokes and laughs we shared together. For being there for me despite the physical distance.

Rashmi Goyat: For all the support, motivation and love I get from you. For not hesitating in telling me when I am wrong, for being there for me and for moving to the United States, it made life much easier. I am very lucky to have you in my life.

My friends; Ankur Jain, Alaknanda Mudumby, Maninder Malik, Avani Mody, Yogesh Mishra, Monika Mittal, Harish Rathore, and all my friends from high school, DIPSAR, UNT and WVU for their friendship and love. I really admire you all, I am lucky to have you all in my life. 


\section{TABLE OF CONTENTS}

TITLE.

ABSTRACT

.ii

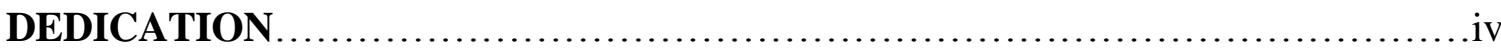

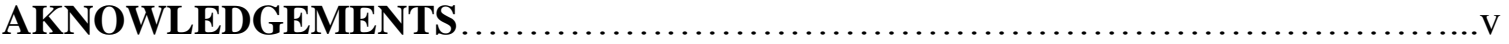

TABLE OF CONTENTS ................................................... vii

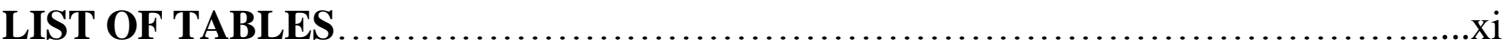

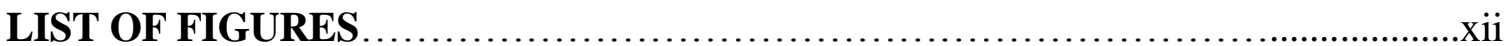

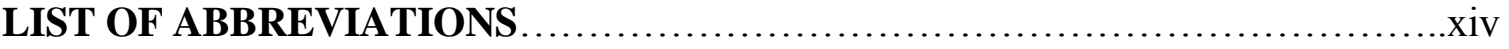

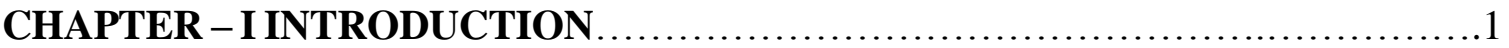

Clinical Use of Carisoprodol..............................................2

Pharmacokinetics and Metabolism........................................... 3

Abuse and Withdrawal Syndrome....................................... 8

Pharmacology of Carisoprodol..........................................13

GABA $_{\mathrm{A}}$ Receptors.................................................16

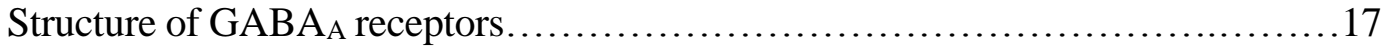

Ion conduction and Mechanism of action..................................26

Modulation of $\mathrm{GABA}_{\mathrm{A}}$ receptors....................................28

Distribution and Physiological or Pharmacological Role of $\mathrm{GABA}_{\mathrm{A}} \mathrm{R}$ Subunits....33

Mechanism of Addiction of Benzodiazepines................................37

Objective of the dissertation.........................................40 
References

\section{CHAPTER - II ASSESSMENT OF SUBUNIT-DEPENDENT DIRECT GATING}

\section{AND ALLOSTERIC MODULATORY EFFECTS OF CARISOPRODOL AT}

GABAA RECEPTORS

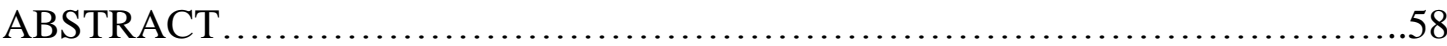

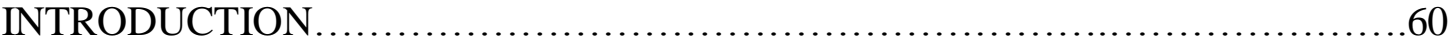

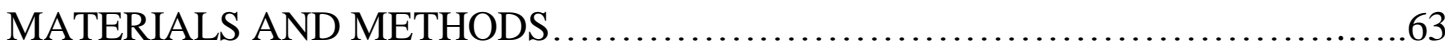

Cell Culture and Transfection...............................................63

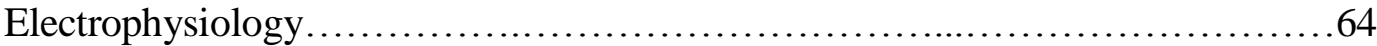

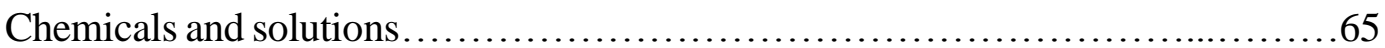

Experimental protocol........................................................65

Data Analysis....................................................67

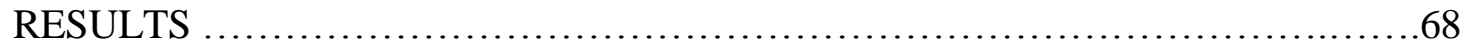

Influence of $\alpha$ subunit isoform of carisoprodol-mediated activity of the

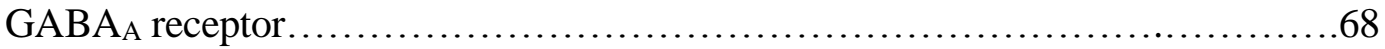

Influence of $\beta$ subunit isoform of carisoprodol-mediated activity of the

$\mathrm{GABA}_{\mathrm{A}}$ receptor

Direct gating and allosteric modulatory effects of carisoprodol do not

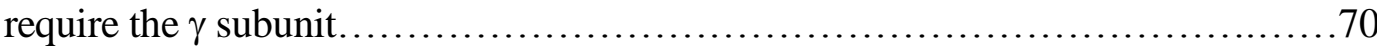

Effects of carisoprodol in "extrasynaptic" receptors...........................71 
Effect of membrane voltage on direct gating and allosteric modulatory

effects of carisoprodol.................................................73

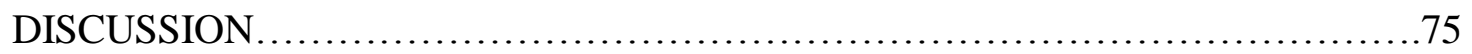

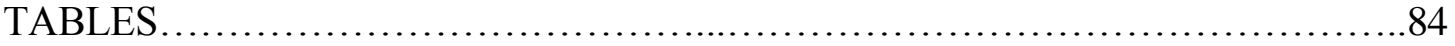

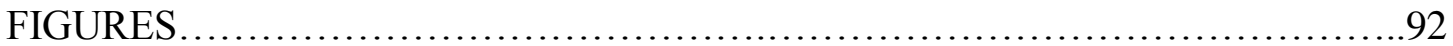

AUTHORSHIP CONTRIBUTIONS........................................... 104

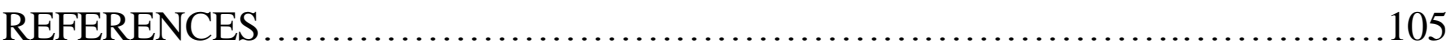

CHAPTER - III A SINGLE AMINO ACID RESIDUE AT TRANSMEMBRANE 4

OF THE ALPHA 1 SUBUNIT INFLUENCES CARISOPRODOL DIRECT

GATING EFFICACY AT GABAA RECEPTORS ................................ 115

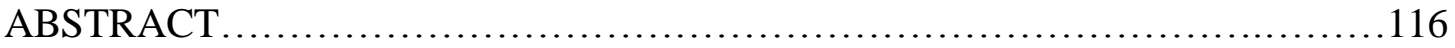

INTRODUCTION ........................................................ 117

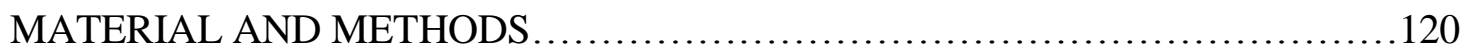

Plasmids and site-directed-mutagenesis................................ 120

Chemicals and solutions............................................... 120

Cell Culture and Transfection........................................... 120

Whole-cell patch clamp electrophysiology.................................121

Experimental Protocol.................................................. 122

Data Analysis....................................................... 123

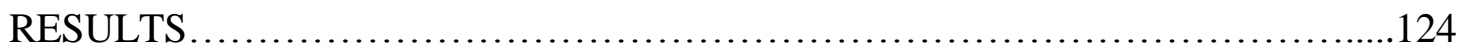

Functional characterization of $\alpha 3$ and $\alpha 1$ TM4 mutant GABA $A_{A}$ receptors..........124 
Mutation of $\alpha 3$ TM4 amino acids to corresponding $\alpha 1$ amino acids increased direct gating effect of carisoprodol but not allosteric modulatory actions

A single mutation of $\alpha 1$ TM4 L415 amino acid to corresponding $\alpha 3$ V440

amino acid decreased direct gating effect of carisoprodol

Amino acid residue at $\alpha 1(415)$ subunit influences carisoprodol

direct gating efficacy.

The $\alpha 1$ (L415S) mutation does not affect allosteric modulation by carisoprodol or direct activation by pentobarbital.

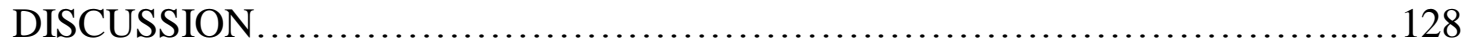

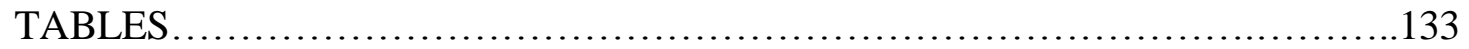

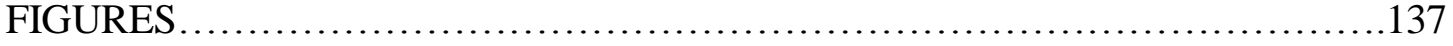

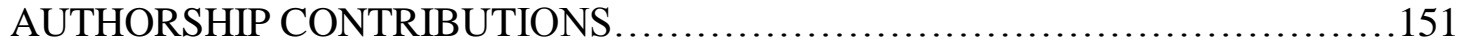

REFERENCES....................................................... 152

\section{CHAPTER- IV SUMMARY AND DISCUSSION}

SUMMARY AND DISCUSSION ............................................ 158

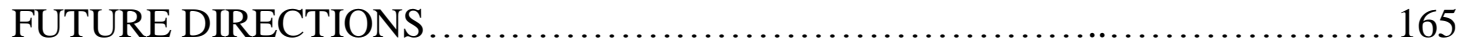

REFERENCES.............................................................. 


\section{LIST OF TABLES}

I-1 Localization of $\mathrm{GABA}_{\mathrm{A}}$ receptor subtypes and their physiological and pharmacological role................................................. 35

II-1 GABA sensitivity of different $\mathrm{GABA}_{\mathrm{A}}$ receptors subunit configurations........84

II-2 Comparison of potency and efficacy of carisoprodol as a direct gating agonist at different $\mathrm{GABA}_{\mathrm{A}}$ receptor subunit configurations $\ldots \ldots \ldots \ldots \ldots \ldots . . . . .66$

II-3 Comparison of potency and efficacy of allosteric effects of carisoprodol at different $\mathrm{GABA}_{\mathrm{A}}$ receptor subunit configurations.........................88

II-4 Comparison of carisoprodol effects on $\delta$ subunit-containing extrasynaptic receptors with synaptic $\mathrm{GABA}_{\mathrm{A}}$ receptors...............................90

III-1 Influence of $\mathrm{GABA}_{\mathrm{A}}$ receptor $\alpha 3 \mathrm{TM} 4$ amino acids mutation to corresponding $\alpha 1$ amino acids on GABA EC50 values, carisoprodol direct activation and allosteric modulation

III-2 Influence of $\mathrm{GABA}_{\mathrm{A}}$ receptor $\alpha 1 \mathrm{TM} 4$ residues mutation to corresponding $\alpha 3$ amino acids and $\alpha 1$ (L415) amino acid substitution on GABA EC50 values and carisoprodol direct activation properties 


\section{LIST OF FIGURES}

I-1 Metabolism of carisoprodol via cytochrome CYP2C19 enzyme..............6

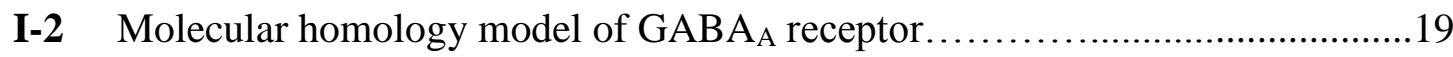

I-3 Schematic representation of major $\mathrm{GABA}_{\mathrm{A}}$ receptor isoform and topological model of a single subunit....................................22

I-4 Localization of synaptic and extrasynaptic $\mathrm{GABA}_{\mathrm{A}}$ receptors on postsynaptic neurons and their properties 24

I-5 Representation of chloride currents gated by $\mathrm{GABA}_{\mathrm{A}}$ receptor ligands and their pharmacological properties.

I-6 Involvement of $\mathrm{GABA}_{\mathrm{A}}$ receptors in drug addiction

pathways

II-1 Influence of $\mathrm{GABA}_{\mathrm{A}} \mathrm{R}$ subunit isoforms on direct activation by carisoprodol.

II-2 Influence of $\mathrm{GABA}_{\mathrm{A}} \mathrm{R}$ subunit isoforms on allosteric modulation by carisoprodol.

II-3 Direct gating action of carisoprodol on extrasynaptic $\mathrm{GABA}_{\mathrm{A}}$ receptors .96

II-4 Allosteric modulation of extrasynaptic $\mathrm{GABA}_{\mathrm{A}}$ receptors by carisoprodol

II-5 Potentiation of saturating GABA current by sub-gating concentration of carisoprodol in extrasynaptic $\mathrm{GABA}_{\mathrm{A}}$ receptors

II-6 Voltage dependent effect of carisoprodol actions on $\mathrm{GABA}_{\mathrm{A}}$ receptors. 102 
III-1 $\mathrm{GABA}_{\mathrm{A}}$ receptor structure and alignment of transmembrane 4 amino acid residue of $\alpha(1-6) \mathrm{GABA}_{\mathrm{A}}$ receptor subunits.

III-2 Influence of the alpha3 subunit TM4 residues mutation on direct activation and allosteric modulation by carisoprodol.

III-3 Influence of the alpha1 subunit TM4 residues mutation on direct activation by carisoprodol.

III-4 Influence of the alpha1 subunit TM4, L415 mutation on carisoprodol direct gating potency and efficacy

III-5 Physiochemical relation of alpha1 415 residue with carisoprodol direct gating efficacy, GABA EC50 and GABA EC50 with carisoprodol efficacy.145

III-6 Influence of the alpha1 subunit TM4, L415S mutation on allosteric modulation by carisoprodol and pentobarbital direct activation....

III-7 Homology molecular model of $\mathrm{GABA}_{\mathrm{A}}$ receptor 


\section{LIST OF ABBREVIATIONS}

GABA

$\mathrm{GABA}_{\mathrm{A}} \mathrm{R}$

LGIC

CSP

BZD

PTX

PB

CYP2C19

TM

HEK

CNS

DMSO

EGTA

HEPES $\gamma$-aminobutyric acid

$\gamma$-aminobutyric acid type A receptor

Ligand-gated ion channel

Carisoprodol

Benzodiazepines

Picrotoxin

Pentobarbital

Cytochrome P450 2C19 enzyme

Transmembrane

Human embryonic kidney

Central nervous system

Dimethyl sulfoxide

Ethylene glycol-bis ( $\beta$-aminoethyl ether)

$\mathrm{N}$-2-hydroxyethylpiperazine-N-2-etanesulfonicacid $\mathrm{N}, \mathrm{N}$, N', N'-tetra acetic acid 


\section{CHAPTER I}

\section{INTRODUCTION}

Carisoprodol (CSP) is a centrally acting muscle relaxant, frequently prescribed to relieve skeletal muscle spasms and associated pain (Toth and Urtis, 2004). Recent evidence confirms carisoprodol abuse leads to several adverse effects, such as psychomotor impairment and severe withdrawal that may predispose to hallucinations, seizures and death (Bramness et al., 2004; Fass, 2010; Zacny and Gutierrez, 2011; Zacny et al., 2012). Carisoprodol abuse has increased rapidly in recent years. Recreational users abuse carisoprodol for its muscle relaxing, anxiolytic and sedating effects, and often mix it with other CNS depressants to enhance its sedative or euphoric effects (Hardon and Ihsan, 2014). The Drug Enforcement Agency (DEA) has reported cases of carisoprodol intoxication are increasing. Seizures induced by carisoprodol misuse increased from 3,988 in 2008 to more than 5000 in 2010, higher than other abused drugs including like lorazepam and methylphenidate (Witenko et al., 2014). Increasing popularity of carisoprodol among high school students is also a topic of concern. According to Monitoring the Future National Survey on Drug Use (2009), annual non-medical use of carisoprodol among all high school seniors was $1.3 \%$ and 1.4\% in 2007 and 2008, respectively (Reeves et al., 2012). These numbers are higher than other prescription drugs that are abused like chlordiazepoxide $(0.2 \%)$ and lorazepam (0.4\%) and comparable to clonazepam (1.3\%) (Reeves et al., 2012). Considering the danger posed by carisoprodol and its increasing abuse rate, an understanding 
of its mechanism of action is of interest. Its physiological effects have generally been attributed to actions of its primary metabolite, meprobamate (Reeves et al., 1999b) on GABA type A receptors $\left(\mathrm{GABA}_{\mathrm{A}} \mathrm{Rs}\right)$, the predominant inhibitory neurotransmitter receptor in the brain (Sigel and Steinmann, 2012). However, it is now known that carisoprodol can directly gate and allosterically modulate the $\mathrm{GABA}_{\mathrm{A}} \mathrm{R}$, likely through a novel site(s) of action (Gonzalez et al., 2009b), and thus many actions may be attributable to the parent drug carisoprodol. In this overview, the current understanding with regard to the abuse potential of carisoprodol, therapeutic and abuse-related actions of this drug, and possible molecular actions that underlie these effects is discussed.

\section{Clinical Use of Carisoprodol}

Carisoprodol was first approved in 1959 by the Food and Drug Administration (FDA) for clinical use as a skeletal muscle relaxant (Fass, 2010). It is/has been marketed in the United States under the brand name Soma, Soridol and Rela in the United States (Littrell et al., 1993a), Carisoma in the United Kingdom, and under the names Sonoma, Somadril, Somacid, Scutamil C, Relacton-C, Mio Relax, and Relaxibys in other countries (Reeves et al., 2012). Carisoprodol is commonly prescribed for acute musculoskeletal spasm and associated pain in adults. The analgesic, muscle relaxant and sedative effects of carisoprodol are the basis for its use in the alleviation of lower back pain and in the short-term treatment of painful, acute musculoskeletal conditions (Toth and Urtis, 2004). Like other muscle relaxants, carisoprodol is often prescribed as an adjunct to rest or physical therapy and is also 
available in preparations with other analgesics such as aspirin or codeine (Soma ${ }^{\circledR}$ Compound or Soma ${ }^{\circledR}$ Compound with codeine) (2004). The onset of action is rapid and effects last for 4-6 hours (Littrell et al., 1993a). It is available in $250 \mathrm{mg}$ and $350 \mathrm{mg}$ tablets, and is administered 3-4 times a day for a maximum duration of 2-3 weeks. Carisoprodol was the $2^{\text {nd }}$ most prescribed muscle relaxant in the US in 2000, accounting for $21 \%$ of all skeletal muscle relaxant prescriptions. Together with cyclobenzaprine and metaxalone, these three drugs accounted for $45 \%$ of all skeletal muscle relaxant prescriptions dispensed in 2003 and 2004 (Luo et al., 2004; Toth and Urtis, 2004). A market intelligence corporation, IMS Health, reported 10.6 million prescriptions were dispensed in 2008 alone. The most common side effects of carisoprodol when taken medicinally are drowsiness, dizziness, and headaches (Bramness et al., 2007a). Other side effects include nausea, vomiting, hypotension, tachycardia, ataxia, vertigo, tremors and seizures. Adverse effects are generally observed after high dose administration or sudden cessation. Toxic doses of carisoprodol elicit agitation, myoclonus and bizarre movements (Bramness et al., 2005a; Roth et al., 1998).

\section{Pharmacokinetics and Metabolism}

Carisoprodol is a white crystalline powder with mild characteristic odor and a bitter taste. It is a racemic mixture of two stereoisomers, $(R S)-2-\{[($ aminocarbonyl)oxy $]$ methyl $\}-$ 2-methylpentyl isopropylcarbamate. Its molecular weight is 260.33 and its octanollwater partition coefficient is 2.36. Carisoprodol solubility is independent of $\mathrm{pH}$. It is freely soluble in organic solvents DMSO, chloroform, acetone and alcohol and moderately soluble in water 
(30 mg/100 mL at $25^{\circ} \mathrm{C}$ (Littrell et al., 1993a). The structure of carisoprodol is closely related to meprobamate, differing only by a hydrogen atom substituting for the isopropyl group on one of the carbamyl nitrogens (Figure 1). Carisoprodol's structure is also closely related to felbamate, an anti-epileptic drug used to treat partial and generalized seizures. However, later reports of liver failure and aplastic anemia limits its usage to severe refractory seizures. The CYP2C19 genotype influences the pharmacokinetics of carisoprodol, and thus carisoprodol and meprobamate blood concentrations. EMs and IMs (extreme and intermediate metabolizers) metabolize carisoprodol with a half-life of 1.5 hours (Dalen et al., 1996; Olsen et al., 1994). Around 2-3\% of Caucasians are PMs (poor metabolizers); they eliminate carisoprodol with a half-life of more than 6 hours and generate meprobamate to a small extent (Tamminga et al., 2001). Carriers of deficient CYP2C19 alleles accumulate higher concentrations of carisoprodol that may lead to intoxication, while potentially high levels of the active metabolite meprobamate can accumulate in CYP2C19*17 carriers. However, CYP2C19 genetics alone do not appear to play a significant role in carisoprodol-related mortality (Hoiseth et al., 2012). Instead, interaction with other drugs likely plays a key role in carisoprodol-related fatalities (McIntyre et al., 2012). Postmortem evaluation of carisoprodol concentration in blood and liver has shown carisoprodol concentrations as low as $15 \mathrm{mg} \backslash \mathrm{L}$ in blood and $50 \mathrm{mgkg}$ in liver can be fatal in the presence of other sedative/hypnotics like alcohol, diazepam, alprazolam and temazapam (McIntyre et al., 2012). 
Age, sex and co-administration of other drugs that interact with CYP2C19 enzyme also affect carisoprodol metabolism and thus blood concentrations (Tse et al., 2014). A retrospective study conducted on 14,965 subjects assessed effects of age, sex and drugs that inhibit CYP2C19 enzymes (esomeprazole, fluoxetine or omeprazole). Metabolic rates were twice as high in young subjects compared to elderly, and were approximately $20 \%$ higher in females than males (Tse et al., 2014). Also, esomeprazole and fluoxetine, but not omeprazole, significantly decreased the metabolic rate of carisoprodol. Use of oral contraceptives inhibits the metabolism of carisoprodol in a CYP2C19 genotype-dependent manner; IMs using oral contraceptives accumulate more carisoprodol than EMs using them (Bramness et al., 2005b). As more than $25 \%$ of women aged 20-40 use oral contraceptives (Ronning, 2001), it is important for clinicians to be aware of the potential effects on carisoprodol concentration in those taking oral contraceptives. 
Figure I-1. Metabolism of carisoprodol via cytochrome CYP2C19 enzyme. Carisoprodol is metabolized by cytochrome CYP2C19 enzyme via $\mathrm{N}$-dealkylation of its isopropyl group to form active metabolite meprobamate. Carisoprodol also metabolized to an inactive metabolite, hydroxyl- carisoprodol, but to a very small extent by an unknown enzyme. Meprobamate and hydroxyl- carisoprodol are further metabolized to hydroxyl-meprobamate and conjugate and excreted by in urine. 


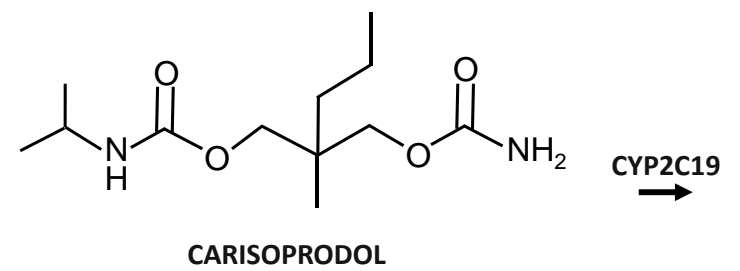<smiles>CCCC(C)(COC(N)=O)COC(N)=O</smiles><smiles>CC(O)CC(C)(COC(N)=O)COC(=O)NC(C)C</smiles>
HYDROXYL-CARISOPRODOL

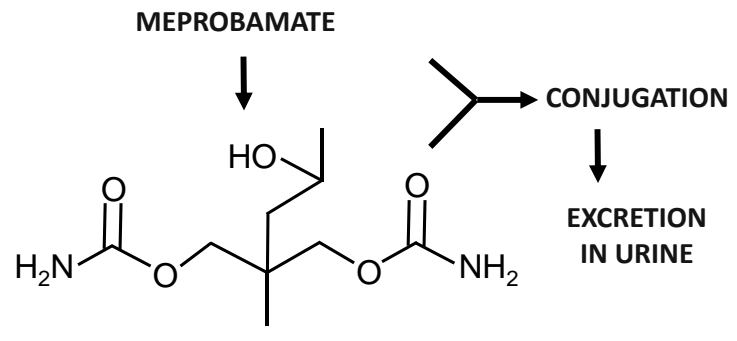
HYDROXYL-MEPROBAMATE

Figure I-1 


\section{Abuse and Withdrawal Syndrome}

Carisoprodol was developed as an analog of meprobamate, promoted as having less abuse liability and better muscle-relaxing properties (Nebhinani et al., 2013). An early report suggested carisoprodol did not substitute for morphine or barbiturate and did not produce morphine- or barbiturate-like intoxication or withdrawal symptoms, and it was thus concluded carisoprodol does not pose abuse liability (Littrell et al., 1993a). However, more recent reports confirmed its abuse potential as well as subjective and psychological impairment and severe withdrawal syndrome that may predispose to seizures and even death (Fass, 2010; Gonzalez et al., 2009a; McIntyre et al., 2012; Ni et al., 2007; Reeves and Burke, 2010; Reeves et al., 2012; Zacny et al., 2012). The American Association of Poison Control Centers reported 2632 cases of intentional carisoprodol ingestion requiring medical attention in 2008 (Bronstein et al., 2009).

Studies conducted in healthy individuals showed a single supra-therapeutic $700 \mathrm{mg}$ dose of carisoprodol produced both subjective and psychomotor impairments, whereas a single therapeutic dose $(350 \mathrm{mg}$ ) produced mainly psychomotor impairments and minimum subjective impairments (Zacny et al., 2011). Administration of $10 \mathrm{mg}$ oxycodone within 1 hour of $350 \mathrm{mg}$ carisoprodol further affected the psychomotor impairments (Zacny et al., 2012). A study conducted in northern India also assessed dose-dependent effects of carisoprodol (Nebhinani et al., 2013). In that study, consumption of 1-3 tablets produced feelings of well-being and an energetic state, consumption of 4-10 tablets produced psychomotor excitement, cheerfulness, increased socialization and self-confidence, while 
consumption of a one-time dose of 10 tablets produced an acute organic brain syndrome-like state with disorientation and partial amnesia of the events occurring during intake. In a study conducted by Reeves and Burke (Reeves and Burke, 2010), subjects consuming 12-30 tablets a day alone or in combination with other drugs like tramadol, benzodiazepines or alcohol reported euphoria and hallucinations. Misuse of carisoprodol has also been associated with suicide attempts (Bailey and Briggs, 2002).

In patients taking prescribed carisoprodol for extended use, the desire to continue its use is strong. Owens et al (Owens et al., 2007) found in approximately $80 \%$ of reported cases, patients continued to purchase carisoprodol even after their insurance declined to cover the bills. A survey of 40 individuals who had been taking carisoprodol for more than 3 months showed half of them had a history of drug abuse. Out of those 20 people, $40 \%$ admitted to taking more than the prescribed dose, $30 \%$ admitted taking for effects other than low back pain, $10 \%$ admitted taking to stimulate effects of other drugs being abused, and 5\% admitted taking to counter the effects of other drugs (Reeves et al., 1999b). Collectively, the evidence suggesting carisoprodol has addictive properties and abuse potential is high. Of concern is the fact that physician awareness of the potential dangers of carisoprodol may be inadequate. Whereas 95 out of 100 physicians reported knowing meprobamate is a controlled substance, only 18 were aware that carisoprodol is metabolized to meprobamate (Reeves et al., 1999b). Now that carisoprodol is also scheduled, the recognition of dangers associated with its misuse should be improved. 
Carisoprodol is passed to nursing infants during breastfeeding. Serum concentrations of carisoprodol and meprobamate were measured from a nursing mother who took 3 times the normal dose of carisoprodol per day for severe back spasms before and after uncomplicated delivery, and during the first month of breast feeding (Briggs et al., 2008). Significant amounts of carisoprodol and meprobamate were found in both the breast milk and the infant's serum, but no developmental toxicity was observed. Mild sedation in the baby while breast feeding was reported, however no signs of withdrawal were observed after feeding was stopped.

Carisoprodol abuse has increased rapidly in recent years. Low cost and easy accessibility compared to other illegal drugs make it an ideal choice for substance abusers. Abusers often combine carisoprodol with other psychoactive drugs to augment or alter their effects. For example, it may be combined with alcohol or benzodiazepines to increase their sedative effects, with cocaine to attenuate jitteriness associated with its use, and with other drugs to get synergistic relaxation and euphoria (Reeves and Burke, 2010; Reeves and Liberto, 2001). Individuals may substitute carisoprodol for opiates or benzodiazepines if these drugs are not accessible (Reeves et al., 1999a). As per the National Survey on Drug Use and Health in 2009, an estimated 2.9 million people in the United States admitted lifetime consumption of carisoprodol for non-medical purposes. In 2008, the National Forensic Laboratory information system reported carisoprodol as 1 of the 25 most frequently abused drugs (Fass, 2010). In 1996, the DEA proposed scheduling of carisoprodol, but the FDA and drug advisory committee did not take this action, feeling the evidence regarding 
abuse potential of carisoprodol was insufficient (Fass, 2010). Following additional hearings on the possible scheduling of carisoprodol in 2010, carisoprodol was placed in schedule IV of the Controlled Substance Act of 1970 effective January 11, 2012 (see ref: Schedule of control substances). Since the earlier review, a better understanding of the potential mechanism underlying its actions had been developed, and abuse of carisoprodol had risen significantly. For example, in 2009, out of roughly 50,000 emergency department visits related to abuse of musculoskeletal relaxants, 30,000 visits were due to misuse of carisoprodol; this is double the number of visits related to carisoprodol abuse reported just five years earlier (Reeves et al., 2012). Considering the subjective, psychomotor impairment and CNS depressant effects of carisoprodol, it is not surprising that carisoprodol use increases risk of traffic accidents and accidents while operating heavy machine (Zacny et al., 2011). Indeed, carisoprodol and meprobamate have been ranked $7^{\text {th }}$ out of the top 10 classes of drugs associated with driving under the influence of drugs, and this activity may in fact result in a charge of driving while intoxicated (Bramness et al., 2007b).

Carisoprodol abuse is not only an issue in the United States; its abuse has been documented in many other countries (Bramness et al., 2007a; Bramness et al., 2007b; Hardon and Ihsan, 2014; Nebhinani et al., 2013). In 2007, Norway scheduled Carisoprodol as class "A" drug, which is the highest scheduling level in Norway and a category that includes narcotics and hypnotics (Hoiseth et al., 2009). Recently, the Committee for Medicinal Products for Human Use concluded the abuse potential associated with carisoprodol outweighs its benefits as a therapeutic drug; carisoprodol was removed from the market by 
the European Medicines Agency in 2008 and is only available to those for whom there are no other alternatives (Hoiseth et al., 2009). In South Sulawesi, sex workers spend nearly all their earnings to buy carisoprodol (Hardon and Ihsan, 2014). They take up to 10 pills a day, often along with alcohol and other psychoactive prescription drugs, to make their work palatable. Carisoprodol has become a cross-border problem as well. Several thousands of pills can easily be purchased at a time in Mexico to be smuggled over to the United States and sold to teenagers (Davis, 2009). Correspondingly, the Los Angeles police department reported carisoprodol is one of the prescribed drugs they encounter most frequently at the US-Mexico border crossing (Reeves and Burke, 2010).

A significant problem with carisoprodol is that tolerance to its effects develops rapidly, and increased consumption of tablets often follows. Subsequent abrupt cessation results in withdrawal syndrome (Gatch et al., 2012). Abrupt cessation of carisoprodol administration in humans $(100 \mathrm{mg} / \mathrm{kg} / \mathrm{day}, 5$ times the normal daily dosage $)$ results in insomnia, abdominal cramps, headache, chills and nausea (46). Hallucinations, delusions, tremors, seizures and even death have also been reported (Ni et al., 2007; Reeves et al., 2004; Reeves and Burke, 2010). Prisoners in Norway who had been taking 700 - $2100 \mathrm{mg} / \mathrm{day}$ of carisoprodol for at least 9 months showed withdrawal symptoms including insomnia, anxiety, irritability and muscular pain upon sudden discontinuation of drug intake (Wyller et al., 1991). Whereas withdrawal symptoms are generally associated with cessation of large doses of carisoprodol, they have been observed with cessation of as few as 4 to 8 tablets of carisoprodol per day (Reeves et al., 1997). Whereas toxic and withdrawal symptoms have a 
notable GABAergic component (below), other systems may be affected. Bramness et al (Bramness et al., 2005a) reported 4 cases where subject had consumed up to 65 pills of carisoprodol alone or along with other sedative/hypnotics; these subjects showed characteristic effects that might be associated with serotonergic activation, such as tachycardia, hypertension, involuntary, robot-like, choreiform movements, tremors and shivering (Bramness et al., 2004; Roth et al., 1998). In that study, however, signs and symptoms included in the classification of serotonergic syndrome were nonspecific; because a complete drug screening was not performed, one cannot rule out the possibility that other drugs present were eliciting the serotonergic effects. Currently, a suitable and efficient treatment for carisoprodol intoxication and withdrawal is not available. Withdrawal syndromes are treated with barbiturates and benzodiazepines to suppress anxiety and agitation (Reeves et al., 2007). Treating carisoprodol overdose is more complicated because of the presence of serotonergic-like symptoms noted above. A benzodiazepine antagonist is generally given in cases of carisoprodol intoxication, but considering carisoprodol does not act at the benzodiazepine site (below), this is not an entirely appropriate approach.

\section{Pharmacology of Carisoprodol}

Carisoprodol mediates its effects centrally rather than through direct skeletal muscle relaxation (Gonzalez et al., 2009b). Inhibition of inter-neuronal transmission in the descending reticular formation and spinal cord is one of the mechanisms proposed for its muscle relaxant properties. Whereas the precise mechanism of action of carisoprodol is not 
fully understood, it has been thought that carisoprodol exerts its effects via its metabolite, meprobamate. Meprobamate is a sedative-hypnotic that was commonly used in the treatment of anxiety. It is currently classified as a schedule IV controlled substance at the federal level, with abuse potential comparable to that of benzodiazepines (Mounier et al., 2012; Roache and Griffiths, 1987). Meprobamate was introduced in 1955 under the brand names Miltown and Equnil, but within a few years was replaced by benzodiazepines because of high abuse liability (Reeves et al., 2012). Although the central mechanism of action of meprobamate has also not been fully elucidated, $\mathrm{GABA}_{\mathrm{A}}$ receptors are a key target. Meprobamate allosterically potentiates $\mathrm{GABA}_{\mathrm{A}}$ receptors and directly gates the receptor at millimolar concentrations (Rho et al., 1997). Meprobamate intoxication causes cardiogenic hypotension, CNS depression, flaccid muscles and loss of tendon reflexes (Allen et al., 1977). As noted, it was assumed therapeutic effects and abuse potential of carisoprodol are due to its metabolism to meprobamate (Littrell et al., 1993b). Following a single $700 \mathrm{mg}$ dose of carisoprodol, serum levels of meprobamate surpass those of carisoprodol in 2.5 hours, and approximately $90 \%$ of carisoprodol is metabolized to meprobamate in 6 hours (Olsen et al., 1994). Despite the likely contribution of meprobamate to the therapeutic and adverse effects of carisoprodol, the pharmacological and physiological effects of carisoprodol are somewhat distinct, suggesting carisoprodol has its own actions (Gonzalez et al., 2009a). For example, supratherapeutic doses of meprobamate mainly result in CNS depressant effects such as dizziness, drowsiness, ataxia, tremors, blurred vision and headache, whereas agitation and bizarre movements occur with toxic levels of carisoprodol. 
Moreover, signs of toxicity are observed within 30 minutes of overdose of carisoprodol ( $\mathrm{t}$ 1/2 1.5 hours), before it is metabolized to meprobamate ( $\mathrm{t}$ 1/2 11 hours) (Littrell et al., 1993a).

Gonzalez et al., using whole cell patch electrophysiology in HEK cells, showed carisoprodol itself allosterically modulates and directly activates $\mathrm{GABA}_{\mathrm{A}} \mathrm{Rs}(\mathrm{GABA}$ type $\mathrm{A}$ receptors) (Gonzalez et al., 2009b). Carisoprodol inhibits the receptor at high concentration, eliciting rebound currents upon termination of drug application, as observed with barbiturates. In vivo studies showed maximal depression of motor activity was observed within 10 minutes of carisoprodol administration, a timeframe inconsistent with effects being due to conversion to meprobamate (Gonzalez et al., 2009b). In addition, in rats trained to discriminate carisoprodol from saline, the GABAergic ligands pentobarbital, chlordiazepoxide and meprobamate substituted for carisoprodol. These results suggest $\mathrm{GABA}_{\mathrm{A}}$ receptors as potential targets of carisoprodol, and demonstrate its capacity to enhance the sedative effects of CNS depressants, contributing to its potential for abuse. Discriminative stimulus effects of carisoprodol were blocked by the barbiturate antagonist bemegride, but not by the benzodiazepine antagonist flumazenil. Similarly, carisoprodolgated currents were blocked by bemegride but not by flumazenil. These results rule out the involvement of the benzodiazepine binding site in carisoprodol modulation of $\mathrm{GABA}_{\mathrm{A}}$ receptors. Recently, Gatch et al. (Gatch et al., 2012) characterized tolerance and dependence potential in mice. Tolerance (measured as loss of righting reflex) developed quickly, as mice showed a decrease in the loss of righting reflex following just 4 doses of carisoprodol. Whereas spontaneous withdrawal symptoms were not produced within 24 hours following 
withdrawal from carisoprodol, precipitated withdrawal signs were observed with administration of either the benzodiazepine antagonist flumazenil or the barbiturate antagonist bemegride. Although drug discrimination and electrophysiological studies suggest possible overlap of the mechanism of action of carisoprodol and barbiturate effects, site-directed mutagenesis on homomeric $\rho 1$ GABA receptors have shown functional domains are not equivalent. Specifically, mutation of tryptophan to methionine at position 328 of the $\rho 1$ subunit $(\rho 1 \mathrm{~W} 328 \mathrm{M})$ confers pentobarbital direct gating sensitivity to insensitive wild type $\rho 1$ GABA receptors, but this mutation does not confer sensitivity to carisoprodol (Gonzalez et al., 2009b). Thus whereas carisoprodol shares several properties with barbiturates and a barbiturate antagonist can attenuate some of its effects, the two molecules interact at distinct sites on the $\mathrm{GABA}_{\mathrm{A}}$ receptors.

\section{$\mathrm{GABA}_{\mathrm{A}}$ Receptors}

GABA is the major inhibitory neurotransmitter in the vertebrate central nervous system and in the central and peripheral nervous system of invertebrates (DeLorey and Olsen, 1992). GABA released from GABAergic neurons generate postsynaptic neuronal inhibition through a variety of membrane bound receptors, $\mathrm{GABA}_{(\mathrm{A}-\mathrm{C})}$ type receptors (Sigel and Steinmann, 2012). These GABA receptors can be divided into two categories, ligand-gated ion channels $\left(\mathrm{GABA}_{\mathrm{A}}\right.$ and $\mathrm{GABA}_{\mathrm{C}}$ receptors) and metabotropic receptors (GABA $\mathrm{B}$ receptor) that are G-protein coupled receptors (Bormann, 2000). $\mathrm{GABA}_{\mathrm{A}}$ receptors are the most predominant inhibitory receptor in human CNS and are selective for $\mathrm{Cl}^{-}$ions (DeLorey and 
Olsen, 1992). Influx of chloride ions hyperpolarize the post-synaptic neurons and is essential for the balance between the neuronal excitatory and inhibitory signaling that is critical for normal brain function (McBain et al., 2015; Moss and Smart, 2001). Excessive inhibition or lowered excitation can lead to sedation, hypnosis, sleep, depression and coma whereas excessive excitation or lowered inhibition can result in anxiety, convulsions, restlessness and insomnia (Johnston, 2005). Precise symptoms depend upon the exact region of the brain and nerve cells that are out of balance (Whiting, 2003). Any extreme imbalance can lead to death. The aim of the therapeutic drugs that target $\mathrm{GABA}_{\mathrm{A}} \mathrm{R}$ is to restore balance between inhibition and excitation (Rudolph and Mohler, 2006; Rudolph and Mohler, 2014).

\section{Structure of GABAA receptors}

$\mathrm{GABA}_{\mathrm{A}}$ receptors are a member of the cys-loop receptor superfamily, a structural feature shared by entire superfamily (13 amino acids loop contained by a disulphide bond in the extracellular N-terminal) (Corringer et al., 2012; daCosta and Baenziger, 2013). Other members of the superfamily include nicotinic acetylcholine, type 3 5-hyroxytryptamine, GABAC and glycine receptors. $\mathrm{nACh}$ and $5 \mathrm{HT}_{3}$ receptors are selective for cations that depolarize (excite) the neurons whereas $\mathrm{GABA}_{\mathrm{A}}, \mathrm{GABA}_{\mathrm{C}}$ and glycine receptors are selective for anions that hyperpolarize (inhibit) the neurons (Miller and Smart, 2010). GABA $\mathrm{R}$ are heteromeric assemblies of five subunits forming a central ion conducting pore (figure I-2) (Corringer et al., 2012). Multiple $\mathrm{GABA}_{\mathrm{A}} \mathrm{R}$ subunits as well as their isoforms have been 
identified including $\alpha(1-6), \beta(1-3), \gamma(1-3), \rho, \delta, \varepsilon$ and $\theta$ (Barnard et al., 1998; Olsen and Sieghart, 2008). 
Figure I-2. Molecular homology model of $\mathbf{G A B A}_{\mathbf{A}}$ receptor. A, Side view of pentameric $\mathrm{GABA}_{\mathrm{A}}$ receptor representing five subunits, dimensions and position of the various domains of $\mathrm{GABA}_{\mathrm{A}}$ receptor on the cell membrane; $\alpha$ subunit in red, $\beta$ subunit in blue and $\gamma$ subunit in yellow. $\mathbf{B}$, Top view of pentameric $\mathrm{GABA}_{\mathrm{A}}$ receptor representing channel pore and its dimensions from top of the channel pore to channel gate. Created in Dr. Peter Gannett's lab with the help of Dr. Robyn Ayscue. Template was made available online by Dr. Bergmann (Bergmann et al., 2013). 


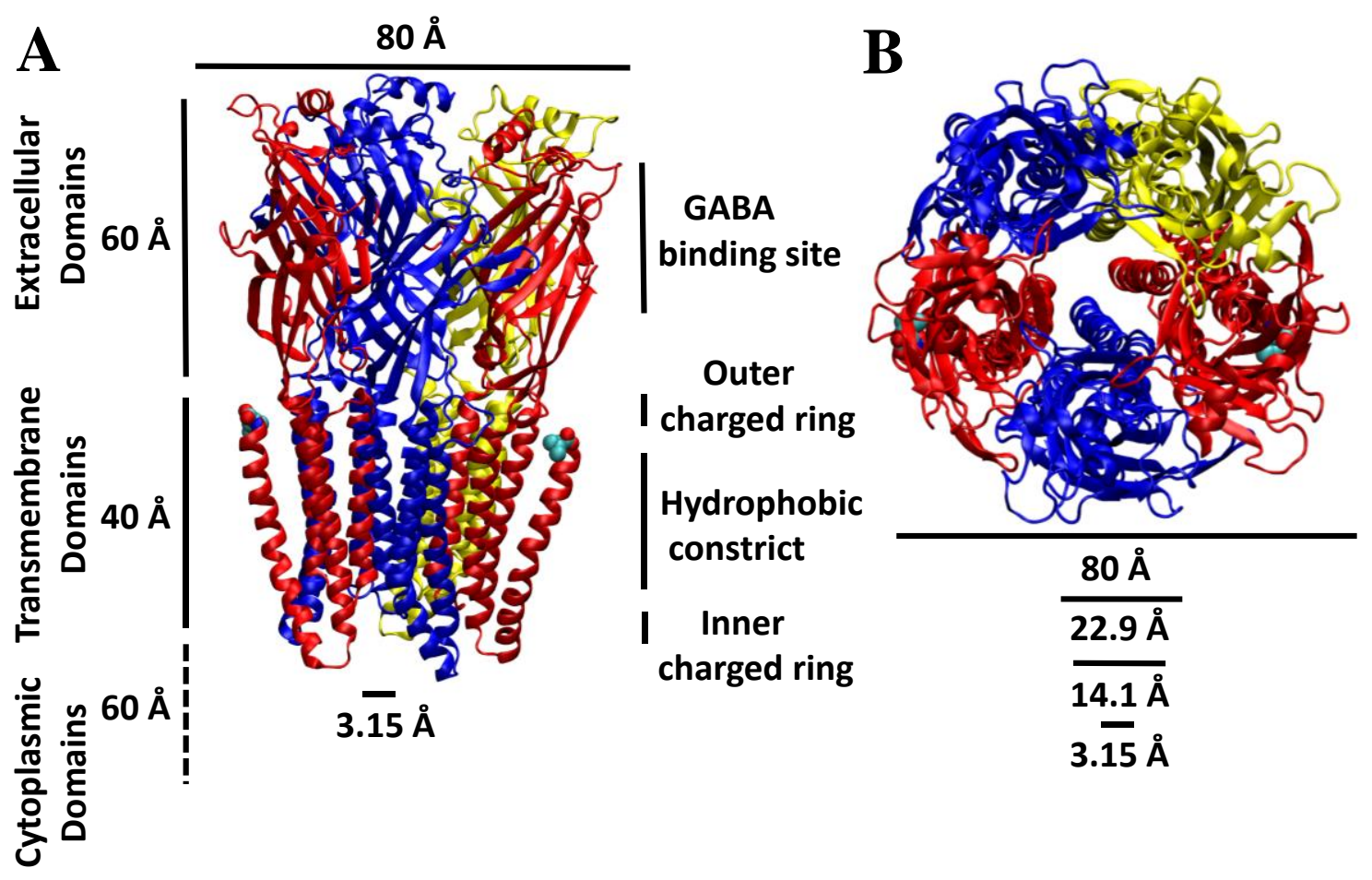

Figure I-2 
Each subunit of the $\mathrm{GABA}_{A} \mathrm{R}$ is composed of a large extracellular $\mathrm{N}$ terminus, four transmembrane helices (TM1-TM4), where TM2 lines the ion channel pore, one extracellular TM2-TM3 loop, two intracellular loops (TM1-TM2 and TM3-TM4), and an extracellular C terminus (figure I-3). Considering the diverse number of subunit isoforms, a large number of $\mathrm{GABA}_{\mathrm{A}} \mathrm{R}$ can be assembled. However, it has been verified that $\alpha \beta \gamma$ and $\alpha \beta \delta$ receptor $(2: 2: 1$ stoichiometry) isoforms are the predominant $\mathrm{GABA}_{\mathrm{A}} \mathrm{Rs}$ in the brain (Quirk et al., 1994) with $\alpha \beta \gamma \mathrm{GABA}_{\mathrm{A}} \mathrm{Rs}$ mainly located within the synapses and $\alpha \beta \delta$ receptors are preferentially expressed at extra- or perisynaptic membranes (figure I-4) (Belelli et al., 2009). While synaptic $\mathrm{GABA}_{\mathrm{A}}$ receptors exhibit phasic inhibition, extra-synaptic $\mathrm{GABA}_{\mathrm{A}}$ receptors exhibit tonic inhibition, persistently activated by low ambient GABA levels present in the extracellular space spilled from synaptic region (Farrant and Nusser, 2005; Glykys and Mody, 2007; Herd et al., 2009). Extra-synaptic $\mathrm{GABA}_{\mathrm{A}}$ receptors have low efficacy but high affinity for GABA compared to other ligands such that GABA is considered partial agonist at these receptors (Bianchi and Macdonald, 2003). Single channel studies have shown $\alpha \beta \delta$ receptors display brief openings whereas $\alpha \beta \gamma$ receptors exhibit burst openings with longer open duration (Akk et al., 2004; Feng et al., 2004; Wohlfarth et al., 2002). Synaptic receptors that respond to millimolar concentrations of GABA exhibit fast inhibitory postsynaptic potentials (IPSPs), whereas extra-synaptic receptors which respond to micromolar concentrations of GABA spilled in the extra-cellular space consistently exhibit slower IPSPs (Belelli et al., 2009). 
Figure I-3. Schematic representation of major GABAA receptor isoform and topological model of a single subunit. A, Side view of a single subunit of $\mathrm{GABA}_{\mathrm{A}}$ receptor representing a large extracellular $\mathrm{N}$ terminus showing cys-loop, four transmembrane helices (TM1-TM4), where TM2 lines the ion channel pore (grey), one extracellular TM2-TM3 loop, two intracellular loops (TM1-TM2 and TM3-TM4), and an extracellular C terminus. $\mathbf{B}$, Top view of $\mathrm{GABA}_{\mathrm{A}}$ receptor representing position of five subunits in anti-clockwise ( $\beta 2: \alpha 1: \beta 2: \alpha 1: \gamma 2)$. Positive side of the $\beta 2$ subunit face negative side of the $\alpha 1$ subunit and negative side of $\alpha 1$ subunit faces positive side of $\gamma 2$ subunit. The Transmembrane2 (TM2) (grey) of each subunit line the channel pore. GABA bind at the interface of $\alpha 1$ and $\beta 2$ subunits and benzodiazepines (BDZ) at the interface of $\alpha 1$ and $\gamma 2$ subunit. $\mathbf{C}$, Representation of binding pocket loops of $\mathrm{GABA}$ on $\mathrm{GABA}_{\mathrm{A}}$ receptors. Principal side on $\beta^{+}$subunit; loop A, B and C and complementary side on $\alpha^{-}$subunit; loops D, E and F. 
A
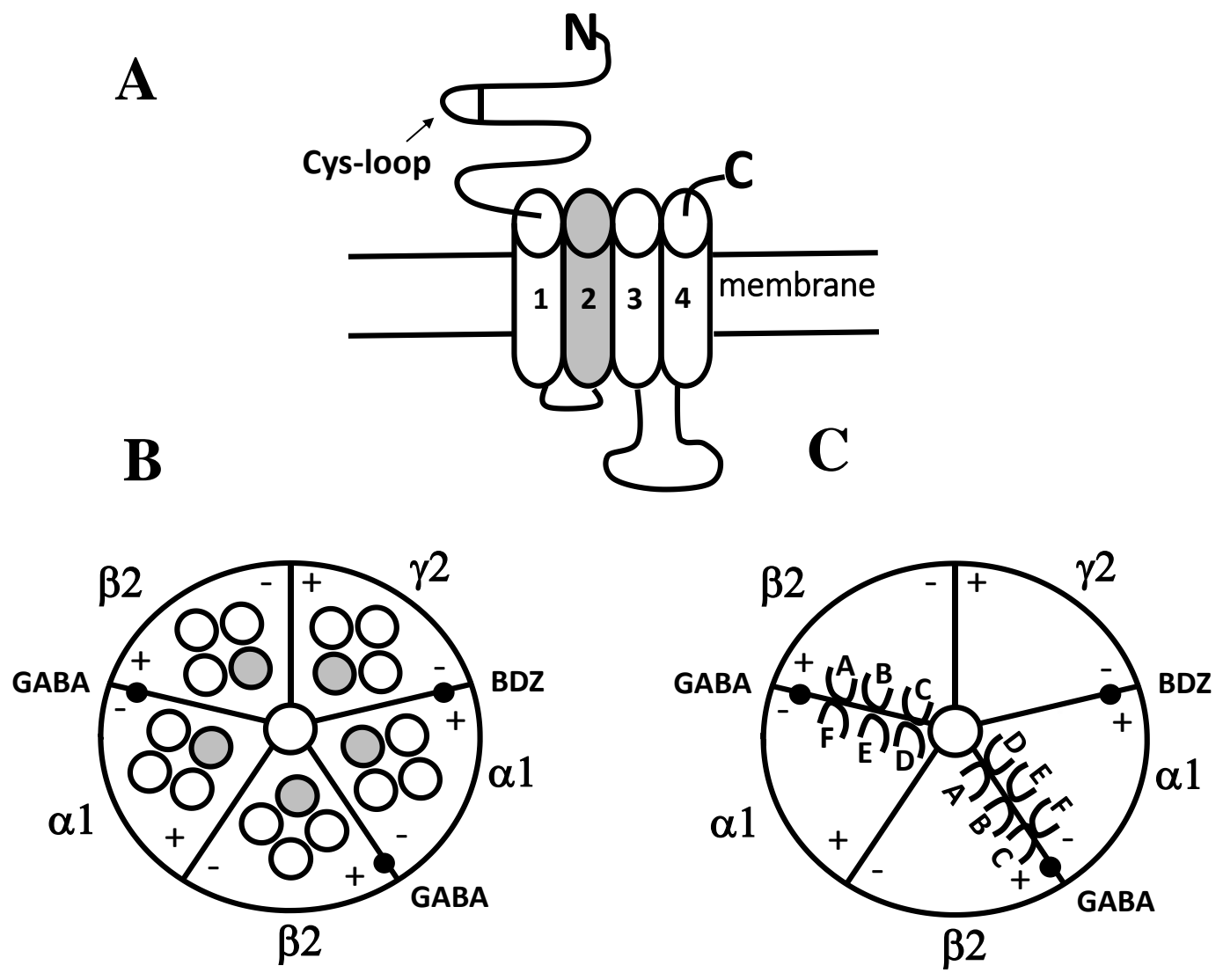

Subunit Diversity: $\alpha_{1-6}, \beta_{1-3}, \gamma_{1-3}, \delta_{1}, \theta_{1}, \varepsilon_{1}$

Figure I-3 
Figure I-4. Localization of synaptic and extrasynaptic $\mathrm{GABA}_{A}$ receptors on postsynaptic neurons and their properties. 


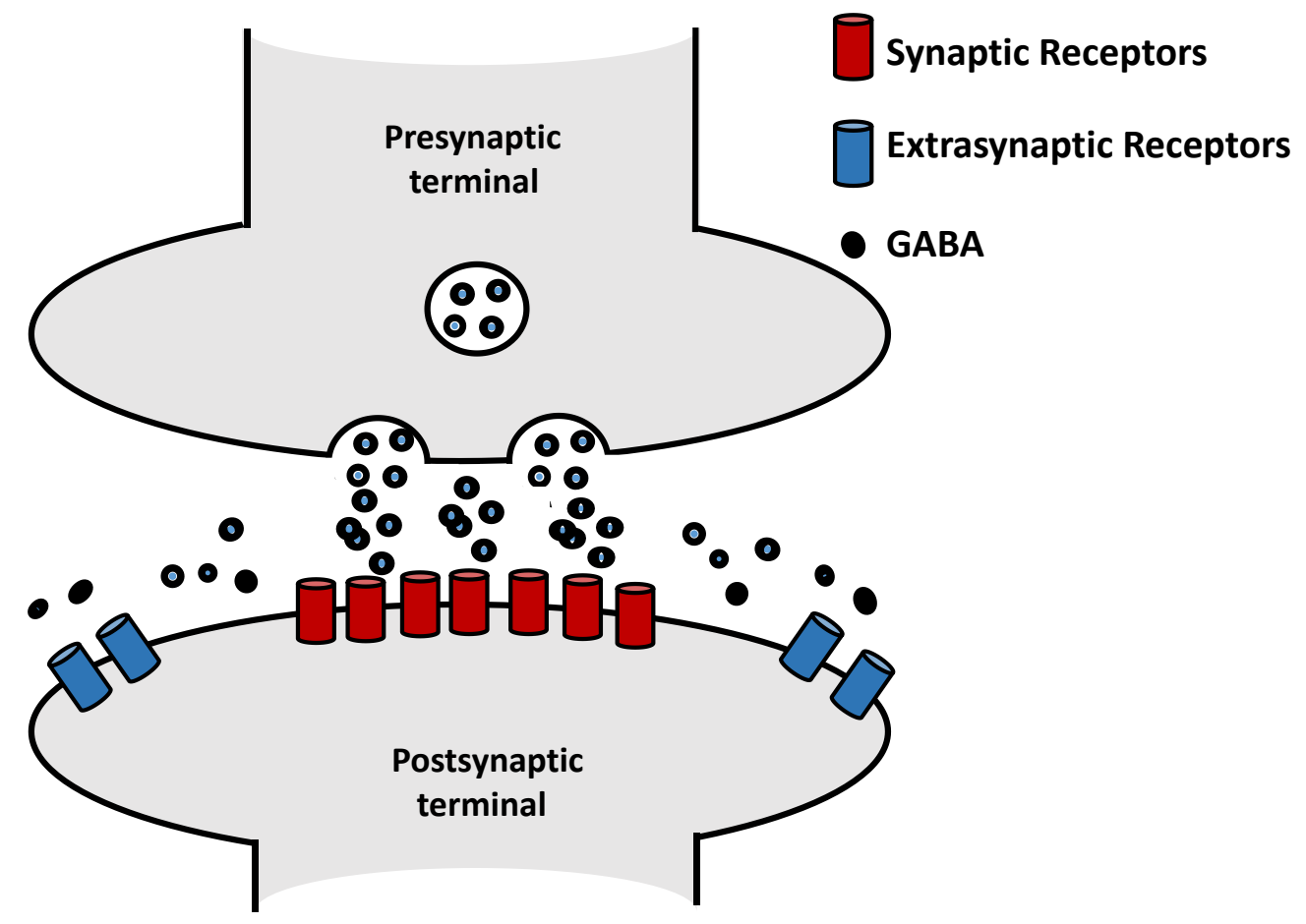

Synaptic

$\mathrm{GABA}_{\mathrm{A}}$ Receptors

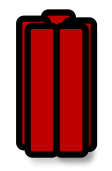

- GABA released at synapse

- Phasic Inhibition

- GABA: Full agonist

- $\alpha \beta \gamma$ configuration receptors
- GABA spilled from synapse

- Tonic Inhibition

- GABA: Partial agonist

- $\alpha \beta \delta$ configuration receptors

Figure I-4 


\section{Ion conduction and mechanism of action}

GABA ${ }_{A}$ Rs are selective for $\mathrm{Cl}^{-}$ion with some permeability for bicarbonate anions (Kaila et al., 1989). However, if the extracellular concentration of $\mathrm{Cl}^{-}$decreases due to down regulation of $\mathrm{KCC}_{2} \mathrm{Cl}^{-}$ion transporter, opening of $\mathrm{GABA}_{\mathrm{A}} \mathrm{R}$ channel pore results in efflux of $\mathrm{Cl}^{-}$ions leading to depolarization of the neurons and thus, excitation (Coull et al., 2005). Equilibrium or reversal potential of $\mathrm{Cl}^{-}$ion is close to the resting membrane potential and thus, $\mathrm{GABA}_{\mathrm{A}} \mathrm{Rs}$ have the capacity to exhibit a different form of dynamics where a small change in $\mathrm{Cl}^{-}$ion concentration can lead to significant changes in the nature of $\mathrm{GABA}_{\mathrm{A}} \mathrm{R}$ mediated transmission (Wright et al. 2011). For example, if equilibrium potential of $\mathrm{Cl}^{-}$is more negative than the resting membrane potential $G_{A B A} R$ activation will result in membrane hyperpolarization and inhibition. If equilibrium potential of $\mathrm{Cl}^{-}$is more positive than the resting membrane potential stimulating $\mathrm{GABA}_{\mathrm{A}} \mathrm{Rs}$ activation will result in membrane depolarization and thus excitation. Excitatory $\mathrm{GABA}_{\mathrm{A}}$ receptors are well documented in early development and neuropathic pain because of low extracellular $\mathrm{Cl}^{-}$levels (Coull et al., 2005; Wright et al., 2011).

Binding of a neurotransmitter "GABA" on $\mathrm{GABA}_{\mathrm{A}} \mathrm{R}$ initiates a series of molecular motions (conformational wave) that begin in the binding pocket, followed by movement in pre TM1 regions to $\mathrm{TM}(1-4)$ helices to open the ion pore, a process called coupling (Miller and Smart, 2010). Binding of the GABA at the binding pocket or site causes the channel to adopt a conformational open stable state. $\mathrm{GABA}_{\mathrm{A}}$ receptors have two binding pockets for GABA at the interface of $\alpha$ and $\beta$ subunits in the extracellular domains region. The binding 
pocket is formed by three amino acid loops (A, B and C) on $\beta^{+}$subunit "principal side" and three amino acid loops (D, E and F) on $\alpha^{-}$subunit "complementary side" (figure I-3C)(Ernst et al., 2003). GABAA receptor extracellular domains also have binding pocket for benzodiazepines at the interface of $\alpha$ and $\gamma$ subunits (Ernst et al., 2005). How binding of a ligand leads to channel opening is not clear yet and many theories have been proposed and studied. One of the regions suggested to be involved in channel gating is a short extracellular loop between TM2-TM3 (also called TM2-3 linker) (Thompson et al., 2010). Movement in TM2-3 linker mediated by extracellular domains, destabilizes the hydrophobic ring in the channel which displaces from the center of the pore to the space between the inner and outer rings, ultimately opening the channel (Miyazawa et al., 2003). Also, inherited mutations in this region have been documented which alters the channel gating without affecting ligand binding (Campos-Caro et al., 1996; Kusama et al., 1994).

Interestingly, opening of cys-loop receptors or $\mathrm{GABA}_{\mathrm{A}}$ receptors can occur in the absence of ligand or GABA as well, but at a very low frequency (Thompson et al., 2010). The binding of ligand increases the probability of channel opening and maximizes as the number of bound ligands reaches two. Since rate of channel opening can be quicker than the dissociation of the ligand, multiple opening states can occur during a single ligand binding (Burzomato et al., 2004). How efficiently ligand docking at binding pocket initiates channel opening and stabilize the open states is dependent upon how efficient is the communication or conformation wave between the extracellular domains to transmembrane domains. Different ligands have different efficacies on $\mathrm{GABA}_{\mathrm{A}}$ receptors with varying open probability. 
Full agonists initiate channel opening faster or stabilize the channel opening for a longer duration compared to partial agonists (Baumann et al., 2003).

\section{Modulation of GABAA receptors}

Like other proteins, $\mathrm{GABA}_{\mathrm{A}}$ receptors are regulated by post-translational modification. Protein kinases have been identified that phosphorylate specific amino acids residues of specific $\mathrm{GABA}_{\mathrm{A}}$ receptor subunits and modulate channel gating, surface stability and trafficking (Adams et al., 2015; Huson et al., 2007). Apart from this covalent modification, $\mathrm{GABA}_{\mathrm{A}}$ receptors are modulated by endogenous and exogenous molecules and may potentiate or suppress the natural response of GABA (Johnston, 2005). Considering the importance of $\mathrm{GABA}_{\mathrm{A}}$ receptors in the central nervous system, several classes of exogenous drug molecules are used. Examples include benzodiazepines, barbiturates, general anesthetics, ethanol, the competitive antagonist, biculline and the channel blocker, picrotoxin (Olsen, 2014). These molecules increase GABA-mediated synaptic inhibition either by directly activating $\mathrm{GABA}_{\mathrm{A}}$ receptors (Barbiturates) or, by potentiating the action of $\mathrm{GABA}$ on $\mathrm{GABA}_{\mathrm{A}}$ receptors (Barbiturates/ Benzodiazepines). This latter action is called positive modulation and is believed to be involved in molecules acting on allosteric sites on $\mathrm{GABA}_{\mathrm{A}}$ receptors remote from the GABA recognition sites (orthosteric sites) (figure I-5). Such allosteric sites are regarded as good targets for the development of subtype specific drugs since there is generally greater diversity between receptor subtypes in amino acid sequence at allosteric sites than at orthosteric sites (Johnston, 1996). Molecules that reduce the action of 
GABA on $\mathrm{GABA}_{\mathrm{A}}$ receptors are known as negative allosteric modulators (Biculline and Picrotoxin). Molecules that block the actions of both positive and negative allosteric modulators are known as neutralizing allosteric modulators (benzodiazepine 'antagonist' flumazenil)(Christopoulos, 2002). Neurosteroids (Allopregnanolone and THDOC) are the most potent positive endogenous modulators of $\mathrm{GABA}_{\mathrm{A}}$ Rs (Akk et al., 2009). Neurosteroids have been found to be involved in various disorders, like depression, anxiety, alcohol abuse, epilepsy, and neurodegenerative diseases (MacKenzie and Maguire, 2013). It has been shown that the endocannabinoid (2-arachidonoylglycerol) specifically positively modulates $\beta 2$ subunit-containing $\mathrm{GABA}_{\mathrm{A}}$ receptors through a binding site located in TM4 (Ernst et al., 2005). However, physiological role of this modulation is still not clear.

It is suggested that $\mathrm{GABA}_{\mathrm{A}}$ receptors are modulated by a large range of molecules because of the numerous binding cavities present in the transmembrane region of the receptor for these molecules (Ernst et al., 2005). Besides the GABA-binding site, $\mathrm{GABA}_{\mathrm{A}} \mathrm{Rs}$ have binding sites for several clinically important drugs, including anxiolytics, sedative-hypnotics, muscle relaxants, and anesthetics (Johnston, 1996). GABA binding site is located at the interface of the $\alpha 1$ and $\beta 2$ subunits in the extracellular domains, whereas the pentobarbital/general anesthetics (propofol) binding sites are believed to be positioned in the water accessible region located between the four TM helices of the receptor (Li et al., 2006). Moreover, the general anesthetics propofol and etomidate also allosterically modulate and directly gate $\mathrm{GABA}_{\mathrm{A}} \mathrm{Rs}$ through single site of action (Bali and Akabas, 2004) whereas distinct $\mathrm{GABA}_{A} \mathrm{R}$ sites confer these properties to neurosteroids (Hosie et al., 2006). Subunit 
composition and arrangement determine drug selectivity (Dawson et al., 2005; Rudolph and Knoflach, 2011). Critical questions are whether the allosteric and direct gating effects of carisoprodol are mediated via a single or multiple sites and how does it modulate GABAA receptors. 
Figure I-5. Representation of chloride currents gated by $\mathrm{GABA}_{\mathrm{A}}$ receptor ligands and their pharmacological properties. A, Representative traces of $\mathrm{GABA}_{\mathrm{A}} \mathrm{R}$ ligands having only positive allosteric modulation effect and not direct gating action of their own. B, Representative traces of $\mathrm{GABA}_{\mathrm{A}} \mathrm{R}$ ligands having both positive allosteric modulation effect and direct gating action. $\mathbf{C}$, Representative traces of $\mathrm{GABA}_{\mathrm{A}} \mathrm{R}$ ligands having only negative allosteric modulation effect and not direct gating action of their own. 
A

\section{Positive \\ Allosteric Modulator \\ Eg. Benzodiazepines}

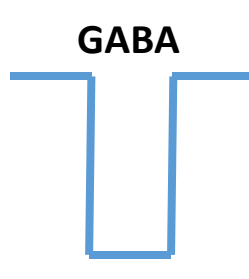

B

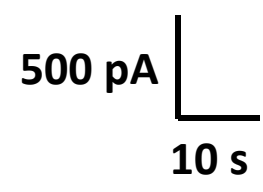

Direct gating and Positive

Allosteric Modulator Eg. Barbiturates

C

$$
\text { Negative }
$$

Allosteric Modulator

Eg. Picrotoxin
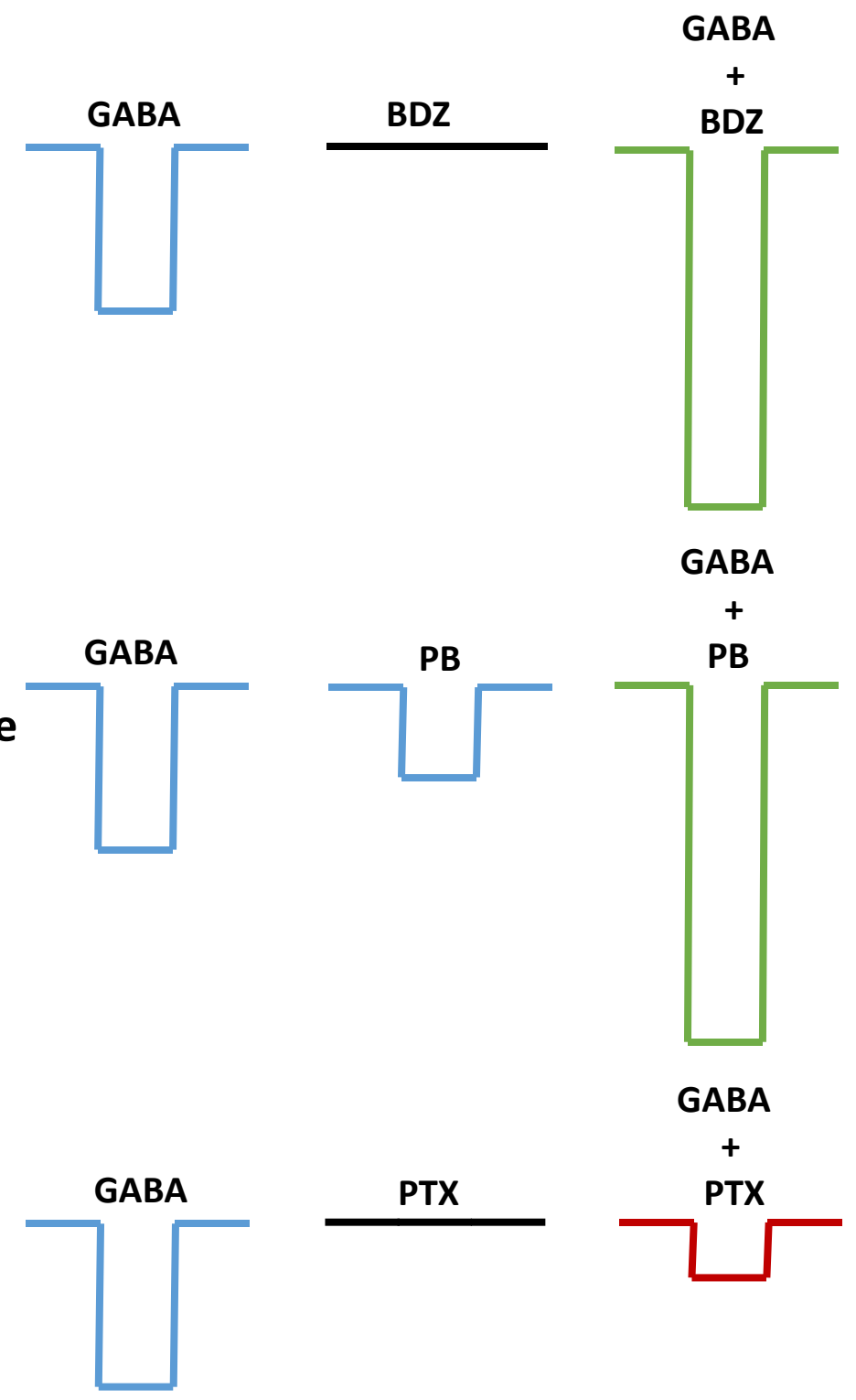

Figure I-5 


\section{Distribution and Physiological or Pharmacological Role of GABA $A_{A}$ Subunits}

Approximately 20-30\% of the neurons in the CNS are GABAergic (Bormann, 2000).

Despite diversity of $\mathrm{GABA}_{\mathrm{A}}$ receptor subunit isoforms, approximately $60 \%$ of all $\mathrm{GABA}_{\mathrm{A}}$ receptors consist of $\alpha 1 \beta 2 \gamma 2$ configuration and $90 \%$ of $\mathrm{GABA}_{\mathrm{A}}$ receptors contain $\gamma 2$ subunit (Fritschy and Mohler, 1995). Approximately 15-20\% of $\mathrm{GABA}_{\mathrm{A}}$ receptors have subunit combination of $\alpha 2 \beta 3 \gamma 2$, approximately $10-15 \%$ have the $\alpha 3 \beta x \gamma 2$ configurations, and approximately $5 \%$ have the $\alpha 4 \beta \mathrm{x} \gamma$ or $\alpha 4 \beta \mathrm{x} \delta$ configurations, less than $5 \%$ have the $\alpha 5 \beta \mathrm{x} \gamma 2$ configurations and similarly less than $5 \%$ have the configuration of $\alpha 6 \beta \mathrm{n} \gamma 2$ subunit combinations (Table 2). It is interesting to note, $\mathrm{GABA}_{\mathrm{A}}$ receptors with two different $\alpha$ subunits and without $\gamma$ or $\delta$ subunit have also been verified to express (Benke et al., 2004).

Given that GABA is the major inhibitory neurotransmitter, it is not surprising that GABA is involved, directly or indirectly, in many disorders of brain function (MacKenzie and Maguire, 2013; McBain et al., 2015). The major disorders for which $\mathrm{GABA}_{\mathrm{A}}$ receptors represent major therapeutic targets include anxiety disorders, cognitive disorders, epilepsies, mood disorders, schizophrenia and sleep disorders (Johnston, 1996; Rudolph and Mohler, 2006; Rudolph and Mohler, 2014). Functional or physiological role of each GABA depends upon both subunit composition and localization of the receptor (Dawson et al., 2005). Malfunctioning of tonic inhibition via $\delta$ expressing extra-synaptic $\mathrm{GABA}_{\mathrm{A}}$ receptors has been documented to be involved in neurological disorders like depression (Maguire et al., 2005), schizophrenia (Maldonado-Aviles et al., 2009) and some forms of epilepsy (Cope et al., 2009) and thus, extra-synaptic receptors are proving to be target of emerging clinical drugs 
(Brickley and Mody, 2012). Also, potentiation of tonic inhibition by neurosteroids, general anesthetics, anti-epileptics and sedatives/hypnotics is well verified (Bianchi and Macdonald, 2003; Feng et al., 2004).

An understanding of subunit isoform association with physiologic effects of GABAergic signaling has also developed over the past several years (Olsen and Sieghart, 2009). In an early study using knock-in technology to study roles of a specific amino acid in the $\alpha 1$ receptor (Histidine at position 101) (Rowlett et al., 2005; Rudolph et al., 1999), mutant mice expressing $\alpha 1(\mathrm{H} 101 \mathrm{R}) \mathrm{GABA}_{\mathrm{A}}$ receptors showed no sedative and anterograde amnestic effects of diazepam, and anticonvulsant effects were significantly reduced. Equivalent knockin mutations of the conserved histidine were subsequently studied in $\alpha 2$ and $\alpha 3$ receptors (Crestani et al., 2001). In $\alpha 2(\mathrm{H} 101 \mathrm{R})$ mice, anxiolytic and myorelaxant effects of diazepam were completely abolished, while sedative effects were present. In $\alpha 3(\mathrm{H} 126 \mathrm{R})$ mutant mice, myorelaxant properties of diazepam were reduced (present at high diazepam doses) while sedative and anxiolytic properties were intact. These results demonstrated diazepam mediates its muscle relaxant effects mainly through $\alpha 2$ containing $\mathrm{GABA}_{\mathrm{A}}$ receptors, and also through $\alpha 3 \mathrm{GABA}_{\mathrm{A}}$ receptors at high concentrations. A drug selective primarily for $\alpha 2$-expressing $\mathrm{GABA}_{\mathrm{A}}$ receptors would likely have better muscle relaxant properties, less abuse potential and fewer sedative effects (Rudolph and Knoflach, 2011) 
Table I-1. Localization of GABAA receptor subtypes and their physiological and pharmacological role. Adapted from (Rudolph and Mohler, 2014). 


\begin{tabular}{|c|c|c|c|}
\hline $\begin{array}{l}\alpha \text { subunit } \\
\text { Isoform }\end{array}$ & $\begin{array}{c}\text { Identified } \\
\text { Configurations }\end{array}$ & $\begin{array}{l}\text { Pharmacological and } \\
\text { Physiological Role }\end{array}$ & $\begin{array}{l}\text { Synaptic or } \\
\text { Extrasynaptic }\end{array}$ \\
\hline $\begin{array}{c}\alpha 1 \\
60 \% \text { of all } \\
\text { GABA } R s\end{array}$ & $\alpha 1 \beta 2 \gamma 2$ & $\begin{array}{l}\text { Sedation, Amnesia, } \\
\text { Anticonvulsant action, } \\
\text { Dependence and } \\
\text { Addiction. }\end{array}$ & Synaptic \\
\hline $\begin{array}{c}\alpha 2 \\
(15-20) \%\end{array}$ & $\alpha 2 \beta 3 \gamma 2$ & $\begin{array}{l}\text { Anxiolysis, } \\
\text { Antihyperanalgesia, } \\
\text { Muscle relaxation and } \\
\text { Cognitive impairment }\end{array}$ & Synaptic \\
\hline $\begin{array}{c}\alpha 3 \\
(10-15) \%\end{array}$ & $\alpha 3 \beta 2,3 \gamma 2$ & $\begin{array}{l}\text { Anxiolysis, } \\
\text { Muscle relaxation, } \\
\text { Sensorimotor gating } \\
\text { and } \\
\text { Antihyperanalgesia }\end{array}$ & Synaptic \\
\hline $\begin{array}{c}\alpha 4 \\
\text { less than } \\
5 \%\end{array}$ & $\alpha 4 \beta 2,3 \delta$ & $\begin{array}{l}\text { Memory, Anxiety, } \\
\text { Nociception, Sleep and } \\
\text { Neuropsychiatric } \\
\text { disorder }\end{array}$ & Extrasynaptic \\
\hline $\begin{array}{c}\alpha 5 \\
\text { less than } \\
5 \%\end{array}$ & $\alpha 5 \beta 3 \gamma 2$ & $\begin{array}{l}\text { Sensorimotor gating, } \\
\text { Cognitive impairment, } \\
\text { Muscle relaxation, } \\
\text { Autism, Down } \\
\text { Syndrome and } \\
\text { Schizophrenia }\end{array}$ & $\begin{array}{l}\text { Synaptic and } \\
\text { Extrasynaptic }\end{array}$ \\
\hline $\begin{array}{c}\alpha 6 \\
\text { less than } \\
5 \%\end{array}$ & $\begin{array}{l}\alpha 6 \beta 2,3 \gamma 2 \\
\alpha 6 \beta 2,3 \delta\end{array}$ & $\begin{array}{l}\text { Memory, Anxiety, } \\
\text { Nociception, Sleep } \\
\text { disorder, abdominal } \\
\text { obesity and cortisol } \\
\text { secretion }\end{array}$ & $\begin{array}{l}\text { Synaptic and } \\
\text { Extrasynaptic }\end{array}$ \\
\hline
\end{tabular}

Table I-1 


\section{Mechanism of Addiction of Benzodiazepines}

The mesolimbic system is well documented for its involvement in the mechanism of addiction of opioids, ethanol, psychostimulants and nicotine (Luscher and Ungless, 2006). These drugs increase dopaminergic transmission in the mesolimbic system, increasing the levels of dopamine in the nucleus accumbens. With regard to additive property at the $\mathrm{GABA}_{\mathrm{A}}$ receptors, the ligand for which we have the most knowledge are the benzodiazepines. Tan et al. showed $\alpha 1$-containing $\mathrm{GABA}_{\mathrm{A}}$ receptors are involved in addictive properties of benzodiazepines, and their activation elicits an increase in nucleus accumbens dopamine levels (Figure I-6) (Tan et al., 2010). GABAergic neurons in ventral tegmental area (VTA) specifically express $\alpha 1$-containing $\mathrm{GABA}_{\mathrm{A}}$ receptors, while dopaminergic neurons transmitting to nucleus accumbens from VTA express $\alpha 3$-containing $\mathrm{GABA}_{\mathrm{A}}$ receptors (Fig. 6). Potentiation of al-containing $\mathrm{GABA}_{\mathrm{A}}$ receptors on GABAergic neurons by benzodiazepines inhibits the neuron and decreases the release of GABA at dopaminergic neuron synapses. This inhibition leads to disinhibition of dopaminergic neurons expressing $\alpha 3$-containing $\mathrm{GABA}_{\mathrm{A}}$ receptors, resulting in more release of dopamine at nucleus accumbens. Theoretically, the effects of benzodiazepines at these two sites would effectively cancel each other out, and thus have nominal effects on dopamine levels. However, the actions of benzodiazepines are more predominant on $\alpha 1$-containing receptors (Heikkinen et al., 2009), thus dopamine levels are increased. A better understanding of the carisoprodol's interaction at these key $\mathrm{GABA}_{\mathrm{A}} \mathrm{R}$ isoforms would be very significant in understanding its addictive effects in addition to its therapeutic actions. 
Figure I-6. Involvement of GABAA receptors in drug addiction pathways. A, Dopaminergic and GABAergic pathways of mesolimbic system. GABAergic neurons of ventral tegmental area (VTA) specifically express $\alpha 1$ containing $\mathrm{GABA}_{\mathrm{A}}$ receptors whereas dopaminergic neurons express $\alpha 3$ containing $\mathrm{GABA}_{\mathrm{A}}$ receptors. Dopaminergic neurons transmits to nucleus accumbens and release dopamine. All addictive drugs increase the dopamine levels in nucleus accumbens via mesolimbic pathways. B, Benzodiazepines (BZP) mechanism of addiction and likely path followed by carisoprodol (CSP). Potentiation of $\alpha 1$ expressing $\mathrm{GABA}_{\mathrm{A}}$ receptors on GABAergic neurons by benzodiazepines or carisoprodol (likely) inhibit the postsynaptic potential and decrease the release of GABA at dopaminergic neuron synapses. Decreased GABA levels at the synapses leads to disinhibition of dopaminergic neurons and increase the dopamine release at nucleus accumbens. Technically $\mathrm{BZP}$ (or CSP) should cancel its effects via potentiation of $\alpha 3$ containing $\mathrm{GABA}_{\mathrm{A}}$ receptors on dopaminergic neurons but BZP's action is predominant on $\alpha 1$ containing $\mathrm{GABA}_{\mathrm{A}}$ receptors. 


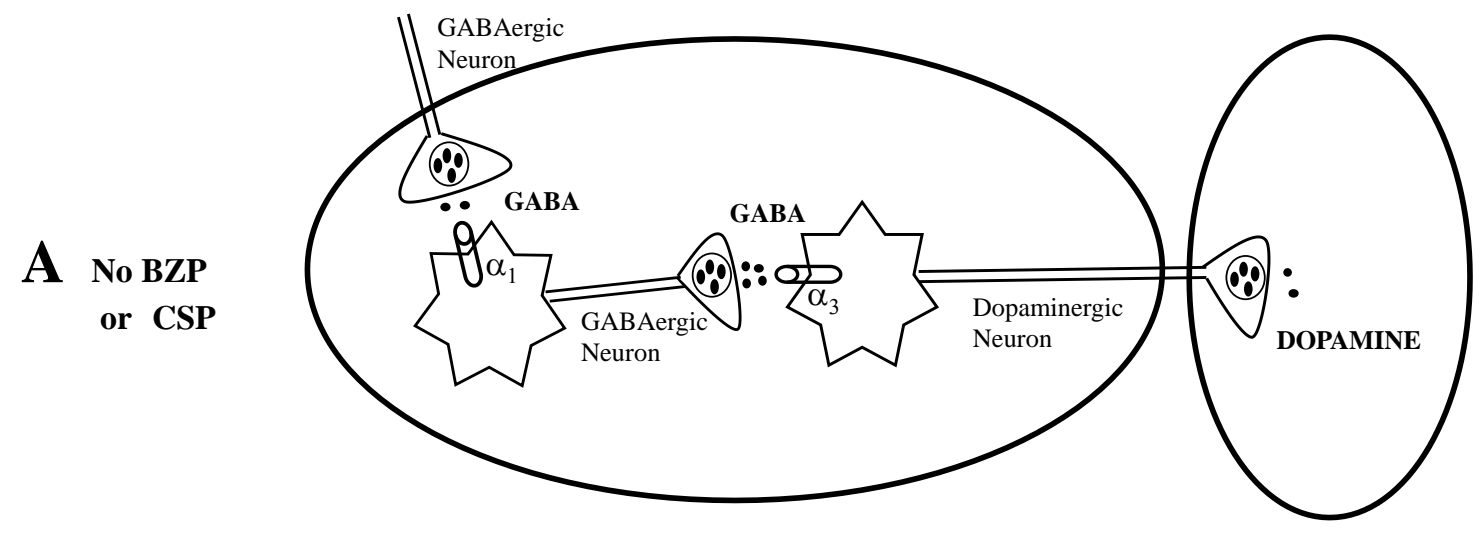

Ventral Tegmental Area

Nucleus Accumbens

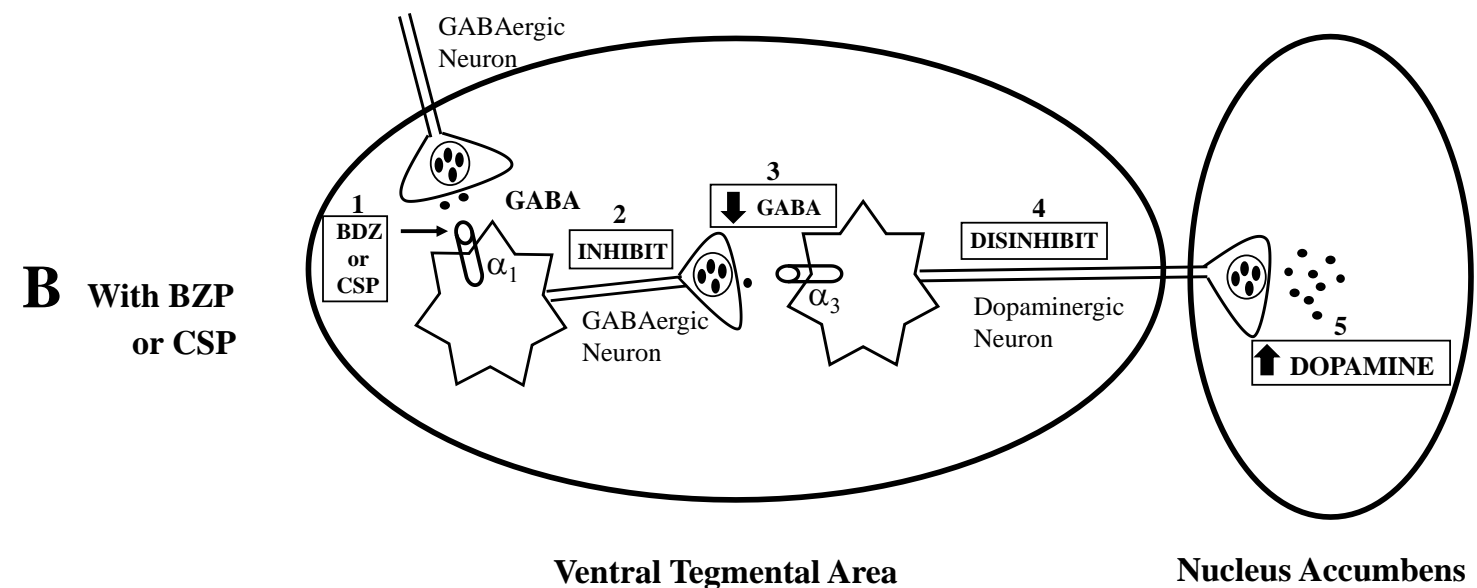

Figure I-6 


\section{Objective of the dissertation}

In light of the fact that $\mathrm{GABA}_{\mathrm{A}}$ receptors subunit isoforms influence physiologic effects like anxiety, sedation, addiction, muscle relaxation and drug tolerance and carisoprodol's therapeutic effects, we hypothesize that carisoprodol modulates GABAA in a subunit-dependent manner, possibly through a novel site of action, with different amino acid domains contributing to direct gating and allosteric modulation actions of carisoprodol. Investigation of $\mathrm{GABA}_{\mathrm{A}} \mathrm{R}$ subunit-dependent effects of carisoprodol and $\mathrm{GABA}_{\mathrm{A}} \mathrm{R}$ subunit amino acid domains that confer carisoprodol sensitivity would provide critical information for carisoprodol's molecular mechanism of action, that would help in understating the mechanism underlying its abuse potential and muscle relaxing properties and thus, in the treatment of tolerance and withdrawal symptoms of carisoprodol. If carisoprodol is highly efficacious on $\alpha 1$ subunit containing $\mathrm{GABA}_{\mathrm{A}}$ receptors, it may be the underlying mechanism for its ability in enhancing the sedative effects of CNS depressants and its high potential for abuse. Moreover, the general anesthetics propofol and etomidate also allosterically modulate and directly gate $\mathrm{GABA}_{\mathrm{A}} \mathrm{Rs}$ through a single site of action whereas distinct $\mathrm{GABA}_{\mathrm{A}} \mathrm{R}$ sites confer these properties to neurosteroids. A critical question is whether the allosteric and direct gating effects of carisoprodol are mediated via a single or two sites. The aim of the dissertation was divided in two; 1) to identify subunit-dependent influence on direct gating and allosteric enhancement effects of carisoprodol on GABA $A_{A}$ s and 2) To identify the GABAARs subunit domains that confer carisoprodol sensitivity. To study the subunit-dependent effect of carisoprodol, we transfected HEK 293 cells with desired 
receptor configuration and tested for direct activation and allosteric modulation by carisoprodol and to gain insight into possible critical amino acid domains in $\mathrm{GABA}_{\mathrm{A}} \mathrm{R}$ subunits, we generated site directed mutants of $\alpha 1$ and $\alpha 3$ subunits and tested carisoprodol sensitivity for direct and allosteric effects.

The quest to develop GABAergic ligands with better delineation of therapeutic and adverse actions has begun to show considerable promise in recent years, and a number of agents with unique subunit-selective profiles are in development for the treatment of anxiety, sleep disorder, down syndrome, autism, schizophrenia and epilepsy (Dawson et al., 2005; Rudolph and Mohler, 2014). With regard to muscle relaxants, a drug selective primarily for $\alpha 2$-expressing $\mathrm{GABA}_{\mathrm{A}}$ receptors would likely have less abuse potential and fewer sedative effects (Rudolph and Knoflach, 2011). Considering the fact that low back pain has been one of the top five reasons for physician visits in the United States for decades (Witenko et al., 2014), the need to develop a safe and efficacious agent for this substantial medical need is clear. The overall aim of the study is to gain insight into molecular action of carisoprodol on $\mathrm{GABA}_{\mathrm{A}} \mathrm{Rs}$ that would help us in understanding the mechanism underlie carisoprodol's abuse, muscle relaxant properties and in development of a new drug with better muscle relaxing properties and reduced abuse potential. 


\section{REFERENCES}

Medical economics company, in Physician's Desk reference, 59th Edition 2005 p 1976, Medical economics company, Montvale, New Jersey.

Schedule of controlled substances: placement of carisoprodol into Schedule IV, in $76 \mathrm{pp}$ 77330-77360, Drug Enforcement Administration, Federal Register.

(2004) Physicians Desk Reference. 58 ed. Thomson PDR, Montvale, New Jersey

Adams JM, Thomas P and Smart TG (2015) Modulation of neurosteroid potentiation by protein kinases at synaptic- and extrasynaptic-type $\mathrm{GABA}_{\mathrm{A}}$ receptors. Neuropharmacology 88: 63-73.

Akk G, Bracamontes J and Steinbach JH (2004) Activation of GABA(A) receptors containing the alpha4 subunit by GABA and pentobarbital. The Journal of physiology 556(Pt 2): 387-399.

Akk G, Covey DF, Evers AS, Steinbach JH, Zorumski CF and Mennerick S (2009) The influence of the membrane on neurosteroid actions at $\operatorname{GABA}(\mathrm{A})$ receptors. Psychoneuroendocrinology 34 Suppl 1: S59-66.

Allen MD, Greenblatt DJ and Noel BJ (1977) Meprobamate overdosage: a continuing problem. Clinical toxicology 11(5): 501-515.

Bailey DN and Briggs JR (2002) Carisoprodol: an unrecognized drug of abuse. American journal of clinical pathology 117(3): 396-400.

Bali M and Akabas MH (2004) Defining the propofol binding site location on the GABA receptor. Molecular pharmacology 65(1): 68-76. 
Barnard EA, Skolnick P, Olsen RW, Mohler H, Sieghart W, Biggio G, Braestrup C, Bateson AN and Langer SZ (1998) International Union of Pharmacology. XV. Subtypes of gamma-aminobutyric acidA receptors: classification on the basis of subunit structure and receptor function. Pharmacological reviews 50(2): 291-313.

Baumann SW, Baur R and Sigel E (2003) Individual properties of the two functional agonist sites in $\mathrm{GABA}(\mathrm{A})$ receptors. The Journal of neuroscience : the official journal of the Society for Neuroscience 23(35): 11158-11166.

Belelli D, Harrison NL, Maguire J, Macdonald RL, Walker MC and Cope DW (2009) Extrasynaptic $\mathrm{GABA}_{\mathrm{A}}$ receptors: form, pharmacology, and function. The Journal of neuroscience : the official journal of the Society for Neuroscience 29(41): 1275712763.

Benke D, Fakitsas P, Roggenmoser C, Michel C, Rudolph U and Mohler H (2004) Analysis of the presence and abundance of $\mathrm{GABA}_{\mathrm{A}}$ receptors containing two different types of alpha subunits in murine brain using point-mutated alpha subunits. The Journal of biological chemistry 279(42): 43654-43660.

Bergmann R, Kongsbak K, Sorensen PL, Sander T and Balle T (2013) A unified model of the $\mathrm{GABA}(\mathrm{A})$ receptor comprising agonist and benzodiazepine binding sites. PloS one 8(1): e52323.

Bianchi MT and Macdonald RL (2003) Neurosteroids shift partial agonist activation of $\mathrm{GABA}(\mathrm{A})$ receptor channels from low- to high-efficacy gating patterns. The 
Journal of neuroscience : the official journal of the Society for Neuroscience 23(34): 10934-10943.

Bormann J (2000) The 'ABC' of GABA receptors. Trends in pharmacological sciences 21(1): 16-19.

Bramness JG, Furu K, Engeland A and Skurtveit S (2007a) Carisoprodol use and abuse in Norway: a pharmacoepidemiological study. British journal of clinical pharmacology 64(2): 210-218.

Bramness JG, Morland J, Sorlid HK, Rudberg N and Jacobsen D (2005a) Carisoprodol intoxications and serotonergic features. Clinical toxicology (Philadelphia, $\mathrm{Pa}$ ) 43(1): 39-45.

Bramness JG, Skurtveit S, Gulliksen M, Breilid H, Steen VM and Morland J (2005b) The CYP2C19 genotype and the use of oral contraceptives influence the pharmacokinetics of carisoprodol in healthy human subjects. European journal of clinical pharmacology 61(7): 499-506.

Bramness JG, Skurtveit S and Morland J (2004) Impairment due to intake of carisoprodol. Drug and alcohol dependence 74(3): 311-318.

Bramness JG, Skurtveit S, Morland J and Engeland A (2007b) The risk of traffic accidents after prescriptions of carisoprodol. Accident; analysis and prevention 39(5): 10501055.

Brickley SG and Mody I (2012) Extrasynaptic GABA(A) receptors: their function in the CNS and implications for disease. Neuron 73(1): 23-34. 
Briggs GG, Ambrose PJ, Nageotte MP and Padilla G (2008) High-dose carisoprodol during pregnancy and lactation. The Annals of pharmacotherapy 42(6): 898-901.

Bronstein AC, Spyker DA, Cantilena LR, Jr., Green JL, Rumack BH and Giffin SL (2009) 2008 Annual Report of the American Association of Poison Control Centers' National Poison Data System (NPDS): 26th Annual Report. Clinical toxicology (Philadelphia, Pa) 47(10): 911-1084.

Burzomato V, Beato M, Groot-Kormelink PJ, Colquhoun D and Sivilotti LG (2004) Single-channel behavior of heteromeric alphalbeta glycine receptors: an attempt to detect a conformational change before the channel opens. The Journal of neuroscience : the official journal of the Society for Neuroscience 24(48): 1092410940.

Campos-Caro A, Sala S, Ballesta JJ, Vicente-Agullo F, Criado M and Sala F (1996) A single residue in the M2-M3 loop is a major determinant of coupling between binding and gating in neuronal nicotinic receptors. Proceedings of the National Academy of Sciences of the United States of America 93(12): 6118-6123.

Christopoulos A (2002) Allosteric binding sites on cell-surface receptors: novel targets for drug discovery. Nature reviews Drug discovery 1(3): 198-210.

Cope DW, Di Giovanni G, Fyson SJ, Orban G, Errington AC, Lorincz ML, Gould TM,

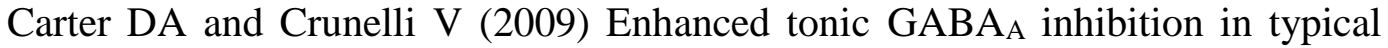
absence epilepsy. Nature medicine 15(12): 1392-1398. 
Corringer PJ, Poitevin F, Prevost MS, Sauguet L, Delarue M and Changeux JP (2012) Structure and pharmacology of pentameric receptor channels: from bacteria to brain. Structure (London, England : 1993) 20(6): 941-956.

Coull JA, Beggs S, Boudreau D, Boivin D, Tsuda M, Inoue K, Gravel C, Salter MW and De Koninck Y (2005) BDNF from microglia causes the shift in neuronal anion gradient underlying neuropathic pain. Nature 438(7070): 1017-1021.

Crestani F, Low K, Keist R, Mandelli M, Mohler H and Rudolph U (2001) Molecular targets for the myorelaxant action of diazepam. Molecular pharmacology 59(3): $442-445$.

daCosta CJ and Baenziger JE (2013) Gating of pentameric ligand-gated ion channels: structural insights and ambiguities. Structure (London, England : 1993) 21(8): $1271-1283$.

Dalen P, Alvan G, Wakelkamp M and Olsen H (1996) Formation of meprobamate from carisoprodol is catalysed by CYP2C19. Pharmacogenetics 6(5): 387-394.

Davis K (2009) The Soma pipeline. Drug Free Az news and events, May 13, 2004., www.drugfreeaz.com/news/articles_soma.html.

Dawson GR, Collinson N and Atack JR (2005) Development of subtype selective GABAA modulators. CNS spectrums 10(1): 21-27.

DeLorey TM and Olsen RW (1992) Gamma-aminobutyric acidA receptor structure and function. The Journal of biological chemistry 267(24): 16747-16750. 
Ernst M, Brauchart D, Boresch S and Sieghart W (2003) Comparative modeling of GABA(A) receptors: limits, insights, future developments. Neuroscience 119(4): 933-943.

Ernst M, Bruckner S, Boresch S and Sieghart W (2005) Comparative models of GABA receptor extracellular and transmembrane domains: important insights in pharmacology and function. Molecular pharmacology 68(5): 1291-1300.

Farrant $\mathrm{M}$ and Nusser Z (2005) Variations on an inhibitory theme: phasic and tonic activation of GABA(A) receptors. Nature reviews Neuroscience 6(3): 215-229.

Fass JA (2010) Carisoprodol legal status and patterns of abuse. The Annals of pharmacotherapy 44(12): 1962-1967.

Feng HJ, Bianchi MT and Macdonald RL (2004) Pentobarbital differentially modulates alpha1beta3delta and alpha1beta3gamma2L GABA $\mathrm{A}_{\mathrm{A}}$ receptor currents. Molecular pharmacology 66(4): 988-1003.

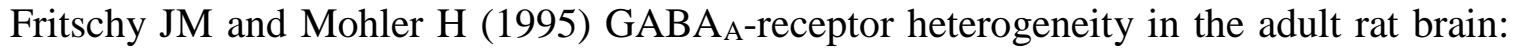
differential regional and cellular distribution of seven major subunits. The Journal of comparative neurology 359(1): 154-194.

Gatch MB, Nguyen JD, Carbonaro T and Forster MJ (2012) Carisoprodol tolerance and precipitated withdrawal. Drug and alcohol dependence 123(1-3): 29-34.

Glykys J and Mody I (2007) Activation of $\mathrm{GABA}_{\mathrm{A}}$ receptors: views from outside the synaptic cleft. Neuron 56(5): 763-770. 
Gonzalez LA, Gatch MB, Forster MJ and Dillon GH (2009a) Abuse Potential of Soma: the GABA(A) Receptor as a Target. Molecular and cellular pharmacology 1(4): 180186.

Gonzalez LA, Gatch MB, Taylor CM, Bell-Horner CL, Forster MJ and Dillon GH (2009b) Carisoprodol-mediated modulation of $\mathrm{GABA}_{\mathrm{A}}$ receptors: in vitro and in vivo studies. The Journal of pharmacology and experimental therapeutics 329(2): 827837.

Hardon AP and Ihsan A (2014) Somadril and edgework in South Sulawesi. The International journal on drug policy 25(4): 755-761.

Heikkinen AE, Moykkynen TP and Korpi ER (2009) Long-lasting modulation of glutamatergic transmission in VTA dopamine neurons after a single dose of benzodiazepine agonists. Neuropsychopharmacology : official publication of the American College of Neuropsychopharmacology 34(2): 290-298.

Herd MB, Foister N, Chandra D, Peden DR, Homanics GE, Brown VJ, Balfour DJ, Lambert JJ and Belelli D (2009) Inhibition of thalamic excitability by 4,5,6,7tetrahydroisoxazolo[4,5-c]pyridine-3-ol: a selective role for delta-GABA(A) receptors. The European journal of neuroscience 29(6): 1177-1187.

Hoiseth G, Karinen R, Sorlid HK and Bramness JG (2009) The effect of scheduling and withdrawal of carisoprodol on prevalence of intoxications with the drug. Basic \& clinical pharmacology \& toxicology 105(5): 345-349. 
Hoiseth G, Majid U, Morland J, Bramness JG and Molden E (2012) CYP2C19 genetics in fatal carisoprodol intoxications. European journal of clinical pharmacology 68(11): 1561-1565.

Hosie AM, Wilkins ME, da Silva HM and Smart TG (2006) Endogenous neurosteroids regulate $\mathrm{GABA}_{\mathrm{A}}$ receptors through two discrete transmembrane sites. Nature 444(7118): 486-489.

Huson DH, Richter DC, Rausch C, Dezulian T, Franz M and Rupp R (2007) Dendroscope: An interactive viewer for large phylogenetic trees. BMC bioinformatics 8: 460.

Johnston GA (1996) GABAA receptor pharmacology. Pharmacology \& therapeutics 69(3): 173-198.

Johnston GA (2005) GABA(A) receptor channel pharmacology. Current pharmaceutical design 11(15): 1867-1885.

Kaila K, Pasternack M, Saarikoski J and Voipio J (1989) Influence of GABA-gated bicarbonate conductance on potential, current and intracellular chloride in crayfish muscle fibres. The Journal of physiology 416: 161-181.

Kusama T, Wang JB, Spivak CE and Uhl GR (1994) Mutagenesis of the GABA rho 1 receptor alters agonist affinity and channel gating. Neuroreport 5(10): 1209-1212.

Li GD, Chiara DC, Sawyer GW, Husain SS, Olsen RW and Cohen JB (2006) Identification of a $\mathrm{GABA}_{\mathrm{A}}$ receptor anesthetic binding site at subunit interfaces by photolabeling with an etomidate analog. The Journal of neuroscience : the official journal of the Society for Neuroscience 26(45): 11599-11605. 
Littrell RA, Hayes LR and Stillner V (1993a) Carisoprodol (Soma): a new and cautious perspective on an old agent. Southern medical journal 86(7): 753-756.

Littrell RA, Sage T and Miller W (1993b) Meprobamate dependence secondary to carisoprodol (Soma) use. The American journal of drug and alcohol abuse 19(1): 133-134.

Luo X, Pietrobon R, Curtis LH and Hey LA (2004) Prescription of nonsteroidal antiinflammatory drugs and muscle relaxants for back pain in the United States. Spine 29(23): E531-537.

Luscher C and Ungless MA (2006) The mechanistic classification of addictive drugs. PLoS medicine 3(11): e437.

MacKenzie G and Maguire J (2013) Neurosteroids and GABAergic signaling in health and disease. Biomolecular concepts 4(1): 29-42.

Maguire JL, Stell BM, Rafizadeh M and Mody I (2005) Ovarian cycle-linked changes in $\operatorname{GABA}(\mathrm{A})$ receptors mediating tonic inhibition alter seizure susceptibility and anxiety. Nature neuroscience 8(6): 797-804.

Maldonado-Aviles JG, Curley AA, Hashimoto T, Morrow AL, Ramsey AJ, O'Donnell P, Volk DW and Lewis DA (2009) Altered markers of tonic inhibition in the dorsolateral prefrontal cortex of subjects with schizophrenia. The American journal of psychiatry 166(4): 450-459.

McBain CJ, Kittler J, Luscher B, Mody I and Orser BA (2015) GABAergic signaling in health and disease. Neuropharmacology 88: 1. 
McIntyre IM, Sherrard J and Lucas J (2012) Postmortem carisoprodol and meprobamate concentrations in blood and liver: lack of significant redistribution. Journal of analytical toxicology 36(3): 177-181.

Miller PS and Smart TG (2010) Binding, activation and modulation of Cys-loop receptors. Trends in pharmacological sciences 31(4): 161-174.

Miyazawa A, Fujiyoshi Y and Unwin N (2003) Structure and gating mechanism of the acetylcholine receptor pore. Nature 423(6943): 949-955.

Moss SJ and Smart TG (2001) Constructing inhibitory synapses. Nature reviews Neuroscience 2(4): 240-250.

Mounier B, Pons B, Delavenne X, Beyens MN, Remy C, Zeni F, Mismetti P and Basset T (2012) [Severe meprobamate poisoning: description of 146 cases in a French department]. Therapie 67(2): 183-189.

Nebhinani N, Aggarwal M, Mattoo SK and Basu D (2013) Carisoprodol: an underrecognized drug of abuse in north India. General hospital psychiatry 35(1): $89-92$.

Ni K, Cary M and Zarkowski P (2007) Carisoprodol withdrawal induced delirium: A case study. Neuropsychiatric disease and treatment 3(5): 679-682.

Olsen H, Koppang E, Alvan G and Morland J (1994) Carisoprodol elimination in humans. Therapeutic drug monitoring 16(4): 337-340.

Olsen RW (2014) Analysis of gamma-Aminobutyric Acid (GABA) Type A Receptor Subtypes Using Isosteric and Allosteric Ligands. Neurochemical research. 
Olsen RW and Sieghart W (2008) International Union of Pharmacology. LXX. Subtypes of gamma-aminobutyric acid(A) receptors: classification on the basis of subunit composition, pharmacology, and function. Update. Pharmacological reviews 60(3): 243-260.

Olsen RW and Sieghart W (2009) GABA A receptors: subtypes provide diversity of function and pharmacology. Neuropharmacology 56(1): 141-148.

Owens C, Pugmire B, Salness T, Culbertson V, Force R, Cady P and Steiner J (2007) Abuse potential of carisoprodol: a retrospective review of Idaho Medicaid pharmacy and medical claims data. Clinical therapeutics 29(10): 2222-2225.

Quirk K, Gillard NP, Ragan CI, Whiting PJ and McKernan RM (1994) Model of subunit composition of gamma-aminobutyric acid A receptor subtypes expressed in rat cerebellum with respect to their alpha and gamma/delta subunits. The Journal of biological chemistry 269(23): 16020-16028.

Reeves RR, Beddingfield JJ and Mack JE (2004) Carisoprodol withdrawal syndrome. Pharmacotherapy 24(12): 1804-1806.

Reeves RR and Burke RS (2010) Carisoprodol: abuse potential and withdrawal syndrome. Current drug abuse reviews 3(1): 33-38.

Reeves RR, Burke RS and Kose S (2012) Carisoprodol: update on abuse potential and legal status. Southern medical journal 105(11): 619-623.

Reeves RR, Carter OS and Pinkofsky HB (1999a) Use of carisoprodol by substance abusers to modify the effects of illicit drugs. Southern medical journal 92(4): 441. 
Reeves RR, Carter OS, Pinkofsky HB, Struve FA and Bennett DM (1999b) Carisoprodol (soma): abuse potential and physician unawareness. Journal of addictive diseases 18(2): 51-56.

Reeves RR, Hammer JS and Pendarvis RO (2007) Is the frequency of carisoprodol withdrawal syndrome increasing? Pharmacotherapy 27(10): 1462-1466.

Reeves RR and Liberto V (2001) Abuse of combinations of carisoprodol and tramadol. Southern medical journal 94(5): 512-514.

Reeves RR, Pinkofsky HB and Carter OS (1997) Carisoprodol: a drug of continuing abuse. The Journal of the American Osteopathic Association 97(12): 723-724.

Rho JM, Donevan SD and Rogawski MA (1997) Barbiturate-like actions of the propanediol dicarbamates felbamate and meprobamate. The Journal of pharmacology and experimental therapeutics 280(3): 1383-1391.

Roache JD and Griffiths RR (1987) Lorazepam and meprobamate dose effects in humans: behavioral effects and abuse liability. The Journal of pharmacology and experimental therapeutics 243(3): 978-988.

Ronning M (2001) Drug consumption in Norway 1996-2000. Norwegian Medicinal Depot, Oslo.

Roth BA, Vinson DR and Kim S (1998) Carisoprodol-induced myoclonic encephalopathy. Journal of toxicology Clinical toxicology 36(6): 609-612.

Rowlett JK, Platt DM, Lelas S, Atack JR and Dawson GR (2005) Different GABAA receptor subtypes mediate the anxiolytic, abuse-related, and motor effects of 
benzodiazepine-like drugs in primates. Proceedings of the National Academy of Sciences of the United States of America 102(3): 915-920.

Rudolph U, Crestani F, Benke D, Brunig I, Benson JA, Fritschy JM, Martin JR, Bluethmann H and Mohler H (1999) Benzodiazepine actions mediated by specific gamma-aminobutyric acid(A) receptor subtypes. Nature 401(6755): 796-800.

Rudolph U and Knoflach F (2011) Beyond classical benzodiazepines: novel therapeutic potential of $\mathrm{GABA}_{\mathrm{A}}$ receptor subtypes. Nature reviews Drug discovery 10(9): 685697.

Rudolph U and Mohler H (2006) GABA-based therapeutic approaches: GABA $A_{A}$ receptor subtype functions. Current opinion in pharmacology 6(1): 18-23.

Rudolph U and Mohler H (2014) $\mathrm{GABA}_{\mathrm{A}}$ receptor subtypes: Therapeutic potential in Down syndrome, affective disorders, schizophrenia, and autism. Annual review of pharmacology and toxicology 54: 483-507.

Sigel E and Steinmann ME (2012) Structure, function, and modulation of GABA(A) receptors. The Journal of biological chemistry 287(48): 40224-40231.

Tamminga WJ, Wemer J, Oosterhuis B, de Zeeuw RA, de Leij LF and Jonkman JH (2001) The prevalence of CYP2D6 and CYP2C19 genotypes in a population of healthy Dutch volunteers. European journal of clinical pharmacology 57(10): 717-722.

Tan KR, Brown M, Labouebe G, Yvon C, Creton C, Fritschy JM, Rudolph U and Luscher C (2010) Neural bases for addictive properties of benzodiazepines. Nature 463(7282): 769-774. 
Thompson AJ, Lester HA and Lummis SC (2010) The structural basis of function in Cysloop receptors. Quarterly reviews of biophysics 43(4): 449-499.

Toth PP and Urtis J (2004) Commonly used muscle relaxant therapies for acute low back pain: a review of carisoprodol, cyclobenzaprine hydrochloride, and metaxalone. Clinical therapeutics 26(9): 1355-1367.

Tse SA, Atayee RS, Ma JD and Best BM (2014) Factors affecting carisoprodol metabolism in pain patients using urinary excretion data. Journal of analytical toxicology 38(3): $122-128$.

Whiting PJ (2003) GABA-A receptor subtypes in the brain: a paradigm for CNS drug discovery? Drug discovery today 8(10): 445-450.

Witenko C, Moorman-Li R, Motycka C, Duane K, Hincapie-Castillo J, Leonard P and Valaer C (2014) Considerations for the appropriate use of skeletal muscle relaxants for the management of acute low back pain. $P \& T:$ a peer-reviewed journal for formulary management 39(6): 427-435.

Wohlfarth KM, Bianchi MT and Macdonald RL (2002) Enhanced neurosteroid potentiation of ternary $\mathrm{GABA}(\mathrm{A})$ receptors containing the delta subunit. The Journal of neuroscience : the official journal of the Society for Neuroscience 22(5): 1541-1549.

Wright R, Raimondo JV and Akerman CJ (2011) Spatial and temporal dynamics in the ionic driving force for GABA(A) receptors. Neural plasticity 2011: 728395. 
Wyller TB, Korsmo G and Gadeholt G (1991) [Dependence on carisoprodol (Somadril)? A prospective withdrawal study among prisoners]. Tidsskrift for den Norske laegeforening : tidsskrift for praktisk medicin, ny raekke 111(2): 193-195.

Zacny JP and Gutierrez S (2011) Subjective, psychomotor, and physiological effects of oxycodone alone and in combination with ethanol in healthy volunteers. Psychopharmacology 218(3): 471-481.

Zacny JP, Paice JA and Coalson DW (2011) Characterizing the subjective and psychomotor effects of carisoprodol in healthy volunteers. Pharmacology, biochemistry, and behavior 100(1): 138-143.

Zacny JP, Paice JA and Coalson DW (2012) Subjective and psychomotor effects of carisoprodol in combination with oxycodone in healthy volunteers. Drug and alcohol dependence 120(1-3): 229-232. 
CHAPTER II

\section{ASSESSMENT OF SUBUNIT-DEPENDENT DIRECT GATING AND \\ ALLOSTERIC MODULATORY EFFECTS OF CARISOPRODOL AT GABAA RECEPTORS}

Manoj Kumar\#, Lorie A. González*^, and Glenn H. Dillon\#\$

Department of Pharmaceutical Sciences, School of Pharmacy\#, Department of Physiology and Pharmacology and Center for Neuroscience, School of Medicine\#\$, West Virginia University, Robert C. Byrd Health Sciences Center Morgantown, WV 26506, Department of Pharmacology and Neuroscience, University of North Texas Health Science Center, Fort Worth, TX 76107*

$\wedge$ current address: Baylor College of Medicine, Department of Molecular Physiology \& Biophysics, One Baylor Plaza, Houston, TX 77030

Foot note: Neuropharmacology (2015), doi: 10.1016/j.neuropharm.2015.04.007. 


\begin{abstract}
Carisoprodol is a widely prescribed muscle relaxant, abuse of which has grown considerably in recent years. It directly activates and allosterically modulates $\alpha 1 \beta 2 \gamma 2$ $\mathrm{GABA}_{\mathrm{A}} \mathrm{Rs}$, although the site(s) of action are unknown. To gain insight into the actions of carisoprodol, subunit-dependent effects of this drug were assessed. Whole-cell patch clamp recordings were obtained from HEK293 cells expressing $\alpha 1 \beta 2, \alpha 1 \beta 3$ or $\alpha x \beta z \gamma 2$ (where $\mathrm{x}$ $=1-6$ and $z=1-3$ ) GABA $\mathrm{A}_{\mathrm{A}}$, and in receptors incorporating the $\delta$ subunit (modeling extrasynaptic receptors). The ability to directly gate and allosterically potentiate GABAgated currents was observed for all configurations. Presence or absence of the $\gamma 2$ subunit did not affect the ability of carisoprodol to directly gate or allosterically modulate the receptor. Presence of the $\beta 1$ subunit conferred highest efficacy for direct activation relative to maximum GABA currents, while presence of the $\beta 2$ subunit conferred highest efficacy for allosteric modulation of the GABA response. With regard to $\alpha$ subunits, carisoprodol was most efficacious at enhancing the actions of GABA in receptors incorporating the $\alpha 1$ subunit. The ability to directly gate the receptor was generally comparable regardless of the $\alpha$ subunit isoform, although receptors incorporating the $\alpha 3$ subunit showed significantly reduced direct gating efficacy and affinity. In extrasynaptic $(\alpha 1 \beta 3 \delta$ and $\alpha 4 \beta 3 \delta$ ) receptors, carisoprodol had greater efficacy than GABA as a direct gating agonist. In addition, carisoprodol allosterically potentiated both $\mathrm{EC}_{20}$ and saturating $\mathrm{GABA}$ concentrations in these receptors. In assessing voltage-dependence, we found direct gating
\end{abstract}


and inhibitory effects were insensitive to membrane voltage, whereas allosteric modulatory effects were affected by membrane voltage. Our findings demonstrate direct and allosteric effects of carisoprodol at synaptic and extrasynpatic $\mathrm{GABA}_{\mathrm{A}} \mathrm{Rs}$ and that subunit isoform influences these effects. 


\section{INTRODUCTION}

$\gamma$-Aminobutyric acid type A receptors $\left(\mathrm{GABA}_{\mathrm{A}} \mathrm{Rs}\right)$ are ion channel-coupled, multisubunit proteins that serve as the primary mediators of inhibitory neurotransmission in the adult central nervous system (CNS). Functional receptors are composed of individual subunits arranged in a pentameric manner. In mammals, the various subunits and their isoforms have been divided into the following classes: $\alpha(1-6), \beta(1-3), \gamma(1-3), \rho, \delta, \varepsilon, \pi$, and $\theta$ (Huang et al., 2006). Subunit architecture is highly conserved among $\mathrm{GABA}_{\mathrm{A}} \mathrm{Rs}$ with each subunit composed of an extracellular amino-terminal, four transmembrane (TM) domains, a large intracellular loop, and an extracellular carboxyl-terminal. Subunit composition determines channel conductance, kinetics, and gating properties of the receptor (Olsen and Sieghart, 2008). Synaptic $\mathrm{GABA}_{\mathrm{A}} \mathrm{Rs}$ are responsible for phasic changes in GABA-mediated post-synaptic inhibition. Extrasynaptic receptors, which typically incorporate a $\delta$ subunit (Mortensen et al., 2010), exert a tonic inhibitory influence on neuronal membrane potential. Given their vital role in inhibitory signaling in the CNS, $\mathrm{GABA}_{\mathrm{A}} \mathrm{Rs}$ are the targets of several clinically relevant compounds. These compounds include benzodiazepines, barbiturates, general and inhalational anesthetics, and certain centrally-acting muscle relaxants.

Carisoprodol is a centrally-acting muscle relaxant indicated in the alleviation of acute musculoskeletal conditions (Toth and Urtis, 2004). With a single dose of $350 \mathrm{mg}$, effects of carisoprodol begin within 30 minutes of administration and plasma concentrations reach 4-7 $\mu \mathrm{g} / \mathrm{mL}$ in 2 to 4 hours (Littrell et al., 1993). The dangers associated with carisoprodol 
abuse, such as psychomotor impairment and severe withdrawal that may lead to seizures and death, are well-documented (Adams et al., 1975; Elder, 1991; Littrell et al., 1993; Reeves and Parker, 2003; Rust et al., 1993; Zacny et al., 2011, 2012). Precipitated withdrawal studies in mice have demonstrated tolerance to carisoprodol develops in as few as four doses (Gatch et al., 2012). In recent years, the ready availability of carisoprodol via internet pharmacies has led to increased recreational use of carisoprodol. Because of the increasing misuse of carisoprodol and associated adverse effects, the United States Drug Enforcement Administration placed carisoprodol into Schedule IV of the Controlled Substances Act in January 2012.

The illicit effects of carisoprodol are generally attributed to the actions of its primary metabolite, meprobamate - a federally controlled substance with barbiturate-like activity at $\mathrm{GABA}_{\mathrm{A}} \mathrm{Rs}$ (Rho et al., 1997). While conversion to meprobamate likely contributes to the therapeutic and illicit effects of carisoprodol, the pharmacological and physiological profiles of carisoprodol are not entirely consistent with that of its metabolite, supporting the possibility that carisoprodol may have effects independent of meprobamate.

The full spectrum of potential targets of carisoprodol has not been established. Adverse effects may be associated with serotonergic-like effects (Bramness et al., 2004). In animal studies, the NMDA receptor antagonist dizocilpine partially substitutes for the discriminative stimulus effects of carisoprodol (M. Gatch, personal communication). Considerable evidence implicates the $\mathrm{GABA}_{A} \mathrm{R}$ in is effects. As noted, the metabolite of carisoprodol has barbiturate-like effects at $\mathrm{GABA}_{\mathrm{A}} \mathrm{Rs}$ (Rho et al., 1997). We have 
demonstrated carisoprodol itself allosterically modulates and directly activates human $\alpha 1 \beta 2 \gamma 2 \mathrm{GABA}_{\mathrm{A}} \mathrm{Rs}$, and its actions are not mediated via reported sites of action for benzodiazepines or barbiturates (Gonzalez et al., 2009b). Although receptors of $\alpha 1 \beta 2 \gamma 2$ subunit composition are the prevalent configuration in the brain, a vast array of $\mathrm{GABA}_{\mathrm{A}} \mathrm{R}$ configurations have been shown to exist throughout the CNS, with each configuration contributing to specific physiological and pharmacological responses (Olsen and Sieghart, 2008). For example, benzodiazepines mediate sedative and anticonvulsant effects through $\alpha 1$-containing $\mathrm{GABA}_{\mathrm{A}} \mathrm{Rs}$, anxiolytic effects primarily through $\alpha 2$-expressing receptors, and myorelaxant effects via receptors expressing $\alpha 3$ and $\alpha 5$ subunits (Tan et al, 2010). It has also been demonstrated that abuse and dependence potential of benzodiazepines and barbiturates are related to their subunit-selective interactions with GABA $\mathrm{A}_{\mathrm{R}}$ (Ator, 2005; Ito et al., 1996; Licata and Rowlett, 2008; Wafford, 2005). Because dependence and withdrawal symptoms are associated with carisoprodol use, a better understanding of its molecular mechanism is needed. Thus, we assessed direct and allosteric actions of carisoprodol in varying configurations of synaptic and extrasynaptic $\mathrm{GABA}_{\mathrm{A}}$ receptors. Given the clinical and adverse effects associated with carisoprodol, we hypothesized it would interact with a number of $\mathrm{GABA}_{\mathrm{A}} \mathrm{Rs}$ in addition to $\alpha 1 \beta 2 \gamma 2$, likely those expressing $\alpha 2$ and/or $\alpha 3$ and/or $\alpha 5$ subunits. Our results indicate that the actions of carisoprodol are influenced by subunit isoforms and that direct and allosteric effects are likely mediated via distinct domains. 


\section{MATERIALS AND METHODS}

\section{Cell Culture and Transfection}

Both stably- and transiently-expressing $\mathrm{GABA}_{\mathrm{A}}$ receptors HEK293 cells were used in the present study. Human embryonic kidney 293 (HEK293) cells were transfected with human $\mathrm{GABA}_{\mathrm{A}} \alpha 1-\alpha 6$; human $\beta 1-2$; and human $\gamma 2 \mathrm{~s}$ (short isoform) cDNA in a 1:1:5 ratio using TransIT ${ }^{\circledR}-293$ (Mirus Bio, Madison, WI) and used for recording 24-48 h later. The $\gamma 2$ s subunit will be referred to as $\gamma 2$ from this point forward. Human $\mathrm{GABA}_{\mathrm{A}} \alpha 1$ subunit cDNA was generously provided by Neil Harrison (Columbia University Medical Center, New York). In resequencing the $\gamma 2$ subunit that was used in many of these studies, we detected a mutation ( $\mathrm{D}$ to $\mathrm{N}$ at position 115). We mutated this residue to the native form (QuikChange ${ }^{\circledR}$ Site-Directed Mutagenesis Kit, Agilent Technologies, Santa Clara, CA), confirmed the mutation via sequencing, and conducted a number of studies to assess possible impact on carisoprodol activity. We observed no effect and thus data with that mutation are included. HEK293 stably expressing human $\alpha 1 \beta 2 \gamma 2$ or $\alpha 2 \beta 2 \gamma 2 \mathrm{GABA}_{\mathrm{A}} \mathrm{Rs}$ were also used. A complete description of the preparation and maintenance of these stable cell lines has been published previously (Hawkinson et al., 1996). For studies assessing carisoprodol effects in a model of extrasynaptic receptors (rat $\alpha 1 \beta 3 \delta$ and $\alpha 4 \beta 3 \delta$ subunits) a transfection ratio of $2: 1: 0.25$ for $\alpha: \beta: \delta$ plasmids was used, as this transfection ratio reliably results in receptors expressing the native $2 \alpha: 2 \beta: 1 \delta$ stoichiometry (Wagoner and Czajkowski, 2010). The rat $\mathrm{GABA}_{\mathrm{A}} \alpha 4$ subunit cDNA was purchased from Genescript (Piscataway, New Jersey). As rat extrasynaptic $\mathrm{GABA}_{\mathrm{A}} \mathrm{Rs}$ have been shown to have 


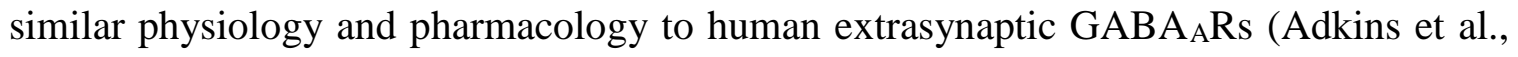
2001; Feng et al., 2004; Feng and Macdonald, 2010; Mortensen et al., 2010), use in these studies is appropriate. For all studies, cells were plated on glass coverslips coated with poly-L-lysine in $35-\mathrm{mm}$ culture dishes. Cells were incubated and maintained at $37^{\circ} \mathrm{C}$ in a humidified incubator with an atmosphere of $5 \% \mathrm{CO}_{2}$.

\section{Electrophysiology}

Whole-cell patch clamp electrophysiology was used to assess GABA- or carisoprodol-activated $\mathrm{Cl}^{-}$currents. Except for studies examining voltage-dependence (below), electrophysiology experiments were conducted at room temperature $\left(22-25^{\circ} \mathrm{C}\right)$ with the membrane potential clamped at $-60 \mathrm{mV}$. Patch pipettes of borosilicate glass (1B150F; World Precision Instruments, Inc., Sarasota, FL) were pulled (Flaming/Brown, P-87/PC; Sutter Instrument Company, Novato, CA) to a tip resistance of 4-6M $\Omega$. Patch pipettes were filled with a solution consisting of $140 \mathrm{mM} \mathrm{CsCl}, 10 \mathrm{mM}$ EGTA-Na ${ }^{+}, 10$ mM HEPES-Na ${ }^{+}$, and $4 \mathrm{mM} \mathrm{Mg}{ }^{2+}-\mathrm{ATP}, \mathrm{pH}$ 7.2. Coverslips containing cultured cells were placed in the recording chamber on the stage of an inverted light microscope and superfused continuously with an external solution consisting of $125 \mathrm{mM} \mathrm{NaCl}, 20 \mathrm{mM}$ HEPES, $3 \mathrm{mM} \mathrm{CaCl}_{2}, 5.5 \mathrm{mM} \mathrm{KCl}, 0.8 \mathrm{mM} \mathrm{MgCl}_{2}$, and $10 \mathrm{mM}$ glucose, pH 7.3. Agonistinduced $\mathrm{Cl}^{-}$currents were obtained with an Axopatch 200B amplifier with a rate of 50 samples per second (Molecular Devices, Sunnyvale, CA) equipped with a CV-203BU headstage. Currents were low-pass filtered at $5 \mathrm{kHz}$, monitored simultaneously on an 
oscilloscope and a chart recorder (Gould TA240; Gould Instrument Systems Inc., Cleveland, $\mathrm{OH}$ ), and stored on a computer using an on-line data acquisition system (pCLAMP 6.0; Axon Instruments) for subsequent off-line analysis

\section{Chemicals and solutions}

Carisoprodol, pentobarbital, THIP (4,5,6,7-tetrahydroisoxazolo(5,4-c)pyridin-3ol), salts and buffers were purchased from Sigma Aldrich (St. Louis, MO). GABA was obtained from Acros Organics (New Jersey, US). GABA stock solution (500 mM) was prepared in de-ionized water. A stock solution (1 or $3 \mathrm{M})$ of carisoprodol and THIP (1M) was made in DMSO. Final concentrations of DMSO in working solutions were $0.3 \%$ or less, a concentration that does not affect GABA-gated current. Diazepam and furosemide were utilized from a stock solution prepared in water. All stock solutions were stored at 20C. On experimental days, drug-containing solutions were prepared from stock by serial dilution into external solution.

\section{Experimental protocol}

GABA (with or without carisoprodol) or carisoprodol were applied to each cell by gravity flow using a Y-shaped tube positioned adjacent to the cell. The modulatory effects of carisoprodol on GABA-gated currents were assessed using an $\mathrm{EC}_{20}$ gating concentration of GABA as the control. This gating concentration was selected to ensure there was a sufficient range to observe the full allosteric potential of carisoprodol. To ensure the gating 
concentration was approximately an $\mathrm{EC}_{20}$, control responses were compared to the maximal GABA-gated current for each individual cell. Carisoprodol was tested only if the gating concentration was within the $\mathrm{EC}_{15-25}$ range. Control responses were established by observing two consecutive agonist-activated currents that varied in amplitude by no more than $\pm 10 \%$. In our analyses of the modulatory effects of carisoprodol, peak current amplitude was defined as the maximum current elicited by carisoprodol. In studies investigating direct gating effects, carisoprodol-gated currents were normalized to maximum GABA-mediated current. In recordings where an inhibitory component was observed (high CSP concentrations), a rebound current was sometimes followed the inhibitory phase. The channel state(s) from which these openings occur may vary (Feng et al., 2004; Williams et al., 1997; Wooltorton et al., 1997), and thus peak current amplitude was taken during the active drug application phase. For $\alpha \beta \gamma$ configurations, incorporation of $\gamma 2$ subunit was confirmed in $\alpha 1-, \alpha 2-, \alpha 3-$ and $\alpha 5 \beta 2 \gamma 2$ GABA $_{A}$ Rs by demonstration of sensitivity of GABA ( $\left.\mathrm{EC}_{50}\right)$-gated currents to allosteric potentiation by diazepam $(1 \mu \mathrm{M})$. Antagonism by furosemide $(100 \mu \mathrm{M})$ was used to confirm expression of $\alpha 4 \beta 2 \gamma 2$ and $\alpha 6 \beta 2 \gamma 2 \mathrm{GABA}_{\mathrm{A}} \mathrm{Rs}$. Presence of the $\delta$ subunit in $\alpha 1 \beta 3 \delta$ and $\alpha 4 \beta 3 \delta$ receptors was confirmed

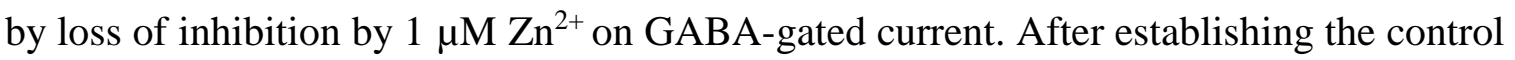
response, effects of the test drugs were determined.

To study the voltage-dependence effect of carisoprodol in $\mathrm{GABA}_{\mathrm{A}}$ receptors, $\alpha 1 \beta 2 \gamma 2$ transfected HEK293 cells were clamped at $-60 \mathrm{mV}$ and $+60 \mathrm{mV}$ and studied for carisoprodol direct gating, allosteric modulatory and blocking effects as described above. 


\section{Data Analysis}

To ensure equipotent concentrations were used for gating, GABA concentrationresponse data were collected for all synaptic and extrasynaptic GABA $\mathrm{A}$ s tested, (Table 1 and 4). From these data, $\mathrm{EC}_{20}$ and saturating $\mathrm{GABA}$ concentrations were calculated for each configuration and used in subsequent investigations of the allosteric and direct effects of carisoprodol, respectively.

Concentration-response profiles for the positive modulatory actions of carisoprodol were generated (Origin; OriginLab Corp., Northampton, MA) using the equation $I / I_{\max }=$ [carisoprodol] $^{\mathrm{n}} /\left(\right.$ [carisoprodol $\left.^{\mathrm{n}}+\mathrm{EC}_{50}{ }^{\mathrm{n}}\right)$, where $I$ is the normalized current amplitude at a given concentration of carisoprodol, $I_{\max }$ is the maximum current induced by carisoprodol, $\mathrm{EC}_{50}$ is the half-maximal effective concentration of carisoprodol, and $n$ is the Hill coefficient. For concentration-response curves illustrating allosteric actions, a correction was applied to subtract direct gating effects. In some cases, the blocking actions of carisoprodol became notable at high concentrations; in these instances, curves were fitted to the data point corresponding to peak effect, and the curve was extrapolated.

All data are presented as mean values \pm S.E.M. Statistical significance $(p<0.05)$ between control and test conditions was determined using Student's $t$-test (paired or unpaired) and one-way analysis of variance. Tukey-Kramer post hoc test for multiple comparisons was performed as needed. 


\section{RESULTS}

\section{Influence of $\alpha$ subunit isoform of carisoprodol-mediated activity of the GABA receptor}

$\alpha$ subunit influences on direct gating by carisoprodol. Table 1 provides $\mathrm{EC}_{50}$ values for the synaptic $\mathrm{GABA}_{\mathrm{A}}$ receptors studied in the present investigation. Both allosteric (assessed using an $\mathrm{EC}_{20}$ GABA gating concentration) and direct effects of carisoprodol $(1 \mu \mathrm{M}-10 \mathrm{mM})$ were assessed in $\alpha x \beta 2 \gamma 2 \mathrm{GABA}_{\mathrm{A}}$ receptors, where $\mathrm{x}=\alpha$ subunit 1-6. Carisoprodol directly gated each of the configurations tested, evoking inward currents in the absence of GABA (Fig. 1A and 1B). Maximal carisoprodol-gated currents were of similar magnitude regardless of $\alpha$ subunit, with efficacies ranging from $13-43 \%$ of maximal GABA-gated current (Fig. 1B, Table 2). However, carisoprodol direct gating potency and efficacy was significantly less at $\alpha 3$-containing receptors compared to other $\alpha$ isoform receptors (Table 2). As originally reported for $\alpha 1$-containing receptors (Gonzalez et al., 2009b), attenuation of current amplitude at high concentrations, followed by rebound current, was consistently observed regardless of the $\alpha$ subunit.

\section{$\alpha$ subunit influences on allosteric modulation by carisoprodol of GABA-gated}

current. We also assessed the ability of carisoprodol to allosterically modulate the response to GABA when $\alpha$ subunits were varied. Carisoprodol positively modulated the effects of an $\mathrm{EC}_{20}$ concentration of GABA in all configurations tested (Fig. 2A and 2B). Carisoprodol potency was not significantly influenced by the $\alpha$ subunit isoform (Table 3 ) whereas the efficacy of carisoprodol modulation was influenced by the $\alpha$ subunit, being 
greatest in $\alpha 1$-containing receptors (Fig. 2B and Table 3). As observed when evaluating direct gating effects of carisoprodol, allosteric enhancement began to diminish with higher concentrations of carisoprodol, and a notable rebound current was observed. Pharmacologically, the presence of carisoprodol increased the apparent affinity of GABA, resulting in a significant leftward shift in the GABA concentration-response profile without increasing maximal GABA current amplitude (Fig. 2E).

\section{Influence of $\beta$ subunit isoform of carisoprodol-mediated activity of the GABAA receptor}

$\beta$ subunit influences on direct gating by carisoprodol. As we reported previously (Gonzalez et al., 2009a), application of carisoprodol to $\alpha 1 \beta 2 \gamma 2$ receptors elicited inward currents in the absence of GABA, with an efficacy approximately $43 \%$ of that observed in response to a saturating concentration of GABA (Fig. 1A). The ability to directly gate the receptor was also observed in $\alpha 1 \beta 1 \gamma 2$ GABA $_{A}$ Rs. Efficacy in $\beta 1$ containing receptors was significantly greater than that observed in $\beta 2$-containing receptors (Fig. 1C and Table 2) and approximated $70 \%$ of the magnitude of maximal GABA-gated current in $\alpha 1 \beta 1 \gamma 2$ GABA $_{\mathrm{A}}$ Rs. Potency of carisoprodol's direct gating effect was similar in $\beta 1$ - and $\beta 2$-expressing receptors (Table 2).

\section{$\beta$ subunit influences on allosteric modulation by carisoprodol of GABA-gated}

current. Carisoprodol modulated the GABA-gated currents of $\alpha 1 \beta 1 \gamma 2 \mathrm{GABA}_{\mathrm{A}} \mathrm{Rs}$ in a manner previously described for $\alpha 1 \beta 2 \gamma 2 \mathrm{GABA}_{\mathrm{A}} \mathrm{Rs}$ - potentiation in a concentration- 
dependent manner accompanied by inhibition and rebound currents at millimolar concentrations (Fig. 2A). The $\beta$ subunit isoform affected both potency $(33.1 \pm 4 \mu \mathrm{M}$ and $88.2 \pm 20 \mu \mathrm{M}$, in $\beta 1$ - and $\beta 2$-containing receptors, respectively) and efficacy (maximum efficacy was $225 \pm 14.6 \%$ of control in $\beta 1$-containing receptors, compared to $474.7 \pm$ $53.5 \%$ in $\beta 2$-containing receptors) of carisoprodol-mediated potentiation of GABA-gated currents (Fig. 2C and Table 3). This is in contrast to the pattern observed for the direct gating effects of carisoprodol, in which carisoprodol was more efficacious at receptors containing the $\beta 1$ isoform.

\section{Direct gating and allosteric modulatory effects of carisoprodol do not require the $\gamma$ subunit}

In assessing the influence of the $\gamma$ subunit on actions of carisoprodol, we found its efficacy as a direct agonist was unchanged with the presence of the $\gamma$ subunit (Fig. 1A and 1D, Table 2). Peak current amplitude of carisoprodol-evoked currents was $45.9 \pm 3 \%$ of the maximum GABA-gated current for $\alpha 1 \beta 2$ receptors, whereas it was $43.6 \pm 4.3 \%$ for $\alpha 1 \beta 2 \gamma 2$ receptors. Consistent with this, we observed the actions of carisoprodol were comparable regardless of whether the $\gamma 2$ short or $\gamma 2$ long isoform was expressed (data not shown).

We also assessed the influence of the $\gamma$ subunit on allosteric actions of carisoprodol. Micromolar concentrations of carisoprodol potentiated the GABA-gated currents of $\alpha 1 \beta 2$ 
$\mathrm{GABA}_{\mathrm{A}} \mathrm{Rs}$ in a concentration-dependent manner (Fig. 2A and 2D, Table 2). The patterns of potentiation and inhibition by carisoprodol at $\alpha 1 \beta 2 \mathrm{GABA}_{\mathrm{A}} \mathrm{Rs}$ were similar to those observed at $\alpha 1 \beta 2 \gamma 2 \mathrm{GABA}_{\mathrm{A}}$ Rs, shown here (Fig. 1A) and previously using a stable $\alpha 1 \beta 2 \gamma 2$ cell line (Gonzalez et al., 2009b). The estimated $\mathrm{EC}_{50}$ for carisoprodol at $\alpha 1 \beta 2 \mathrm{GABA}_{\mathrm{A}} \mathrm{Rs}$ was $87.4 \pm 16.4 \mu \mathrm{M}$ compared to $88.2 \pm 20 \mu \mathrm{M}$ for receptors containing the $\gamma 2$ subunit, with direct gating by carisoprodol likely contributing to maximal current amplitude elicited by higher concentrations of the drug. Maximum potentiation of control currents occurred with $1 \mathrm{mM}$ carisoprodol for each configuration (Fig. 1D), with efficacies of $346.7 \pm 67.6 \%$ and $474.7 \pm 53.5 \%$ for $\alpha 1 \beta 2$ and $\alpha 1 \beta 2 \gamma 2 \mathrm{GABA}_{\mathrm{A}} \mathrm{Rs}$, respectively. Thus, the $\gamma$ subunit did not significantly influence the potency or efficacy of carisoprodol as an allosteric modulator (Table 2). At millimolar concentrations, rebound currents were observed upon termination of drug application, and co-application of $3 \mathrm{mM}$ carisoprodol elicited an inhibitory effect on GABA-gated currents during drug application. Together with the direct gating studies, these findings demonstrate the $\gamma$ subunit is not essential for carisoprodolmediated regulation of $\mathrm{GABA}_{\mathrm{A}} \mathrm{R}$ function.

\section{Effects of carisoprodol in "extrasynaptic" receptors}

$\delta$ subunit influences on direct gating by carisoprodol. To assess carisoprodol mediated-activity in a model of extrasynaptic $\mathrm{GABA}_{\mathrm{A}}$ receptors, we studied its effects in HEK293 expressing rat $\alpha 1$ or $\alpha 4, \beta 3$ and $\delta \mathrm{GABA}_{\mathrm{A}}$ receptor subunits. Carisoprodol was more efficacious than GABA in directly gating $\alpha 1 \beta 3 \delta$ and $\alpha 4 \beta 3 \delta$ extrasynaptic receptors, 
with the latter receptor having the highest sensitivity to CSP (Fig. 3, Table 4). We also compared the efficacy of carisoprodol to that of THIP, which has high efficacy at extrasynaptic $\mathrm{GABA}_{\mathrm{A}}$ receptors (Belelli et al., 2009; Brickley and Mody, 2012). As reported by others, we observed that THIP was a super agonist, with THIP-gated currents being $135.6 \pm 7.2$ and $153.4 \pm 10.7 \%$ of the amplitude of currents obtained with saturating GABA in $\alpha 1 \beta 3 \delta$ and $\alpha 4 \beta 3 \delta$ receptors, respectively. Carisoprodol was thus roughly $90 \%$ as efficacious as THIP in directly gating $\alpha 1 \beta 3 \delta$ and $\alpha 4 \beta 3 \delta$ receptors (Fig. 3). Direct gating efficacy by carisoprodol in rat $\alpha 1 \beta 2, \alpha 1 \beta 3$, and $\alpha 1 \beta 3 \gamma 2$ configurations was similar, indicating neither the $\beta 2 / 3$ isoforms nor the $\gamma$ subunit significantly affects direct activation by carisoprodol. Effects in the rat $\alpha 1 \beta 2, \alpha 1 \beta 3$ and $\alpha 1 \beta 3 \gamma 2$ receptors were also generally comparable to what we observed across a range of human $\mathrm{GABA}_{\mathrm{A}}$ receptors (see Fig. 1). Thus, species differences do not appear to be a significant influence with regard to direct gating effects of carisoprodol, as has been observed for other GABAergic ligands such as pentobarbital, neurosteroids, THIP and general anesthetics (Adkins et al., 2001; Feng et al., 2004; Feng and Macdonald, 2010; Mortensen et al., 2010).

\section{$\delta$ subunit influences on allosteric modulation by carisoprodol of GABA-}

gated current. We also determined the ability of carisoprodol to allosterically modulate GABA-gated current in extrasynaptic receptors. In contrast to what was observed with direct gating, the $\delta$ subunit did not have a significant effect on allosteric modulatory effects of carisoprodol (Fig. 4). These results also confirm carisoprodol is most efficacious on receptors expressing $\beta 2$ compared to $\beta 1$ or $\beta 3$ subunits for its allosteric modulatory effects 
(Table 4). Interestingly, like pentobarbital, neurosteroids, and general anesthetics (Feng et al., 2004; Meera et al., 2009; Wohlfarth et al., 2002), carisoprodol potentiated maximal GABA currents of $\alpha 1 \beta 3 \delta$ and $\alpha 4 \beta 3 \delta$ GABAA $_{A}$ receptors, but not of $\alpha 1 \beta 3$ or $\alpha 1 \beta 3 \gamma 2$ receptors (Fig. 5). These results demonstrate carisoprodol has distinct gating properties on extrasynaptic $\mathrm{GABA}_{\mathrm{A}}$ receptors compared to synaptic receptors.

\section{Effect of membrane voltage on direct gating and allosteric modulatory effects of carisoprodol}

As voltage sensitivity may sometimes provide insight into possible site of action of a ligand, we determined whether direct gating, allosteric modulatory and/or blocking actions of carisoprodol are voltage-dependent, by assessing these actions in $\alpha 1 \beta 2 \gamma 2$ $\mathrm{GABA}_{\mathrm{A}}$ receptors with the membrane voltage clamped at $-60 \mathrm{mV}$ and $+60 \mathrm{mV}$. GABAgated and CSP-gated current at $0 \mathrm{mV}$ was essentially undetectable, consistent with the theoretical reversal potential of $0.4 \mathrm{mV}$, as predicted from the Nernst equation. As reported by others (O'Toole and Jenkins, 2012), we observed outward rectification in response to lower concentrations of GABA (current amplitude at $+60 \mathrm{mV}$ was $110 \%$ of that recorded at $-60 \mathrm{mV}$ ), whereas no significant rectification was observed at saturating GABA. To assess voltage-dependence of the direct gating effects of CSP, we chose a concentration of $1 \mathrm{mM}$, which elicits a robust current, but nominal apparent inhibition. As shown in Figure 6 (A, B), the direct gating effect of CSP was not impacted by membrane voltage. Interestingly, allosteric potentiation of GABA currents by carisoprodol was affected by cell 
membrane polarity; in these studies, $100 \mu \mathrm{M}$ CSP enhanced GABA current to $285.3 \pm$ $17.7 \%$ of control at $-60 \mathrm{mV}$, whereas the extend of potentiation was $204.8 \pm 5.3 \%$ at +60 $\mathrm{mV}$ (Fig. 6C, 6D). To assess voltage-dependence of blocking by carisoprodol, we compared the decrease in current amplitude in response to $5 \mathrm{mM} \mathrm{CSP}$, compared to $3 \mathrm{mM}$ CSP, at both -60 and $+60 \mathrm{mV}$. The magnitude of current attenuation with $5 \mathrm{mM} \mathrm{CSP}$ was similar in both cases (Fig. 6E, 6F). 


\section{DISCUSSION}

Despite the clinical utility of carisoprodol in treatment of low back pain, its use is complicated by its abuse potential. Carisoprodol abuse, tolerance, and withdrawal are welldocumented in the literature (Adams et al., 1975; Elder, 1991; Reeves and Parker, 2003; Rust et al., 1993). This abuse has become particularly apparent in recent years, due in part to ready access of carisoprodol via internet pharmacies. The abuse liability of carisoprodol has often been attributed to meprobamate - the primary metabolite of carisoprodol and a controlled substance at the federal level. Our previous research has demonstrated that carisoprodol itself, independent of its conversion to meprobamate, acts at GABA ${ }_{A} R s$ in a manner described for drugs of abuse that act via the GABAergic system (Gonzalez et al., 2009b). Whereas meprobamate has been federally scheduled for many years, such was not the case for carisoprodol. Effective January 2012, following extensive review of scientific research and data on abuse, law enforcement encounters, and other information, the United States Drug Enforcement Agency placed carisoprodol into Schedule IV of the Controlled Substances Act (Federal Register, vol 76, no 238, pp. 77330-77360, Dec 12, 2011).

The abuse and dependence potential of many GABAergic drugs are related to their subunit-selective interactions with $\mathrm{GABA}_{\mathrm{A}} \mathrm{Rs}$ (Ator, 2005; Ator et al., 2010; Ito et al., 1996; Licata and Rowlett, 2008; Wafford, 2005). Thus, we assessed whether the actions of carisoprodol are subunit-dependent, potentially underlying its physiological effects and abuse liability. The role of the $\gamma$ subunit has been established for several modulators of $\mathrm{GABA}_{\mathrm{A}} \mathrm{R}$ function. The most prominent example is the benzodiazepine class of drugs, 
which require the presence of a $\gamma$ subunit to potentiate GABA-gated currents (Pritchett et al., 1989). The $\gamma$ subunit does not play an essential role in mediating the actions of carisoprodol at $\mathrm{GABA}_{\mathrm{A}}$ Rs because the modulatory and agonistic effects of the drug were not significantly different between $\alpha 1 \beta 2$ and $\alpha 1 \beta 2 \gamma 2$ configurations. These findings support our earlier assertion that carisoprodol does not act at the benzodiazepine site of the receptor (Gonzalez et al., 2009a) and led us to pursue the $\alpha$ and $\beta$ subunits as critical mediators of the actions of carisoprodol.

In the current study, the influence of $\beta$ subunit isoforms was examined via comparison of effects elicited from $\beta 1-, \beta 2$ - and $\beta 3$-containing receptors. Whereas the actions of GABAergic compounds such as etomidate, loreclezole, and furosemide are dependent upon incorporation of $\beta 2$ or $\beta 3$ subunits (Korpi et al., 2002; Korpi et al., 1995; Olsen, 2014; Stewart et al., 2013), carisoprodol-mediated effects were observed at $\alpha 1 \beta 1 \gamma 2$ $\mathrm{GABA}_{\mathrm{A}} \mathrm{Rs}$, suggesting critical domains for carisoprodol activity are located within regions conserved between the $\beta 1$ and $\beta 2$ isoforms. For allosteric modulation, carisoprodol was significantly more efficacious at $\beta 2$-containing receptors. Expression of the $\beta 2$ isoform in the brain is extensive (Sigel and Steinmann, 2012), suggesting the majority of receptor configurations are susceptible to modulation by carisoprodol. In contrast, direct activation by carisoprodol was significantly greater at $\beta 1$-containing receptors. This disparity suggests allosteric modulation and direct gating by carisoprodol may be mediated by distinct sites of the $\beta$ subunit. 
There has been considerable progress in recent years in understanding the involvement of specific $\mathrm{GABA}_{\mathrm{A}}$ receptor $\alpha$ subunits in both desired and adverse pharmacologic actions (for review, see (Rudolph and Mohler, 2006). $\alpha 1$-expressing $\mathrm{GABA}_{\mathrm{A}}$ receptors are critical for the sedative effects of benzodiazepines (McKernan et al., 2000) whereas $\alpha 2$ - and/or $\alpha 3$-expressing receptors underlie their anxiolytic actions (Atack et al., 2005; Dias et al., 2005). In addition, the efficacy of benzodiazepines at $\alpha 1$ containing $\mathrm{GABA}_{\mathrm{A}}$ Rs may predict their abuse potential (Ator, 2005; Licata and Rowlett, 2008). Inhibitory GABAergic interneurons in the ventral tegmental area (VTA) specifically express $\alpha 1$-containing $\mathrm{GABA}_{\mathrm{A}} \mathrm{Rs}$ (Tan et al., 2010). Potentiation of $\alpha 1$ containing $\mathrm{GABA}_{\mathrm{A}} \mathrm{Rs}$ on these interneurons causes disinhibition of VTA dopaminergic neurons, resulting in increased dopamine release in the nucleus accumbens. Addictive drugs increase dopamine levels in the mesolimbic system (Luscher and Ungless, 2006). As physical dependence is more likely to develop with drugs that interact with a broader collection of $\mathrm{GABA}_{\mathrm{A}} \mathrm{R}$ subtypes (Licata and Rowlett, 2008), the high efficacy of carisoprodol for both direct and allosteric effects on $\alpha 1$-containing receptors, coupled with its ability to interact with $\mathrm{GABA}_{\mathrm{A}} \mathrm{R}$ subtypes, is consistent with its high abuse potential (Rudolph and Knoflach, 2011).

The therapeutic goal of carisoprodol use is alleviation of low back pain, which results from centrally-mediated muscle relaxation. Others have demonstrated muscle relaxation is associated preferentially with $\alpha 2$ - and $\alpha 3$-expressing receptors (Crestani et al., 2001; Griebel et al., 2003; Licata et al., 2005; Licata et al., 2009). Although 
carisoprodol did not selectively interact with these subunits, it had notable allosteric modulatory effects on both $\alpha 2$ - and $\alpha 3$-expressing receptors and almost similar potency for direct activation for $\alpha 2$ - containing receptors as compared to most abundant configuration of human CNS, $\alpha 1$-containing receptors (Olsen and Sieghart, 2008). Taken together, the pharmacological profile of carisoprodol is consistent with its clinical effects and its potential for abuse. A molecule that selectively interacts with $\alpha 2 / \alpha 3 \mathrm{GABA}_{\mathrm{A}}$ receptor subunits would seem promising as a muscle relaxant with reduced abuse potential and sedative effects (Rudolph and Knoflach, 2011).

Unlike benzodiazepines, carisoprodol also has the ability to directly gate the $\mathrm{GABA}_{\mathrm{A}} \mathrm{R}$. Misuse of agents that directly gate the receptor is more likely to result in death than those that only allosterically enhance receptor activity, and overdose of carisoprodol is responsible for a substantial number of both unintentional and intentional deaths (Fass, 2010). We observed that carisoprodol elicited significant and concentration-dependent direct gating effects at the $\mathrm{GABA}_{\mathrm{A}} \mathrm{R}$. According to case reports, blood or plasma concentrations of carisoprodol as low as $140 \mu \mathrm{M}$ have proven to be fatal (McIntyre et al., 2012; Robertson and Marinetti, 2003). Interestingly, this concentration correlates well to the onset of direct activation for the majority of receptor subunit complexes tested in the present study.

These studies are the first to explore subunit-dependent actions of carisoprodol, and thus little is known about possible domains that are key for its actions. One fundamental question is whether the site for allosteric and direct gating effects is the same. The general 
anesthetics propofol and etomidate also both allosterically enhance and directly gate the receptor, and evidence suggests a single site of action confers both properties (Forman, 2011; Ruesch et al., 2012). In contrast, the ability of neurosteroids to directly gate and allosterically modulate the receptor is mediated via distinct sites (Hosie et al., 2006). Our data are most consistent with the contention that the two actions of carisoprodol are mediated via distinct sites. First, we observed greatest direct gating efficacy in $\beta 1$ expressing receptors, whereas efficacy for allosteric modulation was greatest in $\beta 2$ expressing receptors. Similarly, we observed decreased potency and efficacy for direct gating capacity in $\alpha 3$-expressing receptors, whereas allosteric effects of those receptors were similar to other $\alpha$ subunit-expressing receptors.

We also studied the actions of carisoprodol on $\delta$ subunit-containing extrasynaptic $\mathrm{GABA}_{\mathrm{A}}$ receptors, which exert a tonic inhibitory tone as opposed to the phasic inhibition characteristic of synaptic receptors (Glykys and Mody, 2007; Herd et al., 2009). It should also be noted that $\alpha 5 \beta 2 \gamma 2$ receptors, in addition to a role at synapses (Serwanski et al., 2006), are present at extrasynaptic sites and have a prominent role in contributing to tonic inhibition (Caraiscos et al., 2004; Glykys and Mody, 2006). The involvement of extrasynaptic $\mathrm{GABA}_{\mathrm{A}}$ receptor dysfunction in neurological disorders like depression (Maguire et al., 2005), schizophrenia (Maldonado-Aviles et al., 2009), and some forms of epilepsy (Cope et al., 2009) has made these receptors an emerging clinical target (Brickley and Mody, 2012). As GABA has high affinity but low efficacy at extrasynaptic GABA receptors, it is considered a partial agonist at these receptors (Bianchi and Macdonald, 
2003). We found that, as reported for other ligands (Bianchi and Macdonald, 2003), carisoprodol has higher efficacy at extrasynaptic $\alpha 1 \beta 3 \delta$ and $\alpha 4 \beta 3 \delta$ receptors than does GABA, and carisoprodol was about $90 \%$ as efficacious as the full agonist THIP. The efficacy of general anesthetics and sedative/hypnotics in potentiation of GABA-gated currents at extrasynaptic $\alpha 6 \beta 2 \delta \mathrm{GABA}_{\mathrm{A}}$ receptors depends upon the ambient $\mathrm{GABA}$ concentration or GABA occupancy of the receptors (Houston et al., 2012). The general anesthetic propofol and sleep-inducing drug THIP potentiate only when the ambient GABA levels are low and cease to modulate at saturating GABA. On the other hand, the

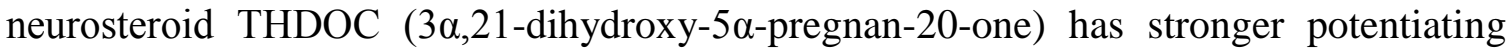
effects on saturated GABA currents compared to submaximal GABA currents (Houston et al., 2012; Wohlfarth et al., 2002). We found that carisoprodol potentiated at both subsaturating and saturating GABA concentrations. This is also true for pentobarbital (Feng et al., 2004). The N-terminal domain of the $\delta$ subunit has been shown to be involved in pentobarbital potentiation of saturated GABA currents of $\alpha 1 \beta 3 \delta$ receptors (Feng and Macdonald, 2010). The profile of carisoprodol at both synaptic and extrasynaptic $\mathrm{GABA}_{\mathrm{A}} \mathrm{R}$ is similar to that of barbiturates, although equivalent domains for action at synaptic receptors are unlikely (Gonzalez et al., 2009b). Whether the N-terminal domains of the $\delta$ subunit that influence pentobarbital potentiation of saturated GABA current also influence carisoprodol sensitivity remains to be determined.

At high concentrations, carisoprodol also inhibits $\mathrm{GABA}_{\mathrm{A}} \mathrm{R}$ function; this is evidenced by decreasing current amplitude and/or rebound currents associated with 
termination of drug application. A similar phenomenon also exists for barbiturates and gamma-butyrolactones (Akk et al., 2004; Feng et al., 2004; Rho et al., 1996; Williams et al., 1997; Wooltorton et al., 1997). This rebound current has been explained as reentry into an active state following desensitization (Wooltorton et al., 1997), or as relief from ligand binding to a low affinity inhibitory site, which permits reopening of the channel (Akk et al., 2004; Feng et al., 2004; Rho et al., 1996; Williams et al., 1997). In the case of carisoprodol, rebound from block seems most likely. We have reported in abstract form (Kumar and Dillon, 2014) that in wild type homomeric $\beta 3$ GABA receptors, which are spontaneously open, application of carisoprodol by itself blocks the spontaneously open channels. In homomeric receptors with introduction of a transmembrane domain 2 mutation (mutation of the $6^{\prime} \mathrm{T}$ to $\mathrm{F}$ ), blockade of the spontaneously open current is eliminated, and carisoprodol instead activates a significant inward current. Thus rebound currents following high concentrations of carisoprodol appear to be due to CSP dissociation from a low affinity inhibitory site. We did not fully quantitate the inhibitory effect, as it likely play a nominal role in the therapeutic or adverse effects of carisoprodol, and its low affinity combined with drug solubility issues makes accurate quantitation of it difficult.

We also studied whether the actions of carisoprodol on $\mathrm{GABA}_{\mathrm{A}}$ receptors display voltage-dependence. Neither direct gating nor blocking effects were affected by transmembrane voltage. However, we found allosteric modulatory effects of carisoprodol were significantly reduced at $+60 \mathrm{mV}$ compared to $-60 \mathrm{mV}$; a similar effect has been reported for the general anesthetics etomidate, propofol and isoflurane, (O'Toole and 
Jenkins, 2012). One might conclude the differential voltage-dependence of direct and allosteric effects supports the likelihood of two sites for these effects. Whereas collectively our data do support distinct sites, the differences in voltage-dependence for direct and allosteric effects do not necessarily lead to this conclusion. The reduced effect of carisoprodol at $+60 \mathrm{mV}$ may not relate to voltage per se, but instead is likely related to the enhanced open probability $\left(\mathrm{P}_{\mathrm{o}}\right)$ of the channel when clamped at positive potentials, as effects of allosteric potentiators are inversely related to $\mathrm{P}_{\mathrm{o}}\left(\mathrm{O}^{\prime}\right.$ Toole and Jenkins, 2012).

With regard to lack of voltage-dependence of the inhibitory effect, one might conclude a site of action in the channel is unlikely. Whereas the presence of voltagedependence of block is consistent with a site of action in the channel, it is not a requirement for a channel blocking mechanism. Indeed, the prototypical GABA $\mathrm{A}$ blocker, picrotoxin, does not display voltage-dependence (Newland and Cull-Candy, 1992; Yoon et al, 1993), and there is a considerable body of evidence that picrotoxin binds in the ion channel (see Bali and Akabas, 2007, and several references therein). The fact that mutation of the TM2 6' residue does impact carisoprodol-mediated inhibition (Kumar and Dillon, 2014) is consistent with a site of action within the channel, but definitive conclusions regarding the site for inhibitory effects of carisoprodol will require additional study.

The recent scheduling at the federal level of carisoprodol confirms the danger this drug poses when misused and abused. In the current study, we demonstrated carisoprodol preferentially interacts with selective $\mathrm{GABA}_{\mathrm{A}} \mathrm{R}$ subunits. The pharmacological profile of carisoprodol at $\mathrm{GABA}_{\mathrm{A}} \mathrm{Rs}$ we have identified is consistent with the therapeutic effects of 
the drug, and its subunit-selective actions may underlie its potential for abuse. Moreover, the complex interactions of carisoprodol suggest it interacts with multiple sites on the receptor. To our knowledge, no other GABAergic ligand has a subunit-dependent profile equivalent to that of carisoprodol, suggesting this drug may be acting at a novel site. 
Table II-1. GABA sensitivity of different GABAA receptors subunit configurations. GABA EC 50 values and Hill coefficients were calculated from each receptor configuration as mean \pm S.E.M. from $n$ cells. 


\begin{tabular}{cccc}
$\begin{array}{c}\text { Receptor } \\
\text { Configuration }\end{array}$ & $\mathbf{E C}_{\mathbf{5 0}}(\boldsymbol{\mu M})$ & $\begin{array}{c}\text { Hill } \\
\text { Coefficient }\end{array}$ & $\mathbf{n}$ \\
\hline$\alpha 1 \beta 2$ & $14.0 \pm 1.01$ & $1.32 \pm 0.11$ & 4 \\
$\alpha 1 \beta 2 \gamma 2$ & $35.5 \pm 0.64$ & $1.32 \pm 0.03$ & 6 \\
$\alpha 2 \beta 2 \gamma 2$ & $48.4 \pm 5.71$ & $1.09 \pm 0.12$ & 9 \\
$\alpha 3 \beta 2 \gamma 2$ & $34.8 \pm 2.09$ & $1.04 \pm 0.06$ & 8 \\
$\alpha 4 \beta 2 \gamma 2$ & $4.48 \pm 0.29$ & $1.36 \pm 0.11$ & 6 \\
$\alpha 5 \beta 2 \gamma 2$ & $2.50 \pm 0.20$ & $1.11 \pm 0.09$ & 6 \\
$\alpha 6 \beta 2 \gamma 2$ & $0.47 \pm 0.06$ & $1.02 \pm 0.12$ & 8 \\
$\alpha 1 \beta 1 \gamma 2$ & $6.6 \pm 1.07$ & $1.17 \pm 0.09$ & 6 \\
\hline
\end{tabular}

TABLE II-1. 
Table II-2. Comparison of potency and efficacy of carisoprodol as a direct gating agonist at different $\mathrm{GABA}_{\mathbf{A}}$ receptor subunit configurations. Carisoprodol $\mathrm{EC}_{50}$ was determined relative to maximum current elicited by carisoprodol. Carisoprodol efficacy is normalized to maximum GABA-gated currents. The potency and efficacy of carisoprodol was significantly less at $\alpha 3$-containing receptors relative to other $\alpha$ - subunit isoforms of $\mathrm{GABA}_{A}$ receptors. Each data point represents the mean \pm S.E.M from $n$ cells. Significant differences compared to $\alpha 1 \beta 2 \gamma 2$ receptor are denoted by ${ }^{*}, \mathrm{p}<0.05 ; * *, \mathrm{p}<0.01$. 


\begin{tabular}{cccc}
$\begin{array}{c}\text { Receptor } \\
\text { Configuration }\end{array}$ & $\mathbf{E C}_{\mathbf{5 0}}(\boldsymbol{\mu M})$ & Efficacy $(\%)$ & $\mathbf{n}$ \\
\hline$\alpha 1 \beta 2$ & $679.3 \pm 24.3$ & $45.9 \pm 3.0$ & 9 \\
$\alpha 1 \beta 2 \gamma 2$ & $685.5 \pm 30.4$ & $42.6 \pm 4.3$ & 31 \\
$\alpha 2 \beta 2 \gamma 2$ & $829.4 \pm 50.2$ & $30.1 \pm 1.4$ & 9 \\
$\alpha 3 \beta 2 \gamma 2$ & $1867.6 \pm 92.4^{*}$ & $13.4 \pm 1.4^{* *}$ & 29 \\
$\alpha 4 \beta 2 \gamma 2$ & $757.7 \pm 61.3$ & $37.3 \pm 5.0$ & 8 \\
$\alpha 5 \beta 2 \gamma 2$ & $834.7 \pm 60.3$ & $37.7 \pm 3.5$ & 9 \\
$\alpha 6 \beta 2 \gamma 2$ & $294.3 \pm 28.1$ & $36.8 \pm 4.7$ & 12 \\
$\alpha 1 \beta 1 \gamma 2$ & $728.8 \pm 58.1$ & $69.7 \pm 5.4^{*}$ & 12 \\
\hline
\end{tabular}

TABLE II-2. 
Table II-3. Comparison of potency and efficacy of allosteric effects of carisoprodol at different $\mathrm{GABA}_{\mathrm{A}}$ receptor subunit configurations. $\mathrm{EC}_{50}$ for allosteric modulation by carisoprodol was calculated in the presence of GABA $\left(\mathrm{EC}_{20}\right)$. Efficacy was calculated as maximum current elicited by carisoprodol plus GABA $\left(\mathrm{EC}_{20}\right)$ normalized to $\mathrm{GABA}\left(\mathrm{EC}_{20}\right)$ currents. Carisoprodol was significantly more efficacious at receptors incorporating the $\alpha 1$ subunit compared to receptors expressing any other $\alpha$ subunit isoform. Potency was not affected by $\alpha$ subunit isoform, but was enhanced in $\beta 1$ vs. $\beta 2$ expressing receptors. Each data point represents the mean \pm S.E.M. from $n$ cells. Significant differences compared to $\alpha 1 \beta 2 \gamma 2$ receptors are denoted by $*, p<0.05$. 


\begin{tabular}{cccc}
$\begin{array}{c}\text { Receptor } \\
\text { Configuration }\end{array}$ & $\mathbf{E C}_{\mathbf{5 0}}(\boldsymbol{\mu M})$ & Efficacy (\%) & $\mathbf{n}$ \\
\hline$\alpha 1 \beta 2$ & $87.4 \pm 16.4$ & $346.7 \pm 67.6$ & 3 \\
$\alpha 1 \beta 2 \gamma 2$ & $88.2 \pm 19.9$ & $474.7 \pm 53.5$ & 7 \\
$\alpha 2 \beta 2 \gamma 2$ & $64.9 \pm 19.1$ & $198.5 \pm 9.5^{*}$ & 6 \\
$\alpha 3 \beta 2 \gamma 2$ & $63.7 \pm 16.5$ & $242.7 \pm 35.1^{*}$ & 4 \\
$\alpha 4 \beta 2 \gamma 2$ & $72.3 \pm 10.1$ & $240.0 \pm 16.4^{*}$ & 11 \\
$\alpha 5 \beta 2 \gamma 2$ & $90.8 \pm 14.7$ & $247.6 \pm 23.0^{*}$ & 5 \\
$\alpha 6 \beta 2 \gamma 2$ & $79.8 \pm 13.8$ & $232.6 \pm 26.9^{*}$ & 9 \\
$\alpha 1 \beta 1 \gamma 2$ & $33.1 \pm 4.0^{*}$ & $225.6 \pm 14.6^{*}$ & 6 \\
\hline
\end{tabular}

TABLE II-3 
Table II-4. Comparison of carisoprodol effects on $\delta$ subunit-containing extrasynaptic receptors with synaptic $\mathbf{G A B A}_{\mathbf{A}}$ receptors. Carisoprodol direct gating $\mathrm{EC}_{50}$ was determined relative to maximum current elicited by carisoprodol and efficacy is normalized to maximum GABA gated currents. $\mathrm{EC}_{50}$ for allosteric modulation was calculated in the presence of GABA $\left(\mathrm{EC}_{20}\right)$ and efficacy was calculated as maximum current elicited by carisoprodol plus GABA $\left(\mathrm{EC}_{20}\right)$ normalized to GABA $\left(\mathrm{EC}_{20}\right)$ currents. Carisoprodol was supra-efficacious at $\delta$ containing extrasynaptic $\mathrm{GABA}_{\mathrm{A}}$ receptors for direct gating effects and significantly more efficacious at synaptic receptors incorporating the $\beta 2$ subunit for allosteric modulatory effects. Each data point represents the mean \pm S.E.M. from $n$ cells. Significant differences are denoted by \#, $\mathrm{p}<0.01$ (compared to synaptic receptors); $\wedge, \mathrm{p}<$ 0.05 (compared to $\alpha 1$ extrasynaptic receptor) and $* *, \mathrm{p}<0.01$ (compared to rest of the receptors studied). 


\begin{tabular}{|c|c|c|c|c|c|c|c|c|}
\hline \multirow{2}{*}{$\begin{array}{c}\text { Receptor } \\
\text { Configuration }\end{array}$} & \multicolumn{2}{|c|}{ GABA EC 50} & \multicolumn{3}{|c|}{ CSP gating } & \multicolumn{3}{|c|}{ CSP modulation } \\
\hline & $\mu \mathbf{M}$ & $\mathbf{n}$ & Efficacy & $\mathbf{E C}_{50}$ & $\mathbf{n}$ & Efficacy & $\mathbf{E C}_{50}$ & $\mathbf{n}$ \\
\hline$\alpha 1 \beta 2$ & $1.15 \pm 0.08$ & 4 & $31.5 \pm 7.87$ & $400 \pm 37.4$ & 6 & $442.2 \pm 27.7 * *$ & $120 \pm 10.5$ & 8 \\
\hline$\alpha 1 \beta 3$ & $0.67 \pm 0.06$ & 6 & $37.1 \pm 3.28$ & $390 \pm 48.3$ & 9 & $234.5 \pm 18.9$ & $135 \pm 12.8$ & 4 \\
\hline$\alpha 1 \beta 3 \gamma 2$ & $04.3 \pm 0.68$ & 6 & $44.8 \pm 3.23$ & $436 \pm 73.2$ & 4 & $200.4 \pm 09.5$ & $131 \pm 12.4$ & 7 \\
\hline$\alpha 1 \beta 3 \delta$ & $1.37 \pm 0.09$ & 9 & $119.8 \pm 4.7 \#$ & $718 \pm 36.2$ & 9 & $241.5 \pm 25.1$ & $109 \pm 11.4$ & 8 \\
\hline$\alpha 4 \beta 3 \delta$ & $0.051 \pm 0.03$ & 6 & $135.6 \pm 7.2 \#$ & $242 \pm 38.2^{\wedge}$ & 5 & $181.5 \pm 4.02$ & $92.2 \pm 15.1$ & 5 \\
\hline
\end{tabular}

TABLE II-4 
Figure II-1. Influence of GABA $\mathbf{G}_{A}$ subunit isoforms on direct activation by carisoprodol. A, representative traces demonstrating carisoprodol activates human $\alpha 1 \beta 2 \gamma 2$, $\alpha 3 \beta 2 \gamma 2, \alpha 1 \beta 1 \gamma 2$ and $\alpha 1 \beta 2$ GABA $_{A}$ Rs in a concentration-dependent manner. Carisoprodolactivated currents are presented relative to the maximum current elicited by GABA $(100 \mu \mathrm{M}$ for $\alpha 1 \beta 2$ and $1 \mathrm{mM} \mathrm{GABA}$ for $\alpha 1 \beta 2 \gamma 2, \alpha 3 \beta 2 \gamma 2$ and $\alpha 1 \beta 1 \gamma 2)$. At millimolar concentrations, rebound currents were observed upon termination of drug application. B, concentrationresponse curves for carisoprodol-mediated currents for human $\alpha 1-, \alpha 2-, \alpha 3-, \alpha 4-, \alpha 5-$, and $\alpha 6 \beta 2 \gamma 2$ GABA $_{A}$ Rs. $\alpha 3$ - subunit expressing receptors displayed significantly less potency and efficacy to carisoprodol. Initial peak currents and not rebound currents elicited by carisoprodol were normalized to maximum GABA mediated currents. $\mathbf{C}$, concentrationresponse curves for carisoprodol-mediated currents recorded from $\alpha 1 \beta 2 \gamma 2$ and $\alpha 1 \beta 1 \gamma 2$ $\mathrm{GABA}_{\mathrm{A}}$ Rs. Carisoprodol was significantly more efficacious at $\beta 1$-containing receptors. D, concentration-response curves for carisoprodol-mediated currents recorded from $\alpha 1 \beta 2$ and $\alpha 1 \beta 2 \gamma 2 \mathrm{GABA}_{\mathrm{A}} \mathrm{Rs}$. There were no significant differences between the two configurations at each concentration tested ( $p>0.05)$. Each data point represents the mean \pm S.E.M. of minimum of eight cells. *, $\mathrm{p}<0.05 ; * *, \mathrm{p}<0.01$. 
A
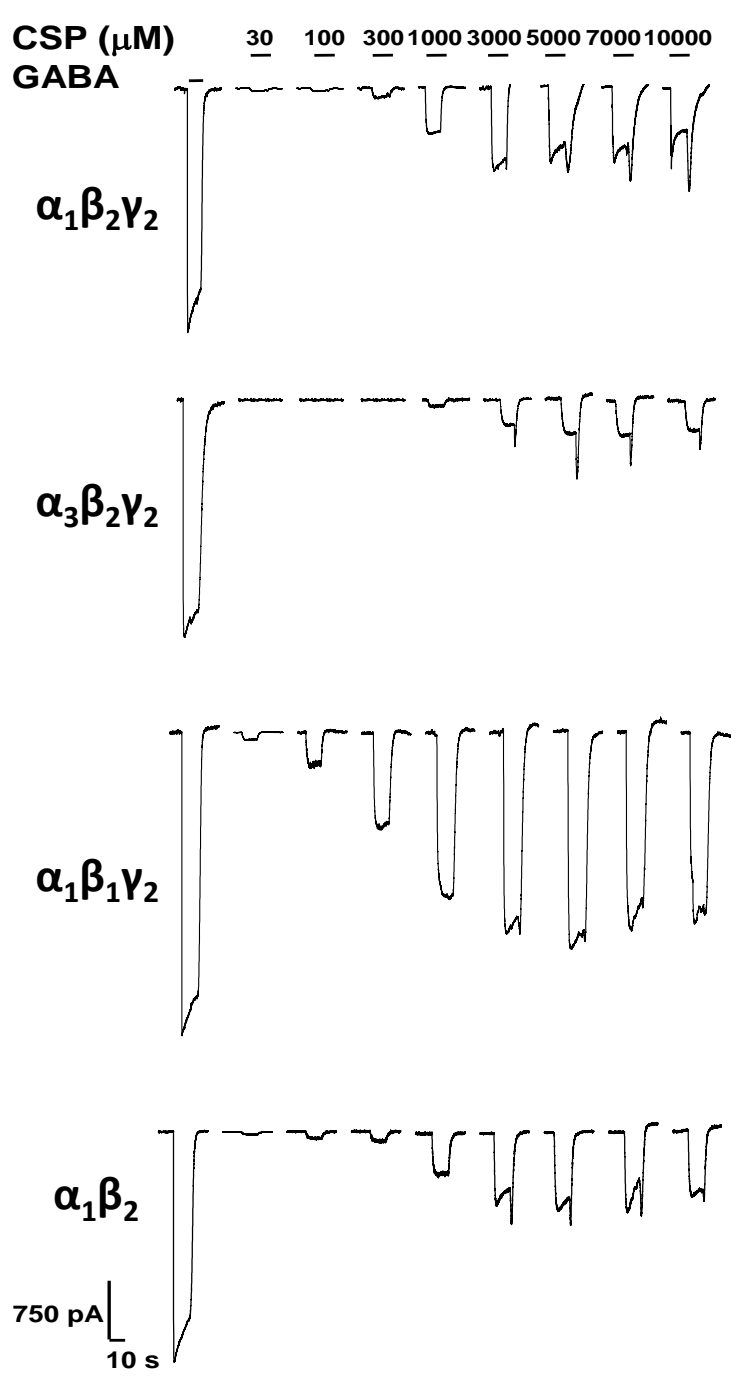

B
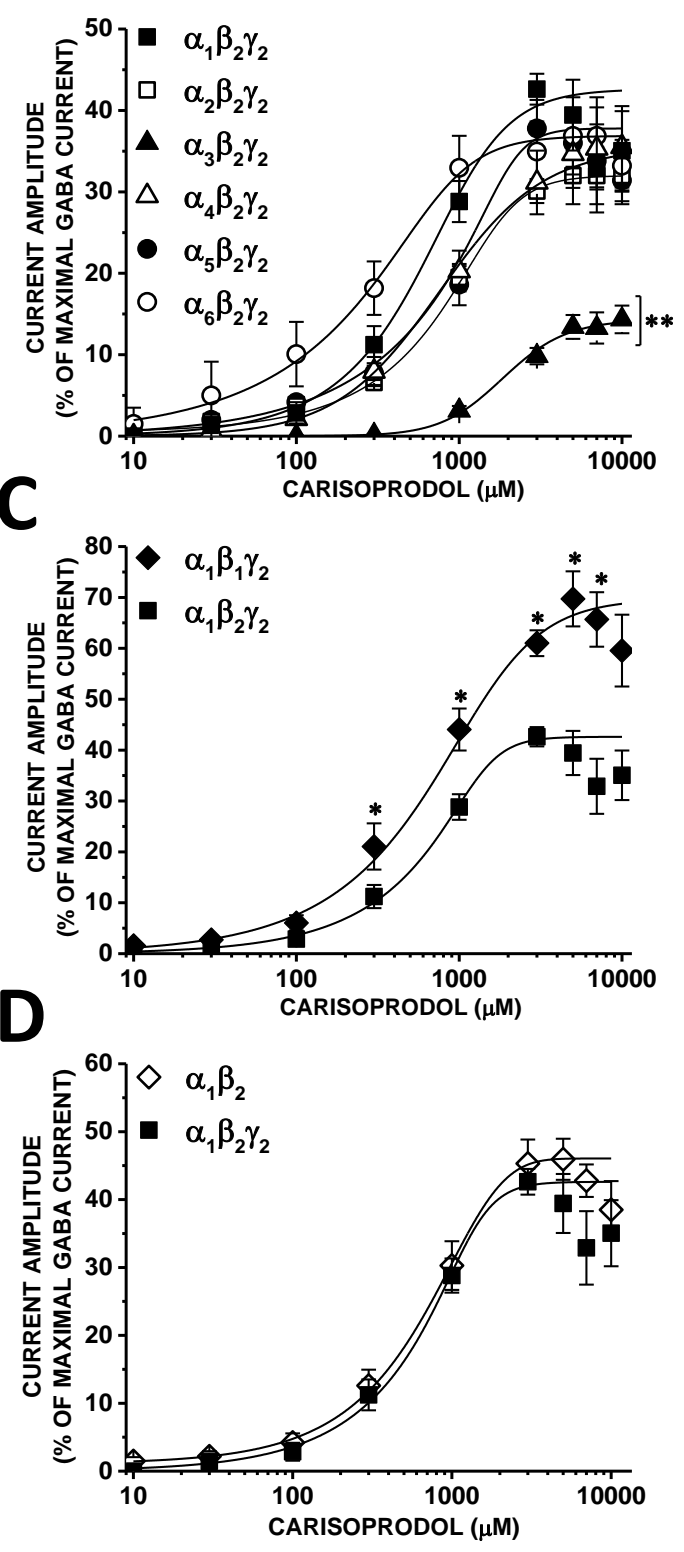

FIGURE II-1 
Figure II-2. Influence of $\mathrm{GABA}_{\mathrm{A}} \mathrm{R}$ subunit isoforms on allosteric modulation by carisoprodol. A, representative traces demonstrating the potentiation of GABA-gated $\left(\mathrm{EC}_{20}\right)$ currents from human $\alpha 1 \beta 2 \gamma 2, \alpha 3 \beta 2 \gamma 2, \alpha 1 \beta 1 \gamma 2$ and $\alpha 1 \beta 2 \mathrm{GABA}_{\mathrm{A}}$ Rs by carisoprodol. B, concentration-response curves for the allosteric modulation of GABA-gated currents from human $\alpha 1-, \alpha 2-, \alpha 3-, \alpha 4-, \alpha 5-$, and $\alpha 6 \beta 2 \gamma 2$ GABA $_{\mathrm{A}}$ Rs by carisoprodol. Peak current elicited by carisoprodol plus $\mathrm{GABA}\left(\mathrm{EC}_{20}\right)$ normalized to $\mathrm{GABA}\left(\mathrm{EC}_{20}\right)$ mediated currents. Carisoprodol was significantly more efficacious at $\alpha 1$-containing receptors. $\mathbf{C}$, concentration-response curves for the allosteric modulation of GABA-gated currents recorded from $\alpha 1 \beta 1 \gamma 2$ and $\alpha 1 \beta 2 \gamma 2 \mathrm{GABA}_{\mathrm{A}} \mathrm{Rs}$ by carisoprodol. Carisoprodol was significantly more efficacious at $\beta 2$-containing receptors. $\mathbf{D}$, concentration-response curves for the allosteric modulation of GABA-gated currents recorded from $\alpha 1 \beta 2$ and $\alpha 1 \beta 2 \gamma 2$ $\mathrm{GABA}_{\mathrm{A}} \mathrm{Rs}$ by carisoprodol. There were no significant differences between the two configurations at each concentration tested $(p>0.05)$. E, GABA concentration response in human $\alpha 1 \beta 2 \gamma 2 \mathrm{GABA}_{\mathrm{A}}$ receptors in the absence (open square) or presence (filled square) of $100 \mu \mathrm{M}$ carisoprodol. Carisoprodol significantly decreased the GABA EC Fo $_{50}$ (from $35.5 \pm$ 0.64 to $8.2 \pm 0.26 \mu \mathrm{M}$ ( $\mathrm{n}=6$ and 4 , respectively). The average carisoprodol direct gating effect at $100 \mu \mathrm{M}$ (2.8\% of maximal GABA-gated current) was subtracted from the summary data. Each data point represents the mean \pm S.E.M. of minimum of three cells. ${ }^{*}, \mathrm{p}<0.05$, $* * *, \mathrm{p}<0.001$. 
A

$\operatorname{CSP}(\mu \mathrm{M}) \quad \underline{3} \quad \underline{10} \quad \underline{30} \quad \underline{100} \quad \underline{300} 1000$

GABA

$\alpha_{1} \beta_{2} \gamma_{2}$
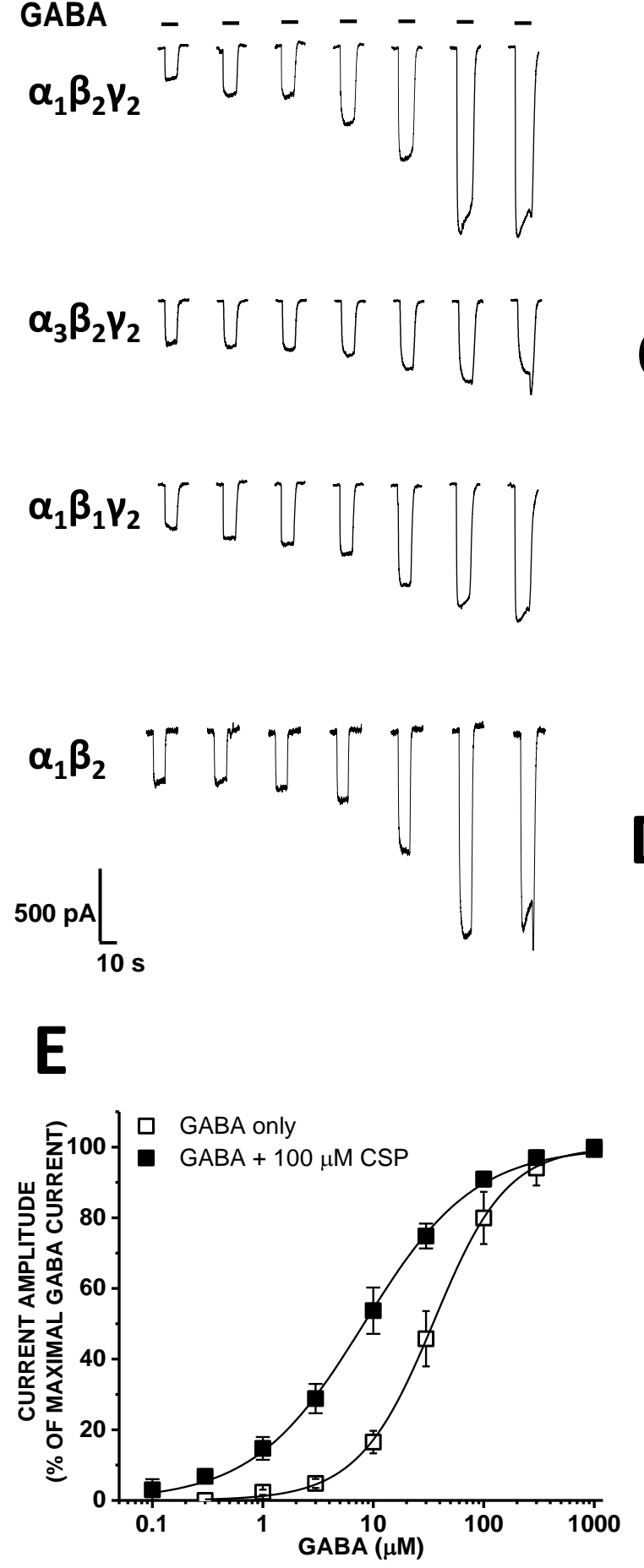

FIGURE II-2
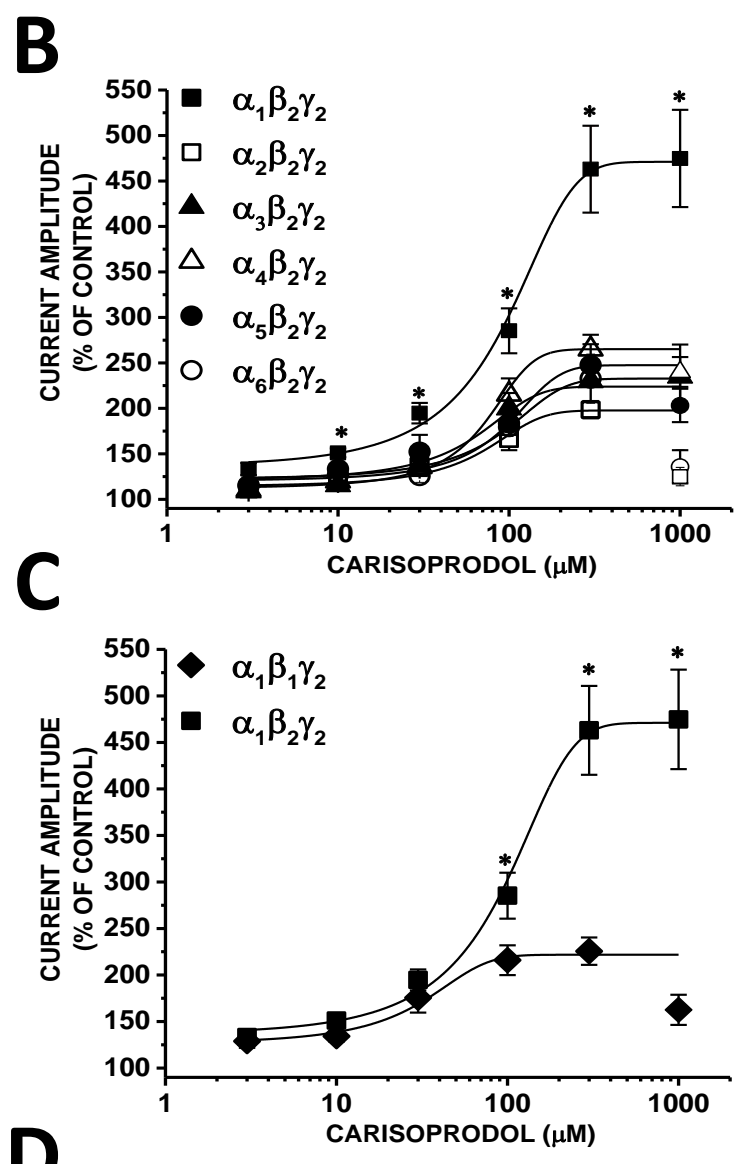

D

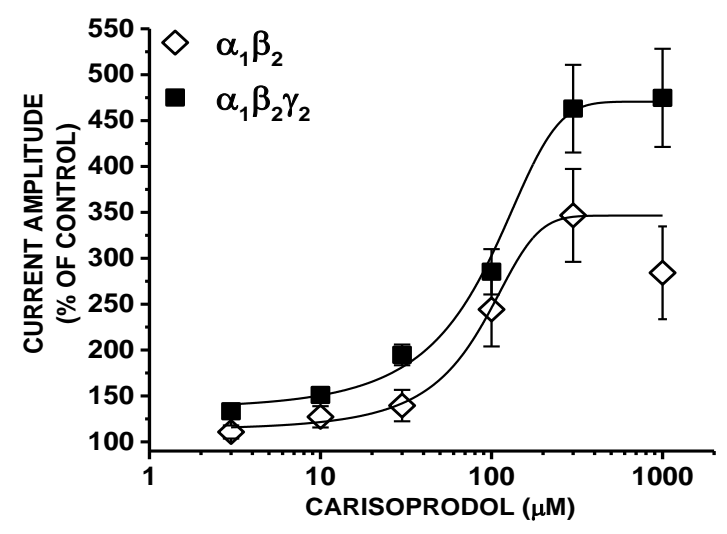


Figure II-3. Direct gating action of carisoprodol on extrasynaptic GABAA receptors. A, representative traces demonstrating carisoprodol (CSP, 1 or $3 \mathrm{mM}$ ) activation of $\alpha 1 \beta 2$, $\alpha 1 \beta 3$ and $\alpha 1 \beta 3 \gamma 2$ compared to $\delta$ - expressing extrasynaptic $\alpha 1 \beta 3 \delta$ and $\alpha 4 \beta 3 \delta$ GABA $_{A}$ Rs. GABA concentrations are saturating at each receptor. At $3 \mathrm{mM}$ and above, the amplitude of CSP-gated current in $\alpha 4 \beta 3 \delta$ decreases significantly, followed by a rebound current. B, concentration-response curves for carisoprodol-mediated currents in $\alpha 1 \beta 3, \alpha 1 \beta 3 \gamma 2, \alpha 1 \beta 2$ and extrasynaptic $\alpha 1 \beta 3 \delta$ and $\alpha 4 \beta 3 \delta$ GABA $_{A}$ Rs. The $\delta$ subunit-containing extrasynaptic $\mathrm{GABA}_{\mathrm{A}}$ Rs showed highest efficacy for carisoprodol. C, effect of the super agonist THIP in $\alpha 1 \beta 3 \delta$ and $\alpha 4 \beta 3 \delta \mathrm{GABA}_{\mathrm{A}} \mathrm{Rs}$, compared to GABA. D, summary data demonstrating carisoprodol's efficacy on $\delta$ - expressing extrasynaptic $\alpha 1 \beta 3 \delta$ and $\alpha 4 \beta 3 \delta \mathrm{GABA}_{\mathrm{A}} \mathrm{Rs}$ compared to THIP. Carisoprodol is approximately $90 \%$ and $88 \%$ efficacious as THIP on $\alpha 1 \beta 3 \delta$ and $\alpha 4 \beta 3 \delta \mathrm{GABA}_{A} \mathrm{Rs}$, respectively. Each data point represents the mean \pm S.E.M. of minimum of four cells. \#, $\mathrm{p}<0.01$. 
A

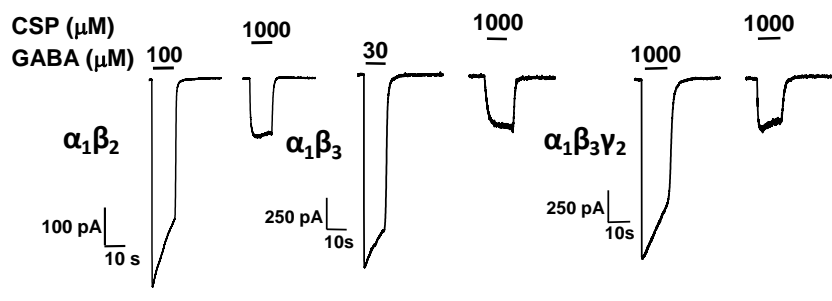

$\operatorname{CSP}(\mu \mathrm{M}) \quad 1000 \quad 3000$ GABA $(\mu M) 30$

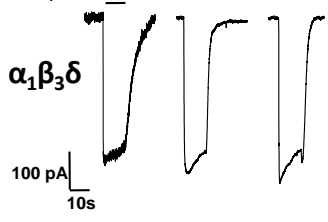

C

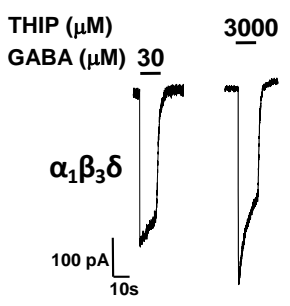

B

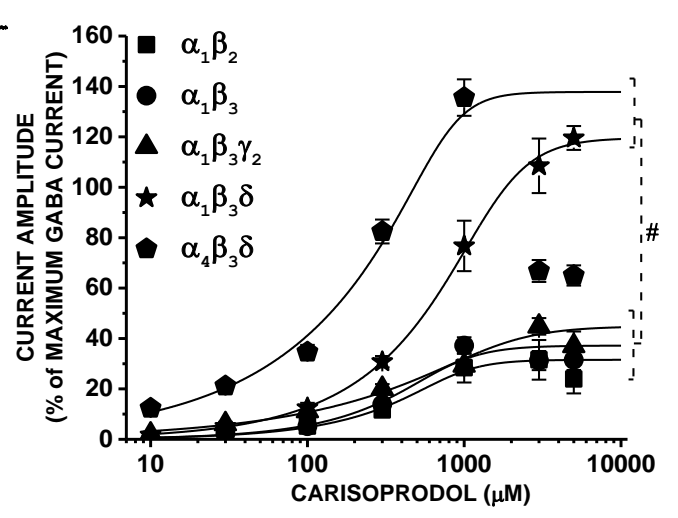

D

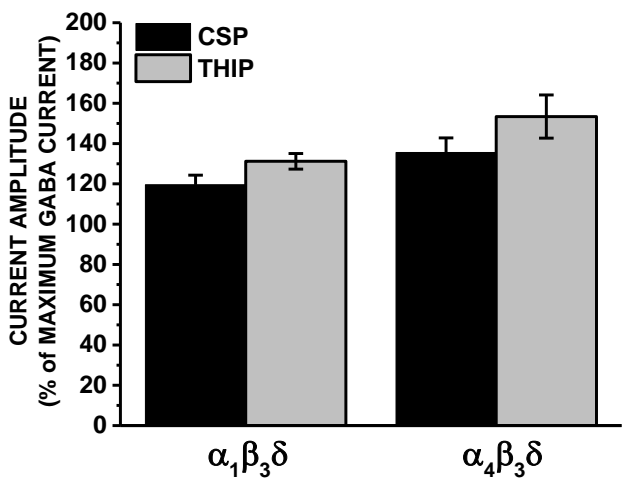

FIGURE II-3 
Figure II-4. Allosteric modulation of extrasynaptic GABA $\mathrm{A}$ receptors by carisoprodol. A, representative traces demonstrating the potentiation by carisoprodol $(300 \mu \mathrm{M})$ of GABAgated $\left(\mathrm{EC}_{20}\right)$ currents in $\alpha 1 \beta 3, \alpha 1 \beta 3 \gamma 2$ and $\alpha 1 \beta 2$ compared to $\delta$-expressing extrasynaptic $\alpha 1 \beta 3 \delta$ and $\alpha 4 \beta 3 \delta \mathrm{GABA}_{\mathrm{A}}$ Rs. B, concentration-response curves showing mean allosteric carisoprodol modulation of GABA-gated currents in $\alpha 1 \beta 3, \alpha 1 \beta 3 \gamma 2, \alpha 1 \beta 2$ and extrasynaptic $\alpha 1 \beta 3 \delta$ and $\alpha 4 \beta 3 \delta$ GABA $_{A}$ Rs. GABA $A_{A}$ Rs containing $\beta 2$ subunits showed highest efficacy for carisoprodol. Each data point represents the mean \pm S.E.M. of a minimum of four cells. *, $\mathrm{p}<0.05 ; * *, \mathrm{p}<0.01$. 
A
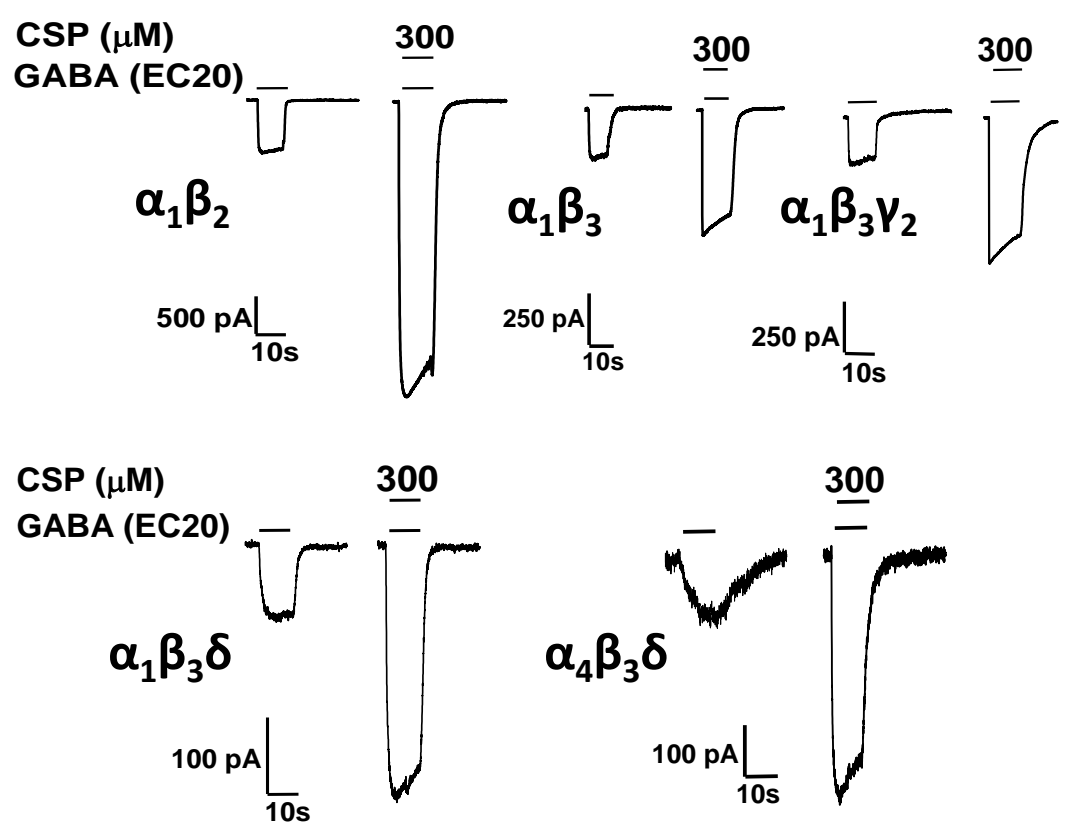

B

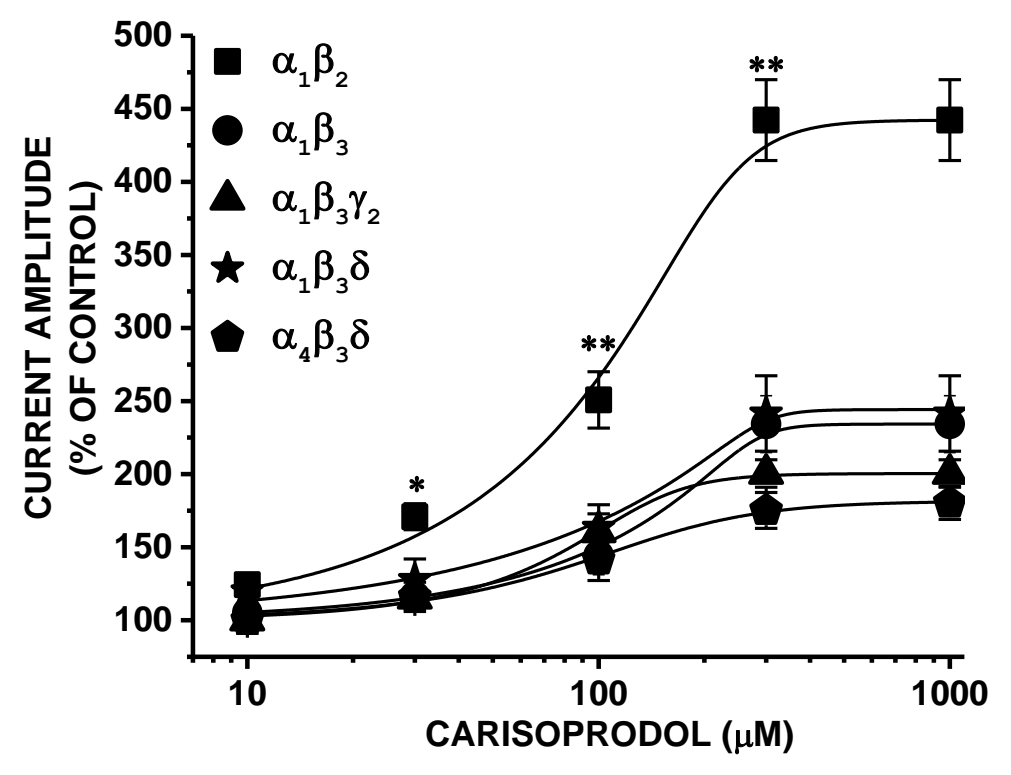

FIGURE II-4 
Figure II-5. Potentiation of saturating GABA current by sub-gating concentration of carisoprodol in extrasynaptic $\mathbf{G A B A}_{\mathbf{A}}$ receptors. A, representative traces demonstrating the potentiation of saturating GABA currents by carisoprodol and pentobarbital in extrasynaptic $\alpha 1 \beta 3 \delta$ and $\alpha 4 \beta 3 \delta$ GABA $_{A}$ Rs. B, bar graph summarizing carisoprodol's significant potentiation of maximal GABA currents in extrasynaptic $\alpha 1 \beta 3 \delta$ and $\alpha 4 \beta 3 \delta$ $\mathrm{GABA}_{A} \mathrm{Rs}$, as seen with pentobarbital. This effect was not seen in $\alpha 1 \beta 3$ and $\alpha 1 \beta 3 \gamma 2$ $\mathrm{GABA}_{\mathrm{A}}$ Rs. Each data point represents the mean \pm S.E.M. of a minimum of four cells. **, $\mathrm{p}<0.01$. 


\section{A}
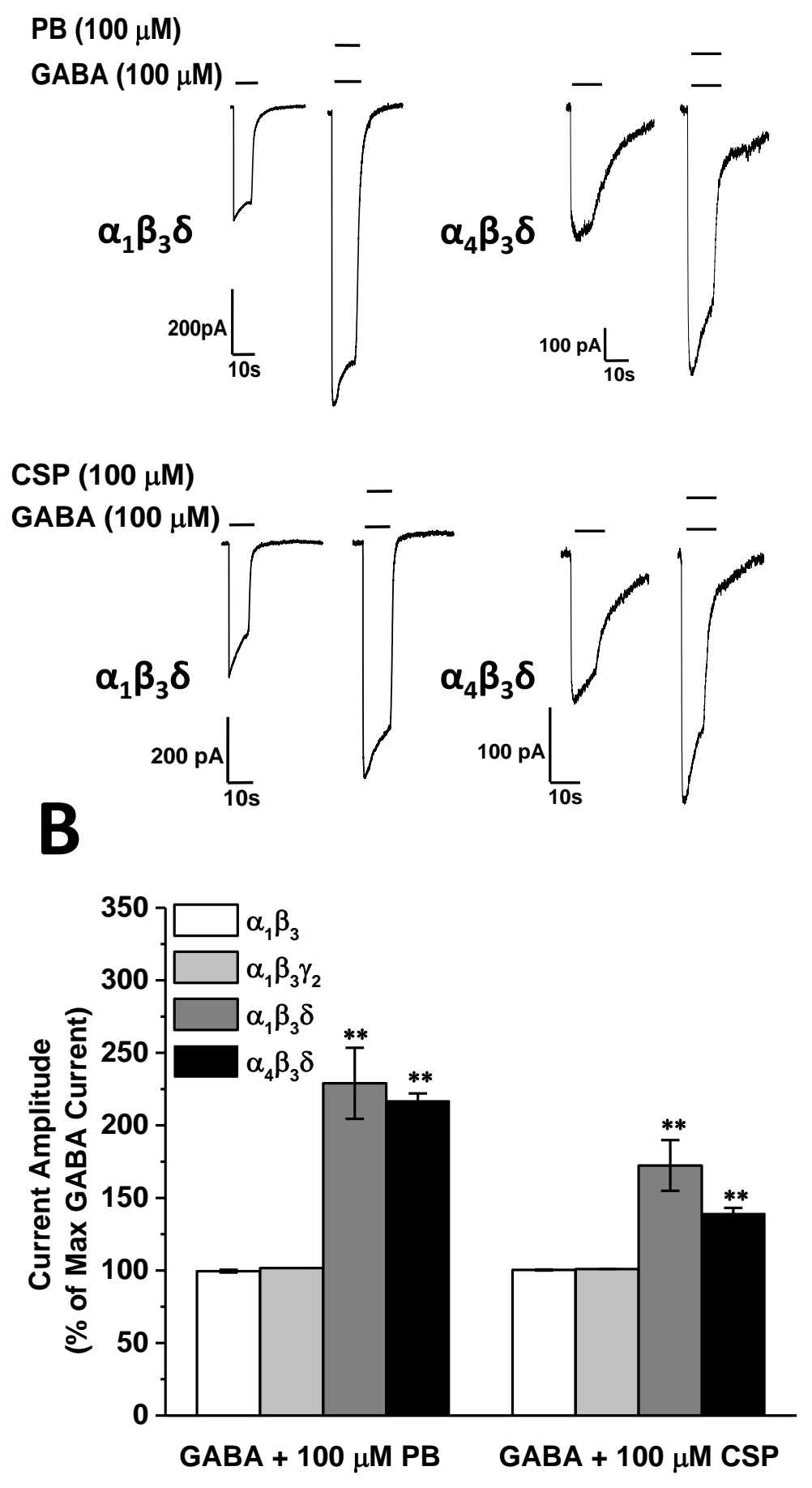

FIGURE II-5 
Figure II-6. Voltage-dependent effect of carisoprodol actions on GABAA receptors. A, $\mathbf{C}$ and E, representative traces from $\alpha 1 \beta 2 \gamma 2 \mathrm{GABA}_{\mathrm{A}} \mathrm{Rs}$ transfected HEK293 cells clamped at $-60 \mathrm{mV}$ and $+60 \mathrm{mV}$ for carisoprodol's direct gating, blocking and allosteric modulatory effects. B, D and F, bar graph summarizing carisoprodol direct gating, blocking and allosteric modulatory actions, respectively, at $-60 \mathrm{mV}$ and $+60 \mathrm{mV}$. Carisoprodol direct gating and blocking effects are independent of voltage. However, allosteric potentiation of GABA currents by carisoprodol $(100 \mu \mathrm{M})$ was significantly reduced compared to the level of potentiation observed at $-60 \mathrm{mV}$. Each data point represents the mean \pm S.E.M. of minimum of four cells. ${ }^{*}, \mathrm{p}<0.01$. 


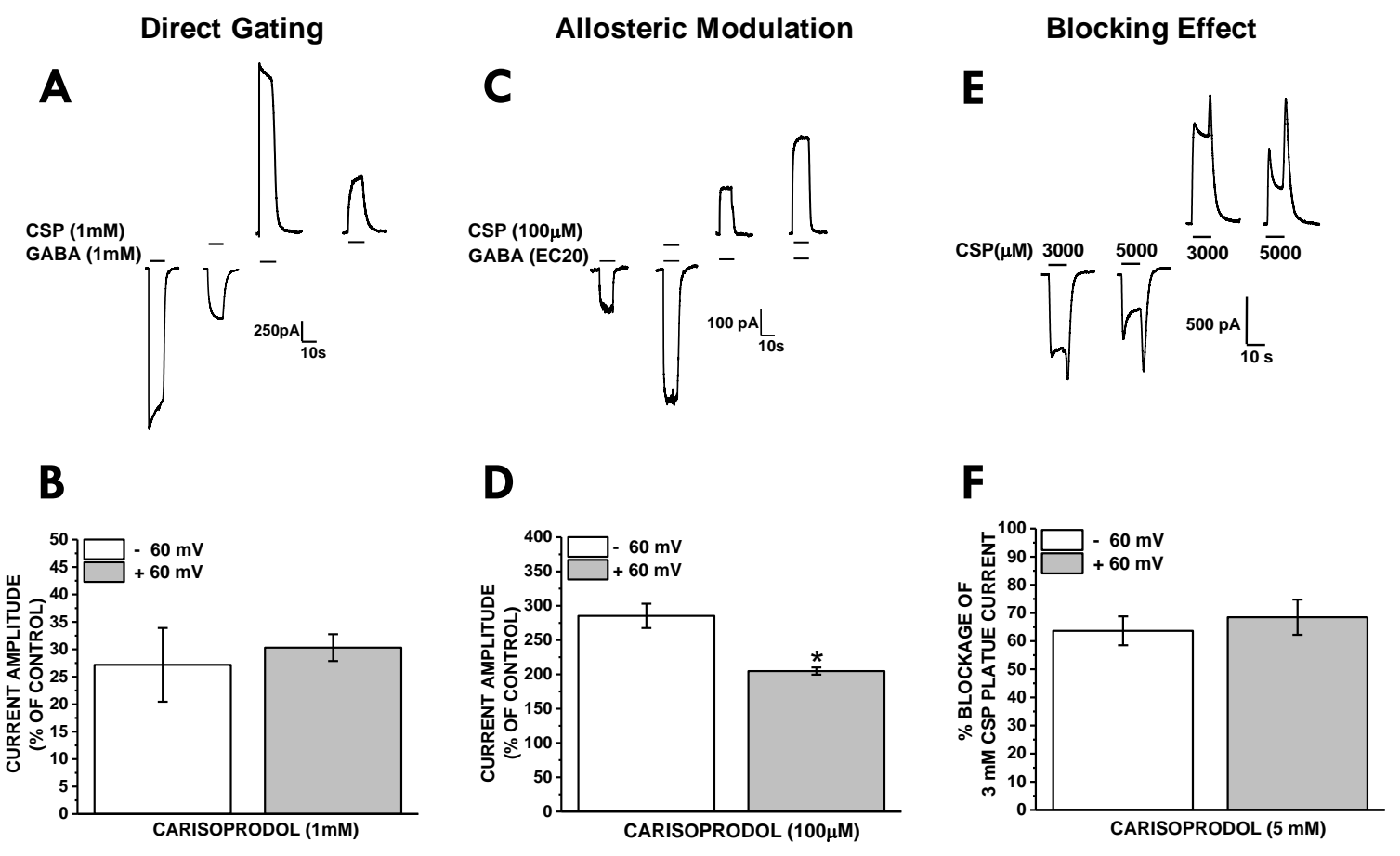

FIGURE II-6 


\section{AUTHORSHIP CONTRIBUTIONS}

Participated in research design: Kumar, Gonzalez, and Dillon

Conducted experiments: Kumar and Gonzalez

Performed data analysis: Kumar, Gonzalez, and Dillon

Wrote or contributed to writing of the manuscript: Kumar, Gonzalez, and Dillon

\section{Acknowledgements}

We gratefully acknowledge Ms. Cathy Bell-Horner for excellent technical assistance.

\section{Footnotes}

This work was supported by the National Institutes of Health National Institute of Drug Abuse [Grant R01 DA DA022370 to GHD and by National Institutes of General Medical Sciences Grant U54GM104942] 


\section{REFERENCES}

Adams HR, Kerzee T and Morehead CD (1975) Carisoprodol-related death in a child. Journal of forensic sciences 20(1): 200-202.

Adkins CE, Pillai GV, Kerby J, Bonnert TP, Haldon C, McKernan RM, Gonzalez JE, Oades K, Whiting PJ and Simpson PB (2001) alpha4beta3delta GABA(A) receptors characterized by fluorescence resonance energy transfer-derived measurements of membrane potential. The Journal of biological chemistry 276(42): 38934-38939.

Atack JR, Hutson PH, Collinson N, Marshall G, Bentley G, Moyes C, Cook SM, Collins I, Wafford K, McKernan RM and Dawson GR (2005) Anxiogenic properties of an inverse agonist selective for alpha3 subunit-containing GABA A receptors. British journal of pharmacology 144(3): 357-366.

Ator NA (2005) Contributions of GABAA receptor subtype selectivity to abuse liability and dependence potential of pharmacological treatments for anxiety and sleep disorders. CNS spectrums 10(1): 31-39.

Ator NA, Atack JR, Hargreaves RJ, Burns HD and Dawson GR (2010) Reducing abuse liability of GABAA/benzodiazepine ligands via selective partial agonist efficacy at alpha1 and alpha2/3 subtypes. The Journal of pharmacology and experimental therapeutics 332(1): 4-16.

Belelli D, Harrison NL, Maguire J, Macdonald RL, Walker MC and Cope DW (2009) Extrasynaptic GABAA receptors: form, pharmacology, and function. The Journal 
of neuroscience : the official journal of the Society for Neuroscience 29(41): 1275712763.

Bianchi MT and Macdonald RL (2003) Neurosteroids shift partial agonist activation of $\operatorname{GABA}(\mathrm{A})$ receptor channels from low- to high-efficacy gating patterns. The Journal of neuroscience : the official journal of the Society for Neuroscience 23(34): 10934-10943.

Brickley SG and Mody I (2012) Extrasynaptic GABA(A) receptors: their function in the CNS and implications for disease. Neuron 73(1): 23-34.

Cope DW, Di Giovanni G, Fyson SJ, Orban G, Errington AC, Lorincz ML, Gould TM, Carter DA and Crunelli V (2009) Enhanced tonic GABAA inhibition in typical absence epilepsy. Nature medicine 15(12): 1392-1398.

Crestani F, Low K, Keist R, Mandelli M, Mohler H and Rudolph U (2001) Molecular targets for the myorelaxant action of diazepam. Molecular pharmacology 59(3): 442-445.

Dias R, Sheppard WF, Fradley RL, Garrett EM, Stanley JL, Tye SJ, Goodacre S, Lincoln RJ, Cook SM, Conley R, Hallett D, Humphries AC, Thompson SA, Wafford KA, Street LJ, Castro JL, Whiting PJ, Rosahl TW, Atack JR, McKernan RM, Dawson GR and Reynolds DS (2005) Evidence for a significant role of alpha 3-containing GABAA receptors in mediating the anxiolytic effects of benzodiazepines. The Journal of neuroscience : the official journal of the Society for Neuroscience 25(46): 10682-10688. 
Elder NC (1991) Abuse of skeletal muscle relaxants. American family physician 44(4): $1223-1226$.

Fass JA (2010) Carisoprodol legal status and patterns of abuse. The Annals of pharmacotherapy 44(12): 1962-1967.

Feng HJ, Bianchi MT and Macdonald RL (2004) Pentobarbital differentially modulates alpha1beta3delta and alpha1beta3gamma2L GABAA receptor currents. Molecular pharmacology 66(4): 988-1003.

Feng HJ and Macdonald RL (2010) Barbiturates require the $\mathrm{N}$ terminus and first transmembrane domain of the delta subunit for enhancement of alpha1beta3delta GABAA receptor currents. The Journal of biological chemistry 285(31): 2361423621.

Forman SA (2011) Clinical and molecular pharmacology of etomidate. Anesthesiology 114(3): 695-707.

Gatch MB, Nguyen JD, Carbonaro T and Forster MJ (2012) Carisoprodol tolerance and precipitated withdrawal. Drug and alcohol dependence 123(1-3): 29-34.

Glykys J and Mody I (2007) Activation of GABAA receptors: views from outside the synaptic cleft. Neuron 56(5): 763-770.

Gonzalez LA, Gatch MB, Forster MJ and Dillon GH (2009a) Abuse Potential of Soma: the GABA(A) Receptor as a Target. Molecular and cellular pharmacology 1(4): 180186. 
Gonzalez LA, Gatch MB, Taylor CM, Bell-Horner CL, Forster MJ and Dillon GH (2009b)

Carisoprodol-mediated modulation of GABAA receptors: in vitro and in vivo studies. The Journal of pharmacology and experimental therapeutics 329(2): 827837.

Griebel G, Perrault G, Simiand J, Cohen C, Granger P, Depoortere H, Francon D, Avenet P, Schoemaker H, Evanno Y, Sevrin M, George P and Scatton B (2003) SL651498, a GABAA receptor agonist with subtype-selective efficacy, as a potential treatment for generalized anxiety disorder and muscle spasms. CNS drug reviews 9(1): 3-20.

Hawkinson JE, Drewe JA, Kimbrough CL, Chen JS, Hogenkamp DJ, Lan NC, Gee KW, Shen KZ, Whittemore ER and Woodward RM (1996) 3 alpha-Hydroxy-3 betatrifluoromethyl-5 alpha-pregnan-20-one (Co 2-1970): a partial agonist at the neuroactive steroid site of the gamma-aminobutyric acidA receptor. Molecular pharmacology 49(5): 897-906.

Herd MB, Foister N, Chandra D, Peden DR, Homanics GE, Brown VJ, Balfour DJ, Lambert JJ and Belelli D (2009) Inhibition of thalamic excitability by 4,5,6,7tetrahydroisoxazolo[4,5-c]pyridine-3-ol: a selective role for delta-GABA(A) receptors. The European journal of neuroscience 29(6): 1177-1187.

Hosie AM, Wilkins ME, da Silva HM and Smart TG (2006) Endogenous neurosteroids regulate GABAA receptors through two discrete transmembrane sites. Nature 444(7118): 486-489. 
Houston CM, McGee TP, Mackenzie G, Troyano-Cuturi K, Rodriguez PM, Kutsarova E, Diamanti E, Hosie AM, Franks NP and Brickley SG (2012) Are extrasynaptic GABAA receptors important targets for sedative/hypnotic drugs? The Journal of neuroscience : the official journal of the Society for Neuroscience 32(11): 38873897.

Huang RQ, Gonzales EB and Dillon GH (2006) GABAA receptors: structure, function and modulation, in Biological and biophysical aspects of ligand-gated ion channel receptor superfamilies (Arias H ed) pp 171-198, Research Signpost.

Ito T, Suzuki T, Wellman SE and Ho IK (1996) Pharmacology of barbiturate tolerance/dependence: GABAA receptors and molecular aspects. Life sciences 59(3): 169-195.

Korpi ER, Grunder G and Luddens H (2002) Drug interactions at GABA(A) receptors. Progress in neurobiology 67(2): 113-159.

Korpi ER, Kuner T, Seeburg PH and Luddens H (1995) Selective antagonist for the cerebellar granule cell-specific gamma-aminobutyric acid type A receptor. Molecular pharmacology 47(2): 283-289.

Licata SC, Platt DM, Cook JM, Sarma PV, Griebel G and Rowlett JK (2005) Contribution of GABAA receptor subtypes to the anxiolytic-like, motor, and discriminative stimulus effects of benzodiazepines: studies with the functionally selective ligand SL651498 [6-fluoro-9-methyl-2-phenyl-4-(pyrrolidin-1-yl-carbonyl)-2,9-dihydro- 
1H-pyridol[3 ,4-b]indol-1-one]. The Journal of pharmacology and experimental therapeutics 313(3): 1118-1125.

Licata SC, Platt DM, Cook JM, Van Linn ML and Rowlett JK (2009) Contribution of alpha1 subunit-containing gamma-aminobutyric acidA (GABAA) receptors to motor-impairing effects of benzodiazepines in squirrel monkeys. Psychopharmacology (Berl) 203(3): 539-546.

Licata SC and Rowlett JK (2008) Abuse and dependence liability of benzodiazepine-type drugs: GABA(A) receptor modulation and beyond. Pharmacology, biochemistry, and behavior 90(1): 74-89.

Littrell RA, Hayes LR and Stillner V (1993) Carisoprodol (Soma): a new and cautious perspective on an old agent. Southern medical journal 86(7): 753-756.

Luscher C and Ungless MA (2006) The mechanistic classification of addictive drugs. PLoS medicine 3(11): e437.

Maguire JL, Stell BM, Rafizadeh M and Mody I (2005) Ovarian cycle-linked changes in GABA(A) receptors mediating tonic inhibition alter seizure susceptibility and anxiety. Nature neuroscience 8(6): 797-804.

Maldonado-Aviles JG, Curley AA, Hashimoto T, Morrow AL, Ramsey AJ, O'Donnell P, Volk DW and Lewis DA (2009) Altered markers of tonic inhibition in the dorsolateral prefrontal cortex of subjects with schizophrenia. The American journal of psychiatry 166(4): 450-459. 
McIntyre IM, Sherrard J and Lucas J (2012) Postmortem carisoprodol and meprobamate concentrations in blood and liver: lack of significant redistribution. Journal of analytical toxicology 36(3): 177-181.

McKernan RM, Rosahl TW, Reynolds DS, Sur C, Wafford KA, Atack JR, Farrar S, Myers J, Cook G, Ferris P, Garrett L, Bristow L, Marshall G, Macaulay A, Brown N, Howell O, Moore KW, Carling RW, Street LJ, Castro JL, Ragan CI, Dawson GR and Whiting PJ (2000) Sedative but not anxiolytic properties of benzodiazepines are mediated by the $\mathrm{GABA}(\mathrm{A})$ receptor alpha1 subtype. Nature neuroscience 3(6): 587-592.

Meera P, Olsen RW, Otis TS and Wallner M (2009) Etomidate, propofol and the neurosteroid THDOC increase the GABA efficacy of recombinant alpha4beta3delta and alpha4beta3 GABA A receptors expressed in HEK cells. Neuropharmacology 56(1): 155-160.

Mortensen M, Ebert B, Wafford K and Smart TG (2010) Distinct activities of GABA agonists at synaptic- and extrasynaptic-type GABAA receptors. The Journal of physiology 588(Pt 8): 1251-1268.

O'Toole KK and Jenkins A (2012) The apparent voltage dependence of GABAA receptor activation and modulation is inversely related to channel open probability. Molecular pharmacology 81(2): 189-197.

Olsen RW (2014) Analysis of gamma-Aminobutyric Acid (GABA) Type A Receptor Subtypes Using Isosteric and Allosteric Ligands. Neurochemical research. 
Olsen RW and Sieghart W (2008) International Union of Pharmacology. LXX. Subtypes of gamma-aminobutyric acid(A) receptors: classification on the basis of subunit composition, pharmacology, and function. Update. Pharmacological reviews 60(3): 243-260.

Pritchett DB, Sontheimer H, Shivers BD, Ymer S, Kettenmann H, Schofield PR and Seeburg PH (1989) Importance of a novel GABAA receptor subunit for benzodiazepine pharmacology. Nature 338(6216): 582-585.

Reeves RR and Parker JD (2003) Somatic dysfunction during carisoprodol cessation: evidence for a carisoprodol withdrawal syndrome. The Journal of the American Osteopathic Association 103(2): 75-80.

Rho JM, Donevan SD and Rogawski MA (1997) Barbiturate-like actions of the propanediol dicarbamates felbamate and meprobamate. The Journal of pharmacology and experimental therapeutics 280(3): 1383-1391.

Robertson MD and Marinetti LJ (2003) Carisoprodol--effects on human performance and behavior. Forensic Sci Rev 15(1): 1-9.

Rudolph U and Knoflach F (2011) Beyond classical benzodiazepines: novel therapeutic potential of GABAA receptor subtypes. Nature reviews Drug discovery 10(9): 685697.

Rudolph U and Mohler H (2006) GABA-based therapeutic approaches: GABAA receptor subtype functions. Current opinion in pharmacology 6(1): 18-23. 
Ruesch D, Neumann E, Wulf H and Forman SA (2012) An allosteric coagonist model for propofol effects on alpha1beta2gamma2L gamma-aminobutyric acid type A receptors. Anesthesiology 116(1): 47-55.

Rust GS, Hatch R and Gums JG (1993) Carisoprodol as a drug of abuse. Archives of family medicine 2(4): 429-432.

Sigel E and Steinmann ME (2012) Structure, function, and modulation of GABA(A) receptors. The Journal of biological chemistry 287(48): 40224-40231.

Stewart DS, Hotta M, Desai R and Forman SA (2013) State-dependent etomidate occupancy of its allosteric agonist sites measured in a cysteine-substituted GABAA receptor. Molecular pharmacology 83(6): 1200-1208.

Tan KR, Brown M, Labouebe G, Yvon C, Creton C, Fritschy JM, Rudolph U and Luscher C (2010) Neural bases for addictive properties of benzodiazepines. Nature 463(7282): 769-774.

Toth PP and Urtis J (2004) Commonly used muscle relaxant therapies for acute low back pain: a review of carisoprodol, cyclobenzaprine hydrochloride, and metaxalone. Clinical therapeutics 26(9): 1355-1367.

Wafford KA (2005) GABAA receptor subtypes: any clues to the mechanism of benzodiazepine dependence? Current opinion in pharmacology 5(1): 47-52.

Wagoner KR and Czajkowski C (2010) Stoichiometry of expressed alpha(4)beta(2)delta gamma-aminobutyric acid type A receptors depends on the ratio of subunit cDNA transfected. The Journal of biological chemistry 285(19): 14187-14194. 
Wohlfarth KM, Bianchi MT and Macdonald RL (2002) Enhanced neurosteroid potentiation of ternary $\mathrm{GABA}(\mathrm{A})$ receptors containing the delta subunit. The Journal of neuroscience : the official journal of the Society for Neuroscience 22(5): $1541-1549$.

Zacny JP, Paice JA and Coalson DW (2011) Characterizing the subjective and psychomotor effects of carisoprodol in healthy volunteers. Pharmacology, biochemistry, and behavior 100(1): 138-143.

Zacny JP, Paice JA and Coalson DW (2012) Subjective and psychomotor effects of carisoprodol in combination with oxycodone in healthy volunteers. Drug and alcohol dependence 120(1-3): 229-232. 


\title{
CHAPTER III
}

\section{A SINGLE AMINO ACID RESIDUE AT TRANSMEMBRANE 4 OF THE ALPHA 1 SUBUNIT INFLUENCES CARISOPRODOL DIRECT GATING EFFICACY AT GABAA RECEPTORS}

\author{
Manoj Kumar\#, John M. Freund* and Glenn H. Dillon\#*
}

Department of Pharmaceutical Sciences, School of Pharmacy\#, Department of Physiology and Pharmacology and Center for Neuroscience, School of Medicine*

West Virginia University, Robert C. Byrd Health Sciences Center, Morgantown, WV 26506 


\begin{abstract}
The muscle relaxant carisoprodol (CSP, trade name Soma) has recently been controlled at the federal level as a Schedule IV drug due to its high abuse potential and consequences of misuse, such as withdrawal syndrome, delusions, seizures and even death. Recent work has shown that carisoprodol can directly gate and allosterically modulate the $\mathrm{GABA}_{\mathrm{A}}$ receptor. These actions are subunit-dependent; compared to other $\mathrm{GABA}_{\mathrm{A}}$ receptors, carisoprodol has nominal direct gating effects in $\alpha 3 \beta 2 \gamma 2$ receptors. Here, using site-directed-mutagenesis and whole cell patch clamp electrophysiology in transiently transfected HEK293 cells, we examined the role of $\mathrm{GABA}_{A}$ receptor $\alpha$ subunit transmembrane domain 4 (TM4) amino acids in direct gating and allosteric modulatory actions of carisoprodol. Mutation of $\alpha 3$ valine at position 440 to leucine (present in the equivalent position in the $\alpha 1$ subunit) increased the direct gating potency and efficacy of carisoprodol significantly, without affecting allosteric modulatory effects. The corresponding reverse mutation, $\alpha 1(\mathrm{~L} 415 \mathrm{~V})$, decreased carisoprodol direct gating potency and efficacy. Subsequent assessment of a series of amino acids at $\alpha 1(415)$ on carisoprodol efficacy showed the following rank order: $(\mathrm{L}=\mathrm{I}=\mathrm{T}=\mathrm{R}>\mathrm{Y}>\mathrm{W}=\mathrm{C}=\mathrm{V}>\mathrm{G}>\mathrm{S})$. We conclude $\alpha 1(415)$ of TM4 is involved in the direct gating, but not in allosteric modulatory, actions of carisoprodol. Also, orientation of alkyl or hydroxyl groups at this position influence direct gating effects. These findings support the likelihood that direct gating and allosteric modulatory effects of carisoprodol are mediated via distinct binding sites.
\end{abstract}




\section{INTRODUCTION}

Carisoprodol ( $N$-isopropyl meprobamate, CSP) is a centrally acting muscle relaxant frequently prescribed for skeleton muscle pain (Luo et al., 2004; Toth and Urtis, 2004). In recent years, misuse and abuse of carisoprodol has become a significant problem. Carisoprodol abuse causes psychomotor impairment and severe withdrawal that may predispose to seizures and death (Bramness et al., 2004; Fass, 2010; Reeves et al., 2012; Zacny and Gutierrez, 2011; Zacny et al., 2011). Tolerance to carisoprodol develops relatively fast, facilitating the problems associated with withdrawal (Gatch et al., 2012; Reeves and Burke, 2010). As per the National Survey on Drug Use and Health in 2009, an estimated 2.9 million people in US admitted that they had consumed carisoprodol for non-medical purpose (see ref: Drugs and chemical of concerns). Indeed, considering its alarming abuse rate, effective January of 2012, carisoprodol was scheduled at the federal level (see ref: Schedule of controlled substances). Considering the danger posed by this drug, there is urgent need for improved treatment for carisoprodol toxicity, and a novel drug with less abuse potential.

Until recently, it was widely accepted that the sedative and muscle relaxing effects of carisoprodol were predominantly due to its primary metabolite, meprobamate (Bramness et al., 2004). More recent work has shown that carisoprodol itself allosterically modulates, directly activates and blocks $\gamma$-Aminobutyric acid, type $\mathrm{A}\left(\mathrm{GABA}_{\mathrm{A}}\right)$ receptors in a concentration-dependent manner (Gonzalez et al., 2009). In vivo studies also support the fact that carisoprodol itself has significant CNS effects due to interaction with $\mathrm{GABA}_{\mathrm{A}}$ receptors (Gonzalez et al., 2009). 
$\mathrm{GABA}_{\mathrm{A}}$ receptors are member of the cys-loop family of ligand-gated ion channels; they are hetero-pentameric $\mathrm{Cl}^{-}$channels and play a critical role in mediating fast inhibition in the brain (Corringer et al., 2012; Sigel and Steinmann, 2012). Multiple GABAA receptor subunits and corresponding isoforms have been identified, including $\alpha(1-6), \beta(1-3), \gamma(1-3)$, $\rho, \delta, \varepsilon$ and $\theta$ (Olsen and Sieghart, 2008). Each subunit is composed of a large extracellular $\mathrm{N}$ terminus, four transmembrane helices (TM1-TM4), an extracellular TM2-TM3 loop, a large TM3-TM4 intracellular loop, and an extracellular C terminus (Cockcroft et al., 1995). The TM2 domains form the pore of the channel (Miyazawa et al., 2003; Xu and Akabas, 1996)) (Fig. 1). In addition to the GABA binding site, $\mathrm{GABA}_{\mathrm{A}}$ receptors have binding sites for several clinically important drugs, including anxiolytics, sedative-hypnotics, muscle relaxants, and anesthetics. The GABA binding site is located at the interface of the $\alpha 1$ and $\beta 2$ subunits, and benzodiazepines bind at the interface of $\alpha 1-\gamma 2$ subunits in the extracellular region (Newell and Czajkowski, 2003; Sigel and Steinmann, 2012) (Fig 1A). Barbiturate and general anesthetic (propofol, etomidate) binding sites are believed to be positioned in the water accessible region located between the TM helices of the receptor (Bali and Akabas, 2004; Siegwart et al., 2002; Zeller et al., 2007a). Carisoprodol actions are not mediated via reported sites of action for benzodiazepines or barbiturates (Gonzalez et al., 2009). While the general anesthetics propofol and etomidate allosterically modulate and directly gate $\mathrm{GABA}_{\mathrm{A}}$ receptors through a single site of action (Siegwart et al., 2002; Stewart et al., 2013), distinct $\mathrm{GABA}_{A}$ receptors sites confer these properties to neurosteroids (Hosie et al., 2006). 
Although not definitive, work to date suggests carisoprodol may mediate its effects via distinct sites of action (Gonzalez et al., 2009).

Our recent studies with carisoprodol on $\mathrm{GABA}_{\mathrm{A}}$ receptors have shown the allosteric modulatory and direct gating properties of carisoprodol are subunit-dependent (Kumar et al., 2015). Allosteric modulatory actions of carisoprodol are most efficacious at receptors incorporating the $\alpha 1$ subunit, whereas $\alpha 3$-expressing receptors show minimal direct gating effects. Characteristics of carisoprodol effects are consistent with it interacting at the transmembrane domains (Hosie et al., 2006). Aligned amino acid sequences of human $\alpha$ subunit isoforms ( $\alpha 1-6)$ revealed that TM1, TM2 and TM3 are fully conserved in all $\alpha$ subunit isoforms. The TM4 region of $\alpha$ subunit isoforms is also largely conserved; however, I419, I423 and V440 residues of $\alpha 3$ differ compared to all other $\alpha$ subunit isoforms (Fig. 1C) (Barnard et al., 1998; Bergmann et al., 2013). We thus explored the extent to which these residues may contribute to the ability of carisoprodol to directly gate and allosterically modulate $\mathrm{GABA}_{\mathrm{A}}$ receptors. We have identified L415 at TM4 of the $\alpha 1$ subunit as being critically involved in direct gating actions of carisoprodol. 


\section{MATERIAL AND METHODS}

\section{Plasmids and site-directed-mutagenesis}

Human cDNA plasmids encoding $\alpha 1, \alpha 3, \beta 2$ and $\gamma 2 \mathrm{GABA}_{\mathrm{A}}$ receptor subunits were used in the present study. Individual and combined mutations in $\alpha 1$ and $\alpha 3$ cDNA plasmids were created using Stratagene's Quik Change II ${ }^{\circledR}$ site-directed-mutagenesis kit (Agilent Technologies; La Jolla, CA) and were sequenced to confirm mutations at West Virginia University’s Genomics Core Facility.

\section{Chemicals and solutions}

Carisoprodol, pentobarbital, salts and buffers were purchased from Sigma Aldrich (St. Louis, MO), GABA was obtained from Acros Organics (New Jersey, US). Pentobarbital and GABA stock solutions $(500 \mathrm{mM})$ were prepared in deionized water. Carisoprodol stock solution (1 M) was made in DMSO. All stock solutions were stored at $-20^{\circ} \mathrm{C}$. On the day of experiment, fresh working drug concentrations were prepared from stock solution by dissolving in physiological buffer solution (below).

\section{Cell Culture and Transfection}

Human embryonic kidney 293 (HEK293) cells were transfected with human cDNA encoding desired $\mathrm{GABA}_{\mathrm{A}}$ receptor subunits. To obtain $\alpha x \beta 2 \gamma 2 \mathrm{GABA}_{\mathrm{A}}$ receptors, HEK293 cells were transfected with human $\mathrm{GABA}_{\mathrm{A}} \alpha 1 / 3$ mutant or wild type ; human $\beta 2$; and human $\gamma 2 \mathrm{~s}$ (short isoform) subunit cDNA in a 1:1:5 $(0.3 \mu \mathrm{g}: 0.3 \mu \mathrm{g}: 1.5 \mu \mathrm{g})$ ratio using poly jet DNA 
in vitro transfection reagent (SigmaGen Laboratories, MD) and used for recording 24-48 h later. The $\gamma 2$ s subunit will be referred to as $\gamma 2$ from this point forward. Human $\mathrm{GABA}_{\mathrm{A}} \alpha 1$ subunit cDNA was generously provided by Neil Harrison (Columbia University Medical Center, New York). Cells were plated on glass coverslips coated with poly-L-lysine in 35$\mathrm{mm}$ culture dishes and were incubated and maintained at $37^{\circ} \mathrm{C}$ in a humidified incubator with an atmosphere of $5 \% \mathrm{CO}_{2}$.

\section{Whole-cell patch clamp electrophysiology}

All experiments were conducted at room temperature $\left(22-25^{\circ} \mathrm{C}\right)$ with the membrane potential clamped at $-60 \mathrm{mV}$. Patch pipettes of borosilicate glass (1B150F; World Precision Instruments, Inc., Sarasota, FL) were pulled (Flaming/Brown, P-87/PC; Sutter Instrument Company, Novato, CA) to a tip resistance of 4-6 M $\Omega$. Patch pipettes were filled with a solution consisting of $140 \mathrm{mM} \mathrm{CsCl}, 10 \mathrm{mM}$ EGTA-Na ${ }^{+}, 10 \mathrm{mM}$ HEPES-Na ${ }^{+}$, and $4 \mathrm{mM}$ $\mathrm{Mg}^{2+}$-ATP, $\mathrm{pH}$ 7.2. Coverslips containing cultured cells were placed in the recording chamber on the stage of an inverted light microscope and superfused continuously with an external solution consisting of $125 \mathrm{mM} \mathrm{NaCl}, 20 \mathrm{mM}$ HEPES, $3 \mathrm{mM} \mathrm{CaCl} 2,5.5 \mathrm{mM} \mathrm{KCl}$, $0.8 \mathrm{mM} \mathrm{MgCl} 2$, and $10 \mathrm{mM}$ glucose, $\mathrm{pH}$ 7.4. Agonist-induced $\mathrm{Cl}^{-}$currents were obtained with an Axopatch 200B amplifier with a rate of 50 samples per second (Molecular Devices, Sunnyvale, CA) equipped with a CV-203BU head stage. Currents were low-pass filtered at $5 \mathrm{kHz}$, monitored simultaneously on an oscilloscope and a chart recorder (Gould TA240; 
Gould Instrument Systems Inc., Cleveland, $\mathrm{OH}$ ), and stored on a computer using an on-line data acquisition system (pCLAMP 6.0; Axon Instruments) for subsequent off-line analysis.

\section{Experimental Protocol}

GABA (with or without carisoprodol) or carisoprodol was prepared in external saline solution from stock solutions and applied to each cell by gravity flow using a Y-shaped tube positioned adjacent to the cell. Recordings were obtained from transfected cells only after establishing that two consecutive $\mathrm{GABA} \mathrm{EC}_{20}$-activated currents varied in amplitude by no more than $\pm 10 \%$. For studies investigating direct activation, carisoprodol-mediated currents were normalized to currents elicited by saturating GABA concentrations. Modulatory effects of carisoprodol on GABA-gated currents were assessed using an $\mathrm{EC}_{20}$ gating concentration of GABA as the control (individually determined for each mutant and wild type receptor studied). This gating concentration was selected to ensure there was a sufficient range to observe the full allosteric potential of carisoprodol. At the initiation of each recorded cell, it was confirmed that gating concentration was approximately the $\mathrm{EC}_{20}$ (range of $\mathrm{EC}_{15}$ to $\mathrm{EC}_{25}$ accepted for an individual cell). In recordings displaying inhibition followed by a rebound current after termination of carisoprodol or carisoprodol plus GABA application (Gonzalez et al., 2009), the maximal current amplitude achieved during active ligand application was taken as the peak current. 


\section{Data Analysis}

Concentration-response profiles for the positive modulatory actions of carisoprodol were generated (Origin 9.1; OriginLab Corp., Northampton, MA) using the equation $I / I_{\max }=$ [carisoprodol $]^{\mathrm{n}} /\left([\text { carisoprodol }]^{\mathrm{n}}+\mathrm{EC}_{50}{ }^{\mathrm{n}}\right)$, where $I$ is the normalized current amplitude at a given concentration of carisoprodol, $I_{\max }$ is the maximum current induced by carisoprodol, $\mathrm{EC}_{50}$ is the half-maximal effective concentration of carisoprodol, and $n$ is the Hill coefficient. For concentration-response curves illustrating allosteric actions, a correction was applied to subtract direct gating effects. In some cases, the blocking actions of carisoprodol became notable at high concentrations; in these instances, curves were fitted to the data point corresponding to peak effect, and the curve was extrapolated. All data are presented as mean values \pm S.E. Statistical significance between control and test conditions was determined using Student's $t$-test (paired or unpaired) and one-way analysis of variance. Tukey-Kramer post hoc test for multiple comparisons was performed as needed. Correlation assessments were performed using linear fit in origin 9.1. 


\section{RESULTS}

\section{Functional characterization of $\alpha 3$ and $\alpha 1$ TM4 mutant GABAA receptors}

For this study, an extensive series of mutations (single point or 2-3 residues) in $\alpha 1$ and $\alpha 3$ subunits were evaluated. In all cases, the mutant subunit was expressed with wild type $\beta 2$ and $\gamma 2$ subunits, and GABA concentration-response profiles were generated to assess overall receptor function and to establish gating concentrations for allosteric studies. GABA $\mathrm{EC}_{50}$ for wild type $\alpha 1$ and $\alpha 3$ receptors were both approximately $35 \mu \mathrm{M}$ (Tables 1 and 2). In general, shifts in GABA EC $\mathrm{E}_{50}$ were modest. Mutations in $\alpha 3$ subunits caused a leftward shift in the GABA concentration-response curve of 1.9- to 4.6-fold (Table 1). Similarly, mutations in the $\alpha 1$ subunit had either insignificant or modest effects on GABA EC 50 , with the maximal effect being a 2.5-fold increase in $\mathrm{GABA}^{\mathrm{E}} \mathrm{EC}_{50}$ relative to wild type $\alpha 1$ receptors (Table 2). Thus the mutations had minimal effects on fundamental receptor gating.

\section{Mutation of $\alpha 3$ TM4 amino acids to corresponding $\alpha 1$ amino acids increased direct gating effect of carisoprodol but not allosteric modulatory actions}

Consistent with our previous report (Kumar et al., 2015), the ability of carisoprodol to directly gate $\alpha 3 \beta 2 \gamma 2$ receptors was significantly attenuated compared to GABAA receptors expressing the $\alpha 1$ subunit (Fig. 2B, Tables 1,2). Maximal current amplitudes generated by 3 $\mathrm{mM}$ carisoprodol were $41.8 \pm 2.4 \%$ and $8.5 \pm 1.1 \%$ of that generated by saturating GABA in $\alpha 1 \beta 2 \gamma 2$ and $\alpha 3 \beta 2 \gamma 2$ receptors, respectively. We thus assessed the potential involvement of three amino acids we identified in TM4 that were unique to the $\alpha 3$ subunit in this 
attenuated direct gating effect. Residues were mutated to the amino acid found at the equivalent position in the $\alpha 1$ subunit, either alone or in combination. As shown in Figure 2, all $\alpha 3$ mutants resulted in a gain-of-function effect, significantly increasing direct gating currents such that current amplitudes in response to $3 \mathrm{mM}$ carisoprodol were not significantly different from that obtained in wild type $\alpha 1 \beta 2 \gamma 2$ receptors (summary values in Table 1 ).

As carisoprodol also has a diminished allosteric modulatory effect in $\alpha 3 \beta 2 \gamma 2$ receptors compared to $\alpha 1 \beta 2 \gamma 2$ receptors (Kumar et al., 2015), we also assessed the extent to which these mutations might increase sensitivity to the allosteric actions of carisorodol. Interestingly, allosteric modulatory effects of carisoprodol were not affected by mutations. Whereas carisoprodol enhanced $\mathrm{GABA} \mathrm{EC}_{20}$ currents in all mutated receptors, the magnitude of the effect for each mutant was not significantly different from that observed in $\alpha 3 \beta 2 \gamma 2$ receptors, and the allosteric potentiation fell far short of that obtained in $\alpha 1 \beta 2 \gamma 2$ receptors (Fig. 2D and Table 1).

\section{A single mutation of $\alpha 1$ TM4 L415 amino acid to corresponding $\alpha 3$ V440 amino acid decreased direct gating effect of carisoprodol.}

To confirm the involvement of the identified $\alpha$ subunit TM4 residues in direct gating action of carisoprodol, we mutated $\alpha 1$ TM4 amino acids to the corresponding $\alpha 3$ TM4 three non-identical amino acids (L394I, A398I, and L415V) (Fig. 1) in all possible combinations of single, double or triple mutation, and assessed direct gating by carisoprodol. Out of seven mutations generated, each of those containing the L415V mutation caused a 
significant loss of carisoprodol $(3 \mathrm{mM})$ direct gating effect compared to wild type $\alpha 1$ expressing receptors, whereas carisoprodol's effects in those receptors not incorporating the L415V mutation were not significantly different from wild type (Fig 3A, 3B and Table 2). These data indicate the leucine residue at position 415 in the $\alpha 1$ subunit has a key role in the direct gating action of carisoprodol.

\section{Amino acid residue at $\alpha 1(415)$ subunit influences carisoprodol direct gating efficacy.}

In an attempt to gain additional insight into physicochemical determinants that influence carisoprodol direct gating capability at the $\alpha 1(415)$ position, we generated and assessed the following series of mutations: $\alpha 1$ (L415S), $\alpha 1(\mathrm{~L} 415 \mathrm{G}), \alpha 1(\mathrm{~L} 415 \mathrm{~T}) \alpha 1(\mathrm{~L} 415 \mathrm{Y})$ $\alpha 1(\mathrm{~L} 415 \mathrm{~W}), \alpha 1(\mathrm{~L} 415 \mathrm{I}), \alpha 1(\mathrm{~L} 415 \mathrm{C})$ and $\alpha 1(\mathrm{~L} 415 \mathrm{R})$. These residues provide a range of amino acid side chain properties, including volume, polarity and hydropathy. We tested each mutant receptor for carisoprodol direct gating potency and efficacy. Similar to valine substitution at $\alpha 1$ (L415) position, L415S, L415G, L415W and L415C all decreased maximal gating efficacy (to $5.5 \pm 1.2,9.1 \pm 1.6,17.8 \pm 4.1$, and $18.0 \pm 1.6 \%$ of saturating GABA current, respectively). Potency to carisoprodol was generally unaffected, with the exception that the $\mathrm{L} 415 \mathrm{~W}$ mutant induced a three-fold rightward shift in $\mathrm{EC}_{50}$ (Fig 4 A, B, C and Table 2). The presence of T, Y, I or R had no effect on either carisoprodol efficacy or potency. Correlation analysis showed positive and negative correlations of amino acid volume and polarity at the 415 position with carisoprodol direct gating efficacy (Fig. 5). These data demonstrate the nature of the amino acid side chain at $\alpha 1(415)$ position is critical for the 
direct gating effect of carisoprodol. In addition, an increase in GABA EC50 correlated negatively with carisoprodol efficacy (Fig. 5F).

The $\alpha 1$ (L415S) mutation does not affect allosteric modulation by carisoprodol or direct activation by pentobarbital

To further assess the extent to which the $\alpha 1(\mathrm{~L} 415)$ residue may be differentially involved in direct gating action allosteric modulatory effects of carisoprodol, we tested if the L415S mutation, which effectively obliterated the ability of carisoprdol to directly gate the receptor (Fig. 4), had an effect on allosteric potentiation. In $\alpha 1(\mathrm{~L} 415 \mathrm{~S}) \beta \gamma 2$ receptors, carisoprodol potentiation of $\mathrm{GABA} \mathrm{EC}_{20}$ currents differed in neither maximum potentiation nor potency when compared to wild type receptors $\left(439.45 \pm 49.4 \%\right.$ potentiation and $\mathrm{EC}_{50}$ of $89.5 \pm 15 \mu \mathrm{M}, \mathrm{n}=7$, in $\alpha 1(\mathrm{~L} 415 \mathrm{~S}) \beta \gamma 2$ receptors compared to $474.75 \pm 53.4 \%$ and 102.2 $\pm 16 \mu \mathrm{M}, \mathrm{n}=5$ in wild type receptors, Fig. $6 \mathrm{~A}, \mathrm{~B})$. As a further assessment of the specificity of the L415S mutation, we evaluated if it had any effect on direct gating by pentorbarbital. Direct gating by $1 \mathrm{mM}$ pentobarbital was not significantly different in $\alpha 1$ (L415S) $\beta \gamma 2$ receptors compared to wild type receptors (current amplitude in comparison to saturating GABA was $70.2 \pm 4.2 \% ; n=5$ and $84.1 \pm 6.4 \% ; n=7$ in mutant and wild type receptors, respectively (Fig 6. C and D). Thus effects of the L415S mutation are not due to non-specific effects on the ability of direct-gating ligands to activate the channel. 


\section{DISCUSSION}

In a recent report (Kumar et al., 2015), we found that direct gating effects of the skeletal muscle relaxant carisoprodol were reduced in $\alpha 3 \beta \gamma 2 \mathrm{GABA}_{\mathrm{A}}$ receptors, compared to those expressing any other $\alpha$ subunit variant ( $\alpha 1-2, \alpha 4-6)$. Here, we identified $\alpha$ subunit TM4 residues, in particular $\alpha 1415$ (equivalent to $\alpha 3440$ ), that are critical for direct gating, but not allosteric modulatory, effects of carisoprodol (Fig 1). Mutation of the native $\alpha 3440 \mathrm{~V}$ residue to the $\mathrm{L}$ residue found in the $\alpha 1$ subunit (V440L) resulted in a significant enhancement of carisoprodol-gated current; the converse mutation (L415V), had the opposite effect (Fig 2 and 3). Subsequent evaluation of a series of mutations resulted in the following rank order effect on carisoprodol gating efficacy $(\mathrm{L}=\mathrm{I}=\mathrm{T}=\mathrm{R}>\mathrm{Y}>\mathrm{W}=\mathrm{C}=\mathrm{V}>\mathrm{G}>\mathrm{S})$, and correlation analysis demonstrated that both amino acid volume and polarity are important determinants of this position's effect on carisoprodol direct gating (Fig 5). The presence of a hydrophobic residue tended to correlate with enhanced carisoprodol gating, although this effect did not reach statistical significance. Interestingly, except for tryptophan (which caused a 3-fold increase in carisoprodol direct gating $\mathrm{EC}_{50}$ ), none of the introduced mutants affected potency of carisoprodol's direct gating effect; the action was nearly exclusively an effect on efficacy.

Transmembrane 4 residues of the $\alpha 1$ subunit have been shown to be involved in allosteric modulatory effect of other $\mathrm{GABA}_{\mathrm{A}}$ receptor ligands, such as neurosteroids and anesthetics (Hosie et al., 2006; Jenkins et al., 2002). Homology modeling has shown that 
N407 and Y410 donate a hydrogen bond to the ketone group of THDOC, and contribute to the binding pocket of neurosteroids. Substitution of polar residues to hydrophobic amino acids at N407A and Y410F reduced THDOC potency significantly (Hosie et al., 2006). Indeed, L415 itself has been implicated in effects on anesthetic agents. In a tryptophan scanning study of TM4, it was found that introduction of tryptophan at position 415 (L415W) of the $\alpha 1$ subunit produced a significant decrease in the ability of the anesthetics halothane and chloroform to potentiate GABA-gated currents (Jenkins et al., 2002). It is possible TM domains forms an important allosteric modulatory site on $\mathrm{GABA}_{\mathrm{A}}$ receptors. However, our results would seem to rule out the potential involvement of the TM4 domain 415 position, as the (L415S) mutation did not affect allosteric potentiation of GABA currents (Fig 6). These results are consistent with our contention that distinct sites exist for the allosteric modulatory and direct gating effects of carisoprodol.

Previous molecular and behavior studies of carisoprodol have shown characteristics of barbiturate-like effects. Both ligands directly gate, allosterically modulate, and inhibit the receptor (at high concentrations). More notably, in drug discrimination studies, the barbiturate pentobarbital substituted for the discriminative stimulus effects of carisoprodol in carisoprodol-trained rats. In addition, the barbiturate antagonist bemegride blocked the locomotor depression effect of carisoprodol in mice, and also antagonized carisoprodol-gated currents in HEK293 cells expressing GABAA receptors (Gonzalez et al., 2009). These findings suggested that behavior and molecular action of carisoprodol may be mediated by a barbiturate-like mechanism of action on $\mathrm{GABA}_{\mathrm{A}}$ receptors. However, in the present study 
the $\alpha 1(\mathrm{~L} 415 \mathrm{~S})$ mutation did not affect the ability of pentobarbital to directly gate $\mathrm{GABA}_{\mathrm{A}}$ receptors. In addition, a rho receptor (wild type is insensitive to barbiturates) mutation that confers sensitivity to barbiturate did not confer sensitivity to carisoprodol (Gonzalez et al., 2009). Thus, although previous studies have shown barbiturate-like action of carisoprodol, collectively the data support distinct binding sites or functional domains for carisoprodol versus barbiturate direct gating effects in $\mathrm{GABA}_{\mathrm{A}}$ receptors. The actions of neurosteroids are also comparable to carisoprodol. A threonine in position 236 of the $\alpha 1$ subunit (T236) has been shown to be involved in direct gating of neurosteroids, as mutation of this residue to I greatly attenuates sensitivity to the neurosteroid THDOC (Hosie et al., 2006). In separate experiments, we tested whether the $\alpha 1$ (T236I) mutation affected carisoprodol direct gating actions. We found this mutation did not produce any change in carisoprodol efficacy relative wild type receptors. Thus, the site of action for carisoprodol appears to also be distinct from that of neurosteroids.

Our subunit-dependent studies of carisoprodol have also demonstrated significant influence of the $\beta$ subunit isoform in direct gating and allosteric modulatory effects of carisoprodol (Kumar et al., 2015). Receptors expressing the $\beta 1$ subunit showed highest efficacy for direct gating, whereas $\beta 2$-containing receptors confer enhanced allosteric modulatory properties. The TM2 $15^{\prime}$ residue lies toward the extracellular aspect of the channel, and faces away from the channel pore; this residue in the $\beta 2$ subunit (N265) has been shown to be involved in alcohol and general anesthetics actions at $\mathrm{GABA}_{\mathrm{A}}$ receptors (McCracken et al., 2010). Mutation of the $\beta 2$ asparagine to methionine (N265M) reduced 
the direct gating currents of propofol, alphaxolone and etomidate, and decreased allosteric potentiation by etomidate, propofol, enflurane, isoflurane, butanol and octanols (Siegwart et al., 2003; Zeller et al., 2007b). Interestingly, TM2 of $\beta$ subunit isoforms is highly conserved. An exception is the $15^{\prime}$ residue, which is $S$ in the $\beta 1$ subunit. In preliminary studies in our lab, mutation of the $\beta 1$ TM2 15' serine to the corresponding $\beta 2$ subunit residue (asparagine, $\mathrm{N})$ decreased the direct gating efficacy of carisoprodol to $22.4 \pm 4.4$ for $\alpha 1 \beta 1\left(\mathrm{~S}_{\mathrm{TM} 2} 15^{\prime} \mathrm{N}\right) \gamma 2$ receptor significantly from $62.2 \pm 1.8$ for $\alpha 1 \beta 1 \gamma 2$ wild type receptors. Based on our model of the TM domains of the $\mathrm{GABA}_{\mathrm{A}}$ receptor (Fig. 7), it is unlikely carisoprodol docks between the 265 residue of the $\beta 2$ subunit and 415 of the $\alpha 1$ subunit. The involvement of the TM2 $15^{\prime}$ position in a diverse array of ligands suggests its effects are more likely on transduction, as opposed to forming part of a binding site for multiple and diverse ligands. A complete understanding of the binding pocket for carisoprodol requires further exploration.

It is known that addictive drugs hijack the reward system by increasing dopamine levels in mesolimbic system (Luscher and Ungless, 2006). Dopaminergic neurons in the ventral tegmental area (VTA) express $\alpha 3$-containing $\mathrm{GABA}_{\mathrm{A}}$ receptors and the GABAergic interneurons in the VTA express $\alpha 1$-containing receptors (Tan et al., 2010). Diazepam binding to the $\alpha 1$-containing $\mathrm{GABA}_{\mathrm{A}}$ receptors on GABAergic VTA neurons leads to a reduction of the activity of these cells, and thus reduced release of GABA, which results in a disinhibition of the dopaminergic VTA neurons (Rudolph and Knoflach, 2011). In turn, this results in an increase in dopamine release in the ventral striatum (Heikkinen et al., 2009). These studies verified the $\alpha 1 \mathrm{GABA}_{\mathrm{A}}$ receptor subtype in the mesolimbic dopaminergic 
system is involved in addiction. Further, behavior studies in mice with mutation of a residue key for benzodiazepine's effects have shown physiological effects of this agent are GABA receptor subunit-dependent. The $\alpha 1(\mathrm{H} 101 \mathrm{R})$ knock-in mice showed absence of sedative effects of diazepam but anxiolytic effects were not affected (Rudolph et al., 1999). If the mutation was instead present in the $\alpha 2$ subunit $\alpha 2(\mathrm{H} 101 \mathrm{R})$, the anxiolytic action of diazepam was absent, its myorelaxant actions (which are observed at higher doses than anxiolytic effects) were reduced, but its sedative action was intact (Low et al., 2000). In a3(H126R) and $\alpha 5(\mathrm{H} 105 \mathrm{R})$ mice, the myorelaxant action of diazepam was reduced without altering sedative and anxiolytic actions (Crestani et al., 2001). Moreover, the development of tolerance to the sedative action of benzodiazepines has been linked to $\alpha 5$-expressing GABA receptors (van Rijnsoever et al., 2004).

The goal of our present study was to identify key amino acid residues that are involved in actions of carisoprodol at $\mathrm{GABA}_{\mathrm{A}}$ receptors. We found that $\alpha 1$ (L415) of transmembrane domain 4 of the $\mathrm{GABA}_{\mathrm{A}}$ receptor is involved in direct gating action of carisoprodol, and identified physicochemical traits that are important for this effect. Mutation of this residue did not impact allosteric modulatory effects of carisoprodol, and it also had no effect on the ability of the barbiturate pentobarbital to directly gate the receptor. These results are consistent with our contention that carisoprodol mediates these two actions through distinct, likely novel, sites on the $\mathrm{GABA}_{\mathrm{A}}$ receptor. 
Table III-1. Influence of $\mathrm{GABA}_{A}$ receptor $\alpha 3$ TM4 amino acids mutation to corresponding $\alpha 1$ amino acids on GABA EC50 values, carisoprodol direct activation and allosteric modulation. Carisoprodol direct gating activation at $3 \mathrm{mM}$ is normalized to saturated GABA current, whereas carisoprodol modulation effect to potentiate GABA-gated current is normalized to $\mathrm{GABA} \mathrm{EC}_{20}$ current. Each data point represents the mean \pm S.E.M of $\mathrm{n}$ cells. ${ }^{*}, \mathrm{p}<0.05 ; * *, \mathrm{p}<0.01$ relative to wild type $\alpha 3 \beta 2 \gamma 2 \mathrm{GABA}_{\mathrm{A}}$ receptors. 


\begin{tabular}{|c|c|c|c|c|c|c|}
\hline \multirow[t]{2}{*}{$\begin{array}{c}\mathbf{G A B A _ { A } \mathbf { R }} \\
\text { Configuration }\end{array}$} & \multicolumn{2}{|c|}{ GABA EC50 } & \multicolumn{2}{|c|}{$\begin{array}{c}\text { CSP gating } \\
(\% \text { of GABA max })\end{array}$} & \multicolumn{2}{|c|}{$\begin{array}{l}\text { CSP modulation } \\
(\% \text { of GABA EC20) }\end{array}$} \\
\hline & $(\mu \mathbf{M})$ & $\mathbf{n}$ & $3 \mathrm{mM}$ & $\mathbf{n}$ & $300 \mu \mathrm{M}$ & $\mathbf{n}$ \\
\hline$\alpha 3 \mathrm{WT}$ & $34.8 \pm 2.1$ & 6 & $08.5 \pm 1.1$ & 11 & $235 \pm 35$ & 6 \\
\hline$\alpha 3(\mathrm{~V} 440 \mathrm{~L})$ & $07.5 \pm 0.9 * *$ & 7 & $37.6 \pm 3.5^{* *}$ & 9 & $301 \pm 14$ & 5 \\
\hline$\alpha 3(\mathrm{I} 419 \mathrm{~L} / \mathrm{I} 423 \mathrm{~A})$ & $18.1 \pm 2.2^{*}$ & 9 & $40.8 \pm 2.4 * *$ & 8 & $252 \pm 14$ & 4 \\
\hline$\alpha 3(\mathrm{I} 419 \mathrm{~L} / \mathrm{I} 423 \mathrm{~A} / \mathrm{V} 440 \mathrm{~L})$ & $15.8 \pm 5.0 *$ & 6 & $35.9 \pm 3.9 * *$ & 10 & $156 \pm 22$ & 6 \\
\hline
\end{tabular}

TABLE III-1 
Table III-2. Influence of GABAA receptor $\alpha 1$ TM4 residues mutation to corresponding $\alpha 3$ amino acids and $\alpha 1$ (L415) amino acid substitution on GABA EC50 values and carisoprodol direct activation properties. Carisoprodol direct gating activation is normalized to saturated GABA current whereas carisoprodol modulation effect to potentiate GABA-gated current is normalized to GABA EC20 current. Each data point represents the mean \pm S.E.M of $n$ cells. ${ }^{*}, \mathrm{p}<0.05 ;{ }^{*}, p<0.01$ relative to wild type $\alpha 1 \beta 2 \gamma 2 \mathrm{GABA}_{\mathrm{A}}$ receptors. 


\begin{tabular}{|c|c|c|c|c|c|}
\hline \multirow[t]{2}{*}{$\begin{array}{c}\mathbf{G A B A}_{\mathrm{A}} \mathbf{R} \\
\text { Configuration }\end{array}$} & \multicolumn{2}{|c|}{ GABA EC50 } & \multicolumn{3}{|c|}{$\begin{array}{l}\text { CSP Direct gating } \\
\text { (\% of GABA max) }\end{array}$} \\
\hline & $(\mu \mathbf{M})$ & $\mathbf{n}$ & $\begin{array}{l}\text { Maximum } \\
\text { Efficacy }\end{array}$ & $\operatorname{EC50}(\mu M)$ & $\mathbf{n}$ \\
\hline$\alpha 1 \mathrm{WT}$ & $35.5 \pm 0.6$ & 5 & $41.8 \pm 2.4$ & $685 \pm 32$ & 15 \\
\hline$\alpha 1(\mathrm{~L} 394 \mathrm{I})$ & $50.8 \pm 4.4$ & 4 & $40.6 \pm 4.6$ & $559 \pm 50$ & 6 \\
\hline$\alpha 1(\mathrm{~A} 398 \mathrm{I})$ & $35.2 \pm 4.1$ & 5 & $36.1 \pm 2.9$ & $617 \pm 83$ & 6 \\
\hline$\alpha 1(\mathrm{~L} 415 \mathrm{~V})$ & $89.0 \pm 2.2 * *$ & 5 & $17.7 \pm 3.1^{* *}$ & $826 \pm 24$ & 9 \\
\hline a1(L394I/A398I) & $27.0 \pm 3.4$ & 3 & $42.0 \pm 5.7$ & $443 \pm 28$ & 9 \\
\hline$\alpha 1(\mathrm{~A} 398 \mathrm{I} / \mathrm{L} 415 \mathrm{~V})$ & $68.4 \pm 4.2 * *$ & 3 & $22.6 \pm 1.8 * *$ & $456 \pm 40$ & 5 \\
\hline$\alpha 1(\mathrm{~L} 394 \mathrm{I} / \mathrm{L} 415 \mathrm{~V})$ & $27.5 \pm 3.1$ & 3 & $20.5 \pm 3.2^{* *}$ & $864 \pm 21$ & 9 \\
\hline$\alpha 1(\mathrm{~L} 394 \mathrm{I} / \mathrm{A} 398 \mathrm{I} / \mathrm{L} 415 \mathrm{~V})$ & $44.1 \pm 2.4$ & 7 & $18.2 \pm 4.5^{* *}$ & $380 \pm 20$ & 7 \\
\hline$\alpha 1(\mathrm{~L} 415 \mathrm{C})$ & $39.4 \pm 4.0$ & 4 & $18.0 \pm 1.6^{* *}$ & $697 \pm 41$ & 9 \\
\hline$\alpha 1(\mathrm{~L} 415 \mathrm{~W})$ & $47.7 \pm 2.3$ & 3 & $17.8 \pm 4.1^{* *}$ & $2056 \pm 122 * *$ & 6 \\
\hline$\alpha 1(\mathrm{~L} 415 \mathrm{G})$ & $68.0 \pm 4.3^{* *}$ & 4 & $09.1 \pm 1.6^{* *}$ & $545 \pm 10$ & 5 \\
\hline$\alpha 1(\mathrm{~L} 415 \mathrm{~S})$ & $65.0 \pm 4.2 * *$ & 7 & $05.5 \pm 1.2^{* *}$ & $651 \pm 24$ & 13 \\
\hline$\alpha 1(\mathrm{~L} 415 \mathrm{~T})$ & $41.0 \pm 2.1$ & 4 & $37.1 \pm 4.4$ & $533 \pm 41$ & 9 \\
\hline$\alpha 1(\mathrm{~L} 415 \mathrm{Y})$ & $45.0 \pm 3.2$ & 4 & $25.4 \pm 3.8$ & $807 \pm 55$ & 6 \\
\hline$\alpha 1(\mathrm{~L} 415 \mathrm{I})$ & $40.3 \pm 2.2$ & 4 & $31.9 \pm 4.1$ & $450 \pm 30$ & 7 \\
\hline$\alpha 1(\mathrm{~L} 415 \mathrm{R})$ & $43.4 \pm 5.2$ & 4 & $32.6 \pm 4.6$ & $492 \pm 24$ & 4 \\
\hline
\end{tabular}

TABLE III-2 
Figure III-1. GABAA receptor structure and alignment of transmembrane 4 amino acid residue of $\alpha(1-6) \mathrm{GABA}_{A}$ receptor subunits. A, Top view of $\mathrm{GABA}_{\mathrm{A}}$ receptor, representing arrangement of $\alpha 1, \beta 2$ and $\gamma 2$ subunits and GABA and benzodiazepine (BDZ) binding sites. B, Lateral view of $\mathrm{GABA}_{\mathrm{A}} \mathrm{R}$ subunit illustrating, 4 transmembrane domains, the extracellular N-terminus, the C-terminus and the intracellular loop. $\mathbf{C}$, Aligned Amino acid sequence of TM4 region of human $\alpha$ subunit ( $\alpha 1-6)$ isoforms showing conserved (*) and non-identical (red) amino acids. 


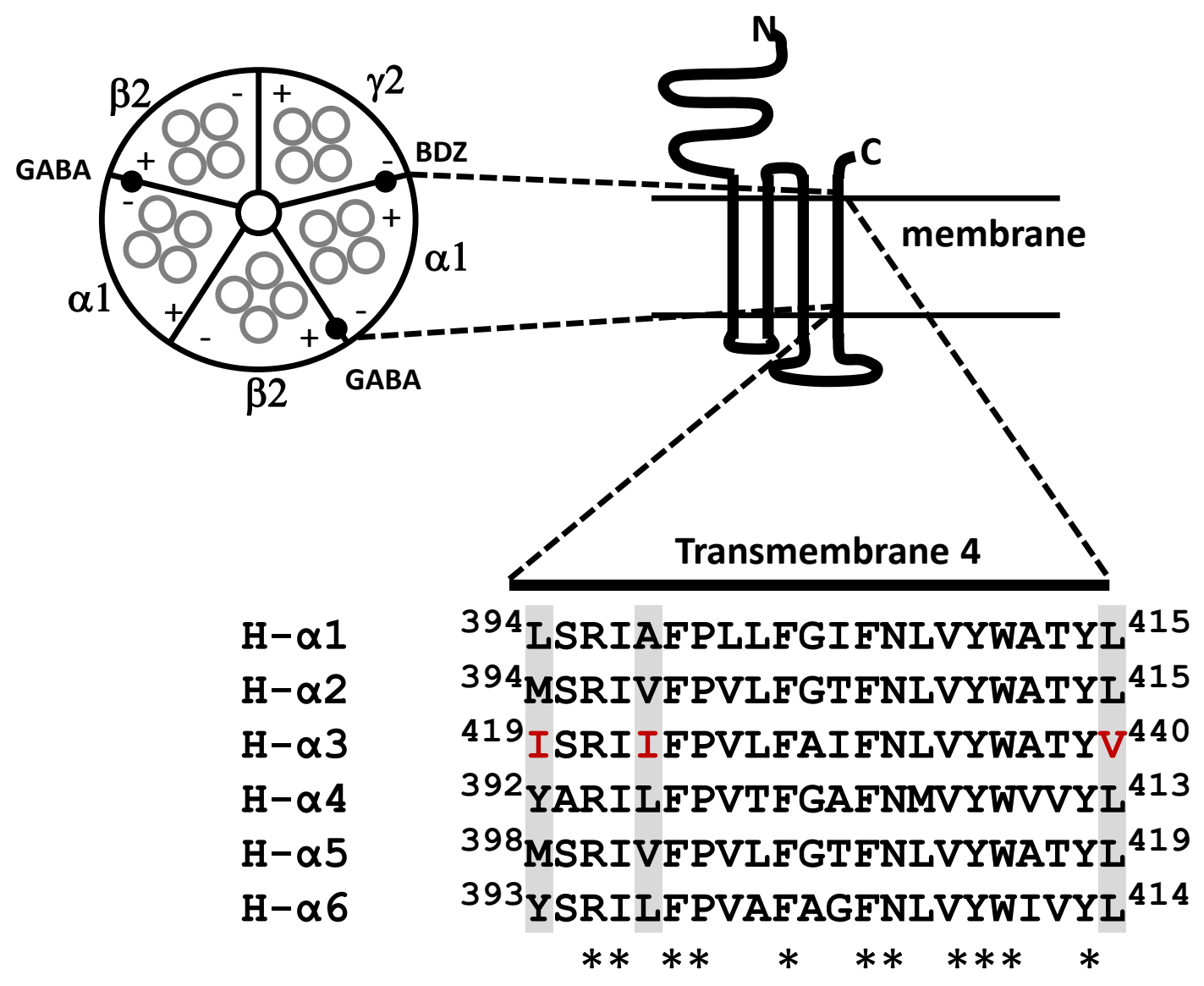

FIGURE III-1 
Figure III-2. Influence of $\alpha 3$ subunit TM4 residues mutation on direct activation and allosteric modulation by carisoprodol. A, representative traces demonstrating carisoprodol (CSP) activates human $\alpha 3 \beta 2 \gamma 2$ WT and $\alpha 3(\mathrm{~V} 440 \mathrm{~L}) \beta 2 \gamma 2 \mathrm{GABA}_{\mathrm{A}} \mathrm{Rs}$. Single mutation of V440 at TM4 of $\alpha 3$ to $\mathrm{L}$, which is present in $\alpha 1$-expressing $\mathrm{GABA}_{\mathrm{A}} \mathrm{Rs}$, increased CSP direct gating potency significantly. B, bar graphs summarizing carisoprodol direct gating currents for human $\alpha 3-, \alpha 3(\mathrm{~V} 440 \mathrm{~L})-, \alpha 3(\mathrm{I} 419 \mathrm{~L} / \mathrm{I} 423 \mathrm{~A})-, \alpha 3(\mathrm{I} 419 \mathrm{~L} / \mathrm{I} 423 \mathrm{~A} / \mathrm{V} 440 \mathrm{~L})$ and $\alpha 1 \beta 2 \gamma 2$ GABA $_{A}$ Rs. Single and combined mutation of TM4 domains of $\alpha 3$ to those present in $\alpha 1$ subunit significantly increased the direct gating potency of carisoprodol as compared to WT $\alpha 3$ receptors. Carisoprodol-gated currents are normalized to currents elicited by saturated GABA concentration $(1 \mathrm{mM})$. C, representative traces demonstrating the potentiation of GABA-gated ( $\left(\mathrm{EC}_{20}\right)$ currents from human $\alpha 3 \beta 2 \gamma 2$ WT and $\alpha 3(\mathrm{~V} 440 \mathrm{~L}) \beta 2 \gamma 2 \mathrm{GABA}_{\mathrm{A}} \mathrm{Rs}$ by carisoprodol. D, concentration-response curves for the allosteric modulation of GABA-gated currents from human $\alpha 3-, \alpha 3(\mathrm{~V} 440 \mathrm{~L})-, \alpha 3(\mathrm{I} 419 \mathrm{~L} / \mathrm{I} 423 \mathrm{~A})-, \alpha 3(\mathrm{I} 419 \mathrm{~L} / \mathrm{I} 423 \mathrm{~A} / \mathrm{V} 440 \mathrm{~L})$ and $\alpha 1 \beta 2 \gamma 2 \mathrm{GABA}_{\mathrm{A}}$ Rs. Mutation of TM4 domains of $\alpha 3$ to those present in $\alpha 1$ subunit did not increased allosteric modulation efficacy of carisoprodol significantly as compared to WT $\alpha 3$ receptors. Carisoprodol potentiated currents are normalized to currents elicited by GABA EC20 concentrations. Each data point represents the mean \pm S.E.M. of a minimum of three cells. **, $p<0.01, *, p<0.05$. 


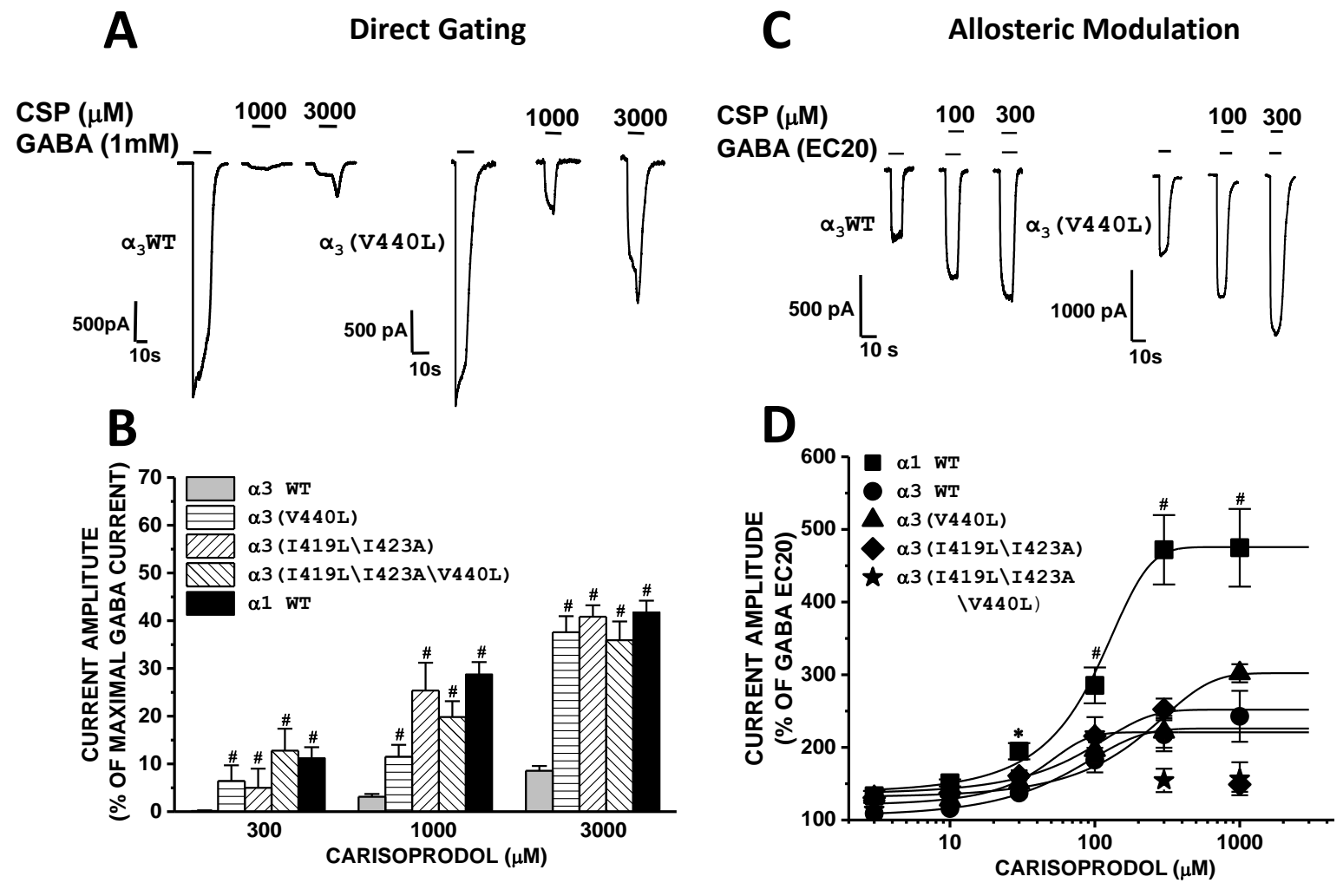

FIGURE III-2 
Figure III-3. Influence of the $\alpha 1$ subunit TM4 residues mutation on direct activation by carisoprodol. A, representative traces demonstrating carisoprodol (CSP) activates human $\alpha 1 \beta 2 \gamma 2 \mathrm{WT}$ and $\alpha 1(\mathrm{~L} 415 \mathrm{~V}) \beta 2 \gamma 2 \mathrm{GABA}_{\mathrm{A}} \mathrm{Rs}$. Corresponding reverse mutation of L415 at TM4 of $\alpha 1$ to $\mathrm{V}$ (present in the $\alpha 3$ subunit) decreased carisoprodol direct gating potency significantly, confirming involvement of TM4 residue L415 in direct gating. B, bar graphs summarizing carisoprodol direct gating currents for human $\alpha 3-, \alpha 1(\mathrm{~L} 394 \mathrm{I})-, \alpha 1(\mathrm{~A} 398 \mathrm{I})-$, a1(L415V)-,$\quad \alpha 1(\mathrm{~L} 394 \mathrm{I} / \mathrm{A} 398 \mathrm{I})-, \quad \alpha 1(\mathrm{~L} 394 \mathrm{I} / \mathrm{L} 415 \mathrm{~V})-, \quad \alpha 1(\mathrm{~A} 398 \mathrm{I} / \mathrm{L} 415 \mathrm{~V})-$ $\alpha 1(\mathrm{~L} 394 \mathrm{I} / \mathrm{A} 398 \mathrm{I} / \mathrm{L} 415 \mathrm{~V})$ and $\alpha 1 \beta 2 \gamma 2 \mathrm{GABA}_{\mathrm{A}}$ Rs. All $\alpha 1-\mathrm{GABA}_{\mathrm{A}}$ Rs containing L415V mutation showed decreased CSP direct gating potency as compared to WT $\alpha 1 \beta 2 \gamma 2$ $\mathrm{GABA}_{\mathrm{A}}$ Rs. Carisoprodol-gated currents are normalized to currents elicited by saturated GABA concentration $(1 \mathrm{mM})$. Each data point represents the mean \pm S.E.M. of a minimum of three cells. **, $p<0.01 *$. 


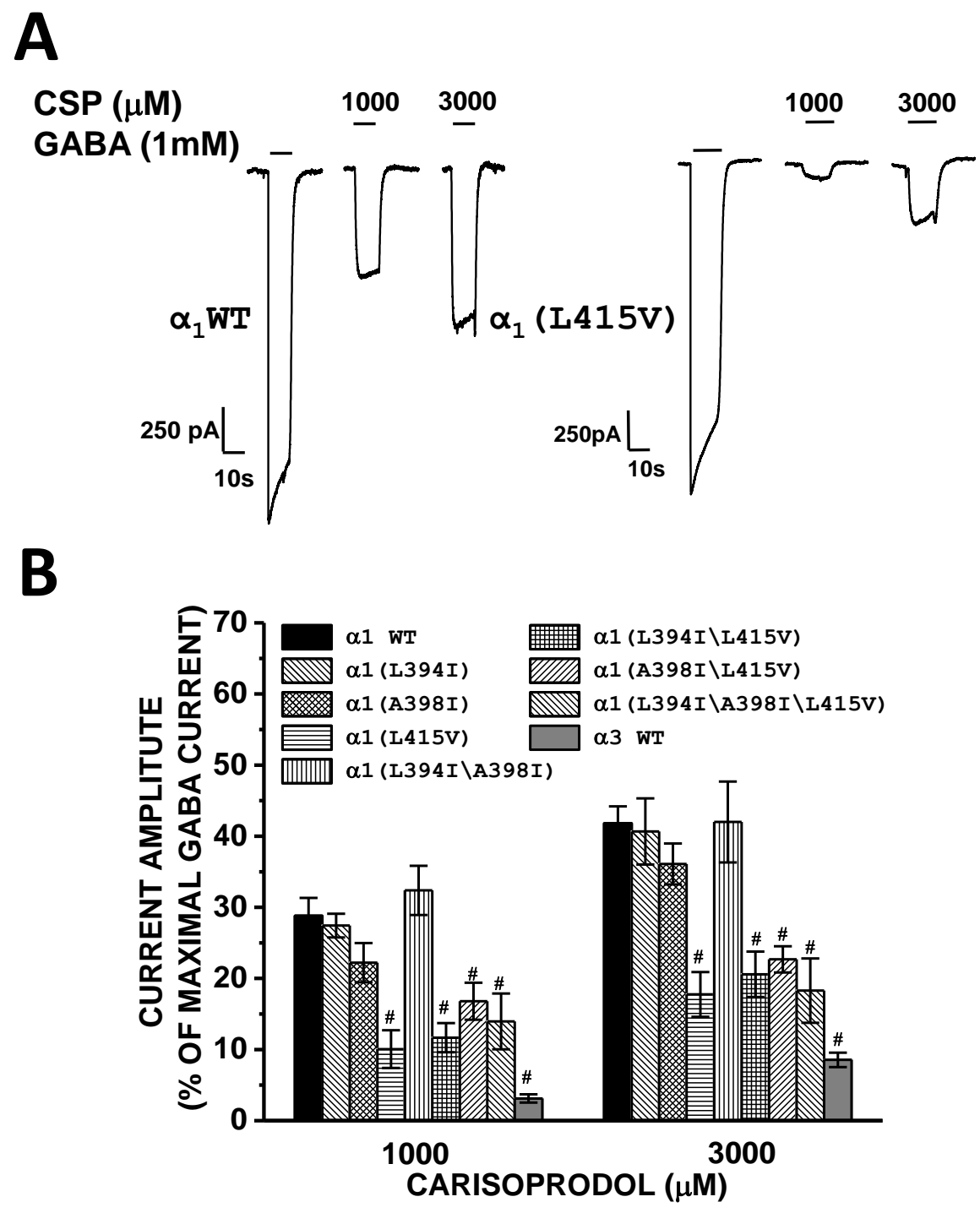

FIGURE III-3. 
Figure III-4. Influence of the $\alpha 1$ subunit TM4 L415 mutations on carisoprodol direct gating potency and efficacy. A, representative traces demonstrating carisoprodol (CSP) activates human $\alpha 1(\mathrm{~L} 415 \mathrm{~S}) \beta 2 \gamma 2 \mathrm{GABA}_{\mathrm{A}} \mathrm{Rs}$. Carisoprodol reached saturation at $5 \mathrm{mM}$ concentration and blocking effects started becoming prominent. B, concentration-response curves for the direct gating effect of carisoprodol from human $\alpha 1$ (L415S)-, $\alpha 1$ (L415V)-, $\alpha 1(\mathrm{~L} 415 \mathrm{G})-, \alpha 1(\mathrm{~L} 415 \mathrm{~W})-, \alpha 1(\mathrm{~L} 415 \mathrm{C})-$ and $\alpha 1 \beta 2 \gamma 2 \mathrm{GABA}_{A}$ Rs. These 5 mutations all decreased carisoprodol efficacy significantly without affecting carisoprodol $\mathrm{EC}_{50}$, expect for a1(L415W) mutant which increased $\mathrm{EC}_{50} 3$-fold relative to wild type receptors. C. Bar graphs summarizing carisoprodol (CSP) direct gating currents for human al WT-, $\alpha 1(\mathrm{~L} 415 \mathrm{I})-,, \alpha 1(\mathrm{~L} 415 \mathrm{~T})-, \alpha 1(\mathrm{~L} 415 \mathrm{R})-, \alpha 1(\mathrm{~L} 415 \mathrm{Y})-, \alpha 1(\mathrm{~L} 415 \mathrm{~W})-, \alpha 1(\mathrm{~L} 415 \mathrm{~V})-,, \alpha 1(\mathrm{~L} 415 \mathrm{C})-$ , $\alpha 1(\mathrm{~L} 415 \mathrm{G})-, \alpha 1(\mathrm{~L} 415 \mathrm{~S}) \beta 2 \gamma 2 \mathrm{GABA}_{\mathrm{A}}$ Rs. Carisoprodol-gated current reached saturation at $5 \mathrm{mM}$; receptors containing $\alpha 1$ (L415T/R/Y/I) mutant residue did not affect carisoprodol direct gating efficacy and thus carisoprodol $\mathrm{EC}_{50}$ values were not calculated. Carisoprodol gated currents are normalized to currents elicited by saturated GABA concentration $(1 \mathrm{mM})$. Each data point represents the mean \pm S.E.M of a minimum of three cells. $* *, p<0.01$. 

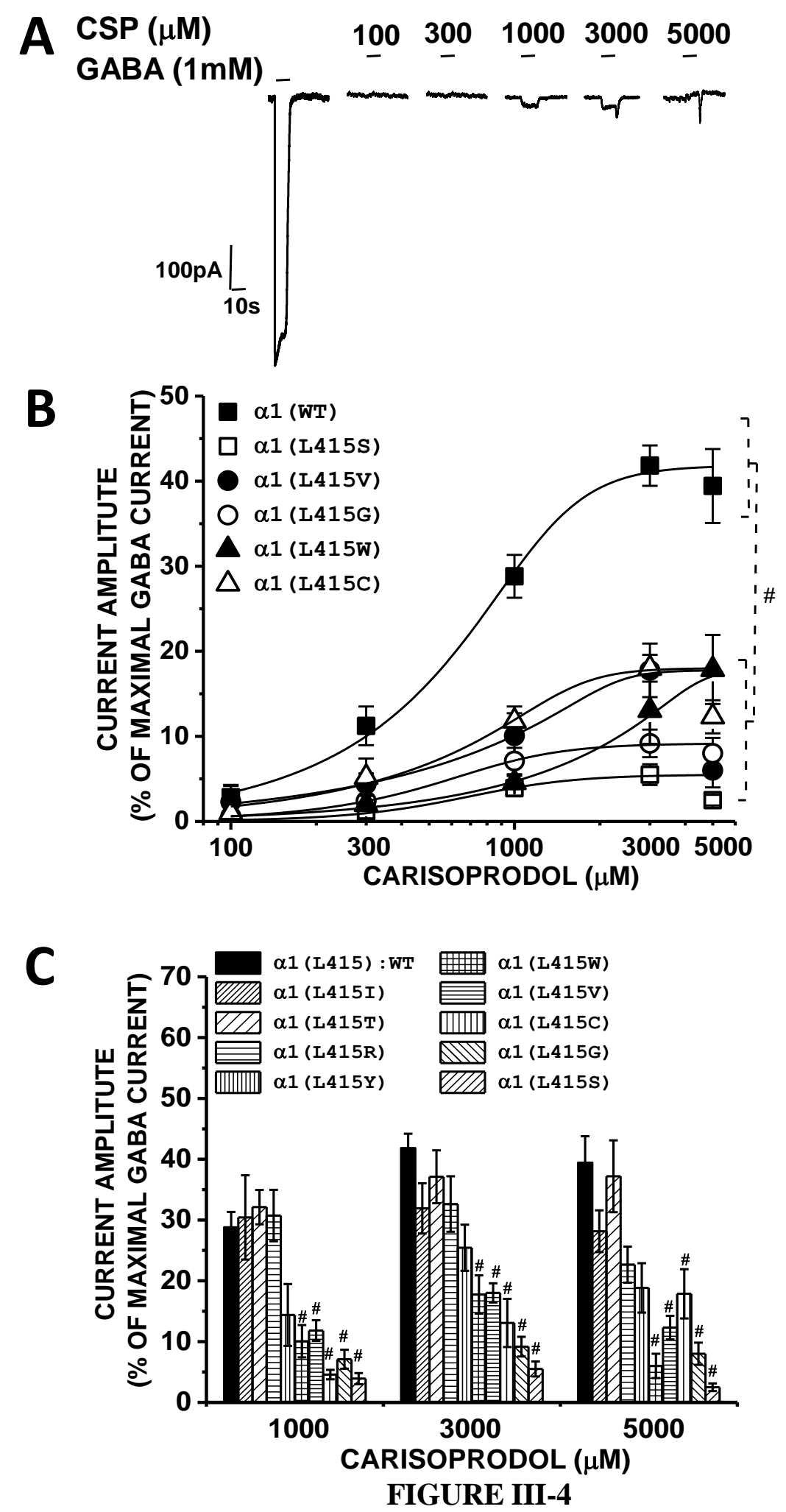
Figure III-5. Physiochemical relation of $\alpha 1415$ residue with carisoprodol direct gating efficacy, GABA EC50 and GABA EC50 with carisoprodol efficacy. Correlations with carisoprodol efficacy with a1(415) position amino acids A, Hydropathy; B, Volume; C, Polarity. Correlations with GABA EC50 with amino acids D, Volume and E, Hydropathy; F, Correlations of $\alpha 1$ mutant GABA EC50 with carisoprodol efficacy. Both amino acid volume and polarity at the 415 position were correlated with carisoprodol efficacy. Each data point represents the mean \pm S.E.M of a minimum of three cells. ${ }^{*}, p<0.05$. 
A

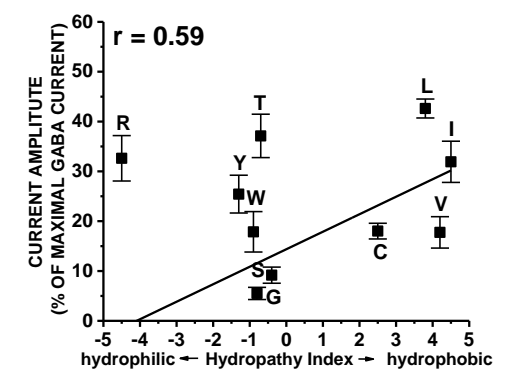

D

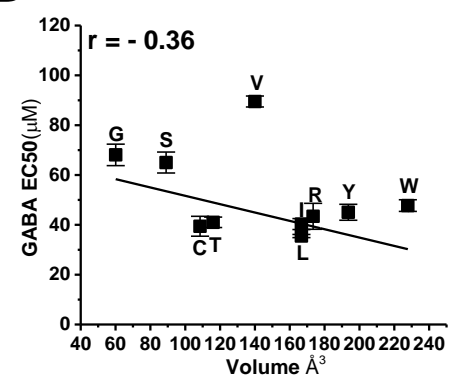

B

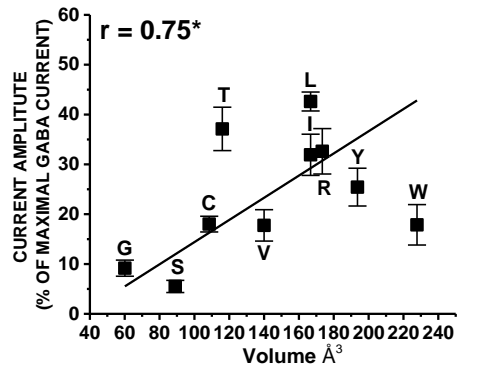

E

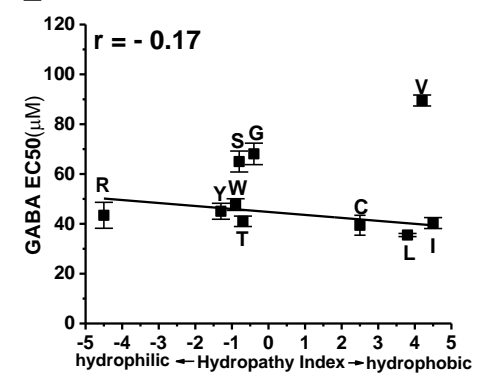

C

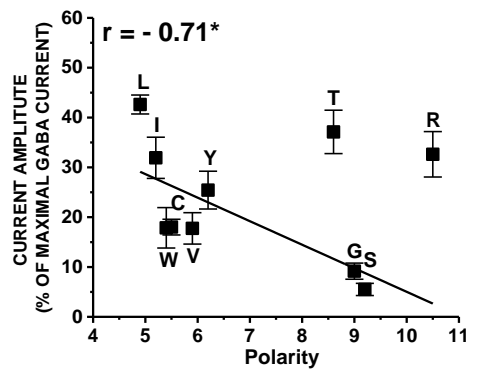

$\mathbf{F}$

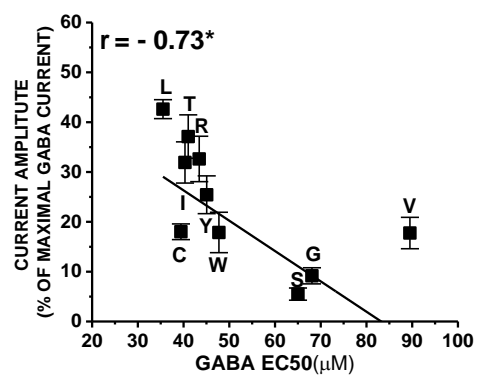

TABLE III-5. 
Figure III-6 Influence of the alpha1 subunit TM4, L415S mutation on allosteric modulation by carisoprodol and pentobarbital direct activation. A, representative traces demonstrating the potentiation of GABA-gated $\left(\mathrm{EC}_{20}\right)$ currents from human $\alpha 1(\mathrm{~L} 415 \mathrm{~S}) \beta 2 \gamma 2$ $\mathrm{GABA}_{\mathrm{A}} \mathrm{Rs}$ by carisoprodol (CSP). B, concentration-response curves for the allosteric modulation of GABA-gated currents from human wild type $\alpha 1 \beta 2 \gamma 2$ and $\alpha 1$ (L415S) $\beta 2 \gamma 2$ $\mathrm{GABA}_{\mathrm{A}}$ Rs. Mutation of leucine to serine at $\alpha 1(415)$ residue, did not affect allosteric modulation by carisoprodol, confirming the amino acid at position 415 is solely involved in the direct gating effects. Carisoprodol-potentiated currents are normalized to currents elicited by $\mathrm{GABA} \mathrm{EC}_{20}$ concentration. $\mathbf{C}$, representative traces demonstrating pentobarbital $(1 \mathrm{mM})$ activation of human $\alpha 1(\mathrm{~L} 415 \mathrm{~S}) \beta 2 \gamma 2 \mathrm{GABA}_{\mathrm{A}} \mathrm{Rs}$. D, bar graphs summarizing pentobarbital direct gating currents for human wild type $\alpha 1 \beta 2 \gamma 2$ and $\alpha 1$ (L415S) $\beta 2 \gamma 2 \mathrm{GABA}_{\mathrm{A}}$ Rs. Mutation of leucine to serine at $\alpha 1(415)$ residue, did not affect direct activation by pentobarbital on $\mathrm{GABA}_{\mathrm{A}}$ Rs. Pentobarbital-gated currents are normalized to the currents elicited by saturating concentration of GABA $(1 \mathrm{mM})$. Each data point represents the mean \pm S.E.M. of a minimum of three cells. 


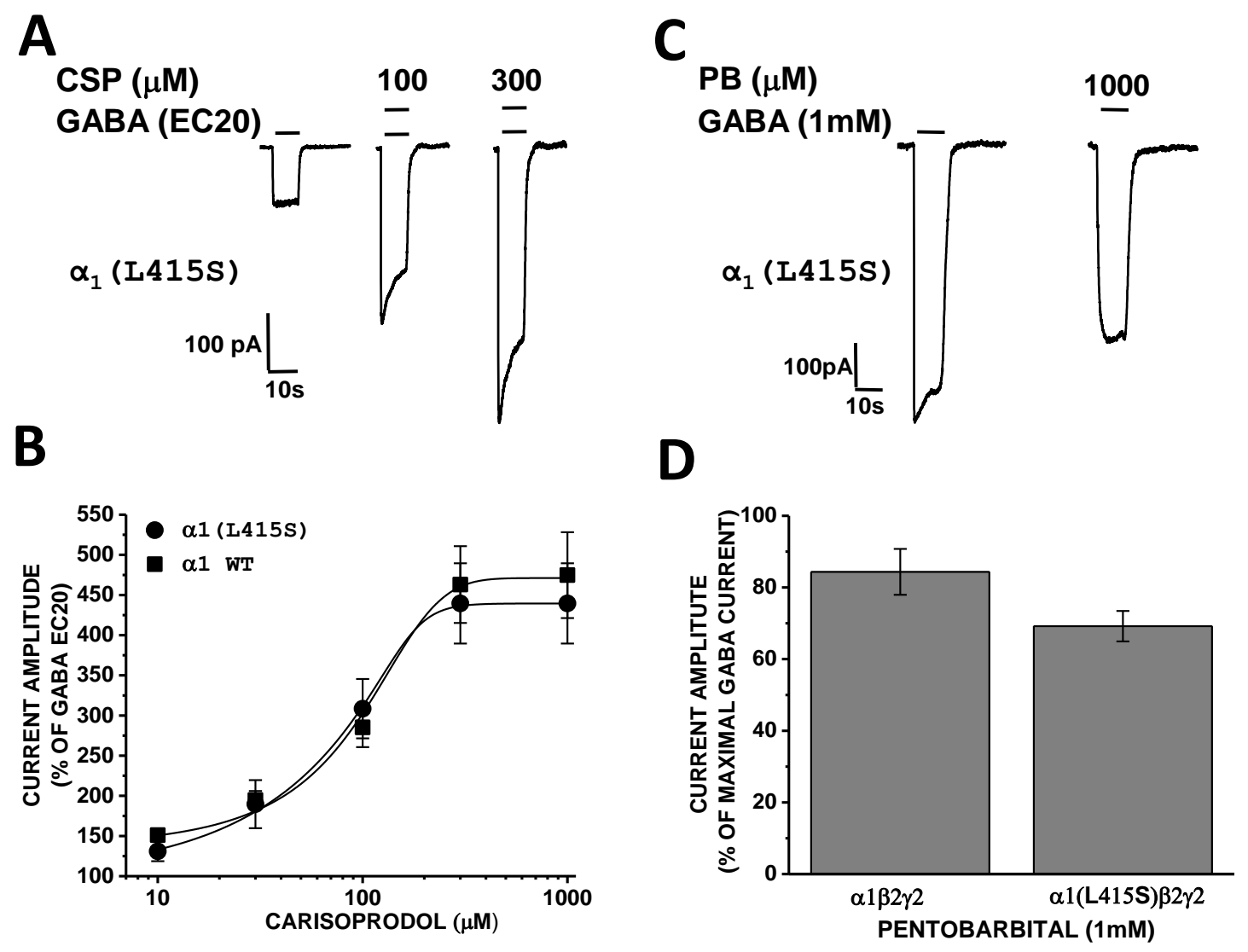

FIGURE III-6 
Figure III-7. Homology molecular model of GABAA receptor. A, Side view illustrating alpha subunits in red, beta subunits in blue and gamma subunit in yellow. B, Highlighted residue leucine 415 of $\alpha 1$ subunit, potential amino acid involved in direct gating action of CSP. 


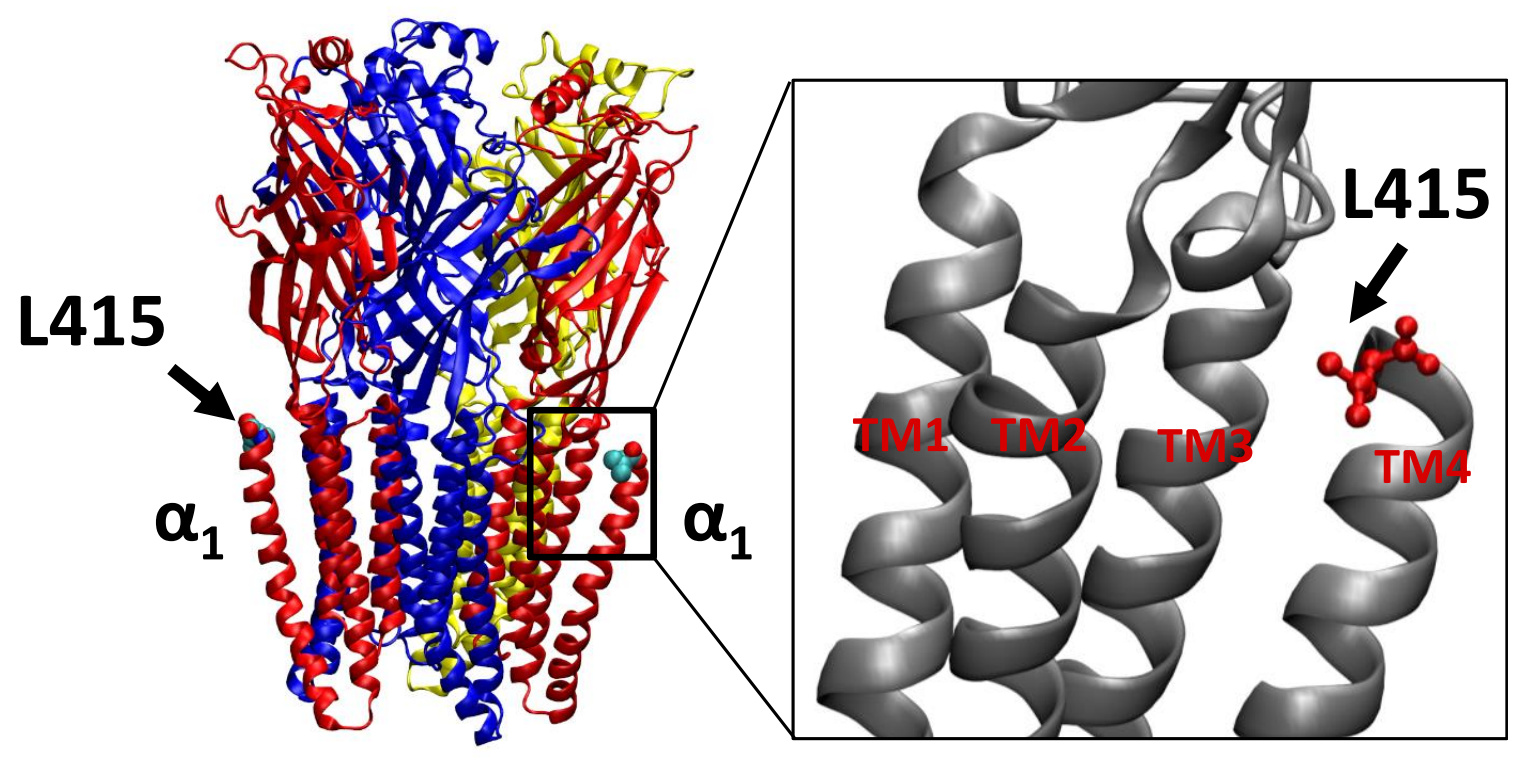

FIGURE III-7 


\section{AUTHORSHIP CONTRIBUTIONS}

Participated in research design: Kumar and Dillon

Conducted mutagenesis: Kumar and Freund

Conducted experiments: Kumar

Performed data analysis: Kumar and Dillon

Wrote or contributed to writing of the manuscript: Kumar and Dillon

\section{Footnotes}

This work was supported by the National Institutes of Health National Institute of Drug Abuse [Grant R01 DA DA022370] 


\section{REFERENCES}

Drugs and chemicals of concern: Carisoprodol, US Department of Justice Drug Enforcement

Administration. http://www.gmhc.org/files/editor/file/a_pa_nat_drug_use_survey.pdf.(Accessed $02 / 03 / 15)$

Schedule of controlled substances: placement of carisoprodol into Schedule IV, in $76 \mathrm{pp}$ 77330-77360, Drug Enforcement Administration, Federal Register. http://www.dea.gov/pr/micrograms/2012/mg0112.pdf. (Accessed 02/03/15)

Bali M and Akabas MH (2004) Defining the propofol binding site location on the GABAA receptor. Molecular pharmacology 65(1): 68-76.

Barnard EA, Skolnick P, Olsen RW, Mohler H, Sieghart W, Biggio G, Braestrup C, Bateson AN and Langer SZ (1998) International Union of Pharmacology. XV. Subtypes of gamma-aminobutyric acidA receptors: classification on the basis of subunit structure and receptor function. Pharmacological reviews 50(2): 291-313.

Bergmann R, Kongsbak K, Sorensen PL, Sander T and Balle T (2013) A unified model of the $\mathrm{GABA}(\mathrm{A})$ receptor comprising agonist and benzodiazepine binding sites. PloS one 8(1): e52323.

Bramness JG, Skurtveit S and Morland J (2004) Impairment due to intake of carisoprodol. Drug and alcohol dependence 74(3): 311-318.

Cockcroft V, Ortells M and Lunt G (1995) Ligands, receptor models, and evolution. Annals of the New York Academy of Sciences 757: 40-47. 
Corringer PJ, Poitevin F, Prevost MS, Sauguet L, Delarue M and Changeux JP (2012) Structure and pharmacology of pentameric receptor channels: from bacteria to brain. Structure (London, England : 1993) 20(6): 941-956.

Crestani F, Low K, Keist R, Mandelli M, Mohler H and Rudolph U (2001) Molecular targets for the myorelaxant action of diazepam. Molecular pharmacology 59(3): $442-445$.

Fass JA (2010) Carisoprodol legal status and patterns of abuse. The Annals of pharmacotherapy 44(12): 1962-1967.

Gatch MB, Nguyen JD, Carbonaro T and Forster MJ (2012) Carisoprodol tolerance and precipitated withdrawal. Drug and alcohol dependence 123(1-3): 29-34.

Gonzalez LA, Gatch MB, Taylor CM, Bell-Horner CL, Forster MJ and Dillon GH (2009) Carisoprodol-mediated modulation of GABAA receptors: in vitro and in vivo studies. The Journal of pharmacology and experimental therapeutics 329(2): 827837.

Heikkinen AE, Moykkynen TP and Korpi ER (2009) Long-lasting modulation of glutamatergic transmission in VTA dopamine neurons after a single dose of benzodiazepine agonists. Neuropsychopharmacology : official publication of the American College of Neuropsychopharmacology 34(2): 290-298.

Hosie AM, Wilkins ME, da Silva HM and Smart TG (2006) Endogenous neurosteroids regulate GABAA receptors through two discrete transmembrane sites. Nature 444(7118): 486-489. 
Jenkins A, Andreasen A, Trudell JR and Harrison NL (2002) Tryptophan scanning mutagenesis in TM4 of the GABA(A) receptor alpha1 subunit: implications for modulation by inhaled anesthetics and ion channel structure. Neuropharmacology 43(4): 669-678.

Kumar M, Gonzalez LA and Dillon GH (2015) Assessment of subuit-dependent direct gating and allosteric modulation effects of carisoprodol at GABAA receptors. Neuropharmacology Revised manuscript under review.

Low K, Crestani F, Keist R, Benke D, Brunig I, Benson JA, Fritschy JM, Rulicke T, Bluethmann H, Mohler H and Rudolph U (2000) Molecular and neuronal substrate for the selective attenuation of anxiety. Science (New York, NY) 290(5489): 131134.

Luo X, Pietrobon R, Curtis LH and Hey LA (2004) Prescription of nonsteroidal antiinflammatory drugs and muscle relaxants for back pain in the United States. Spine 29(23): E531-537.

Luscher C and Ungless MA (2006) The mechanistic classification of addictive drugs. PLoS medicine 3(11): e437.

McCracken ML, Borghese CM, Trudell JR and Harris RA (2010) A transmembrane amino acid in the GABAA receptor beta2 subunit critical for the actions of alcohols and anesthetics. The Journal of pharmacology and experimental therapeutics 335(3): 600-606. 
Miyazawa A, Fujiyoshi Y and Unwin N (2003) Structure and gating mechanism of the acetylcholine receptor pore. Nature 423(6943): 949-955.

Newell JG and Czajkowski C (2003) The GABAA receptor alpha 1 subunit Pro174Asp191 segment is involved in GABA binding and channel gating. The Journal of biological chemistry 278(15): 13166-13172.

Olsen RW and Sieghart W (2008) International Union of Pharmacology. LXX. Subtypes of gamma-aminobutyric acid(A) receptors: classification on the basis of subunit composition, pharmacology, and function. Update. Pharmacological reviews 60(3): 243-260.

Reeves RR and Burke RS (2010) Carisoprodol: abuse potential and withdrawal syndrome. Current drug abuse reviews 3(1): 33-38.

Reeves RR, Burke RS and Kose S (2012) Carisoprodol: update on abuse potential and legal status. Southern medical journal 105(11): 619-623.

Rudolph U, Crestani F, Benke D, Brunig I, Benson JA, Fritschy JM, Martin JR, Bluethmann H and Mohler H (1999) Benzodiazepine actions mediated by specific gamma-aminobutyric acid(A) receptor subtypes. Nature 401(6755): 796-800.

Rudolph U and Knoflach F (2011) Beyond classical benzodiazepines: novel therapeutic potential of GABAA receptor subtypes. Nature reviews Drug discovery 10(9): 685697. 
Siegwart R, Jurd R and Rudolph U (2002) Molecular determinants for the action of general anesthetics at recombinant alpha(2)beta(3)gamma(2)gamma-aminobutyric acid(A) receptors. Journal of neurochemistry 80(1): 140-148.

Siegwart R, Krahenbuhl K, Lambert S and Rudolph U (2003) Mutational analysis of molecular requirements for the actions of general anaesthetics at the gammaaminobutyric acidA receptor subtype, alpha1beta2gamma2. BMC pharmacology 3 : 13.

Sigel E and Steinmann ME (2012) Structure, function, and modulation of GABA(A) receptors. The Journal of biological chemistry 287(48): 40224-40231.

Stewart DS, Hotta M, Desai R and Forman SA (2013) State-dependent etomidate occupancy of its allosteric agonist sites measured in a cysteine-substituted GABAA receptor. Molecular pharmacology 83(6): 1200-1208.

Tan KR, Brown M, Labouebe G, Yvon C, Creton C, Fritschy JM, Rudolph U and Luscher C (2010) Neural bases for addictive properties of benzodiazepines. Nature 463(7282): 769-774.

Toth PP and Urtis J (2004) Commonly used muscle relaxant therapies for acute low back pain: a review of carisoprodol, cyclobenzaprine hydrochloride, and metaxalone. Clinical therapeutics 26(9): 1355-1367.

van Rijnsoever C, Tauber M, Choulli MK, Keist R, Rudolph U, Mohler H, Fritschy JM and Crestani F (2004) Requirement of alpha5-GABAA receptors for the development of tolerance to the sedative action of diazepam in mice. The Journal 
of neuroscience : the official journal of the Society for Neuroscience 24(30): 67856790.

Xu M and Akabas MH (1996) Identification of channel-lining residues in the M2 membrane-spanning segment of the $\operatorname{GABA}(\mathrm{A})$ receptor alpha1 subunit. The Journal of general physiology 107(2): 195-205.

Zacny JP and Gutierrez S (2011) Subjective, psychomotor, and physiological effects of oxycodone alone and in combination with ethanol in healthy volunteers. Psychopharmacology 218(3): 471-481.

Zacny JP, Paice JA and Coalson DW (2011) Characterizing the subjective and psychomotor effects of carisoprodol in healthy volunteers. Pharmacology, biochemistry, and behavior 100(1): 138-143.

Zeller A, Arras M, Jurd R and Rudolph U (2007a) Identification of a molecular target mediating the general anesthetic actions of pentobarbital. Molecular pharmacology 71(3): 852-859.

Zeller A, Arras M, Jurd R and Rudolph U (2007b) Mapping the contribution of beta3containing GABAA receptors to volatile and intravenous general anesthetic actions. BMC pharmacology 7: 2. 


\section{CHAPTER IV}

\section{SUMMARY AND DISCUSSION}

Carisoprodol is a centrally-acting skeletal muscle relaxant frequently prescribed for acute musculoskeletal conditions (Elder, 1991). Recreational use of carisoprodol is an increasing problem (Bramness et al., 2004; Bramness et al., 2007; Ni et al., 2007). Considering its alarming rate of abuse and subsequent consequences, carisoprodol was scheduled (schedule IV) at the federal level effective January 11, 2012 (DEA, 2011). Given the present and potential dangers posed by carisoprodol abuse, it is of crucial importance to determine how this drug mediates its effects. Until recently, it was widely accepted that the sedative and muscle relaxant effects of carisoprodol were due predominantly to its metabolite, meprobamate. However, it is now clear that carisoprodol itself modulates and directly gate $\mathrm{GABA}_{\mathrm{A}} \mathrm{Rs}$. Thus, our studies were aimed at contributing to the current knowledge regarding the mechanism of action of carisoprodol as a therapeutic agent and as a drug of abuse.

Subunit-dependent studies (Chapter II) have shown carisoprodol's actions on $\mathrm{GABA}_{\mathrm{A}}$ receptors are influenced by subunit isoforms present in a receptor. Carisoprodol is most efficacious on $\alpha 1$ subunit containing $\mathrm{GABA}_{A}$ receptors for potentiating the GABAgated currents. This may underlie the ability of carisoprodol in enhancing the sedative effects of CNS depressants, contributing to its potential for abuse. The direct gating action of carisoprodol on $\mathrm{GABA}_{\mathrm{A}}$ receptor is generally comparable regardless of $\alpha$ subunit isoform, however, receptors incorporating the $\alpha 3$ subunit showed significantly lower direct gating 
efficacy and affinity. Presence or absence of the $\gamma 2$ subunit did not affect the ability of carisoprodol to directly gate or allosterically modulate the receptor. Regarding $\beta$ subunit isoforms, incorporation of $\beta 1$ subunit conferred highest efficacy for direct activation relative to maximum GABA currents, while presence of the $\beta 2$ subunit conferred highest efficacy for allosteric modulation of the GABA response. In $\delta$ subunit expressing extrasynaptic $\alpha 1 \beta 3 \delta$ and $\alpha 4 \beta 3 \delta$ receptors, carisoprodol is more efficacious than GABA as a direct gating agonist and allosterically potentiated both saturated and sub-saturating GABA currents. We also studied the voltage-dependent effect of carisoprodol on $\mathrm{GABA}_{\mathrm{A}}$ receptors. We found, allosteric modulatory effect of carisoprodol is voltage sensitive while direct gating effect is voltage independent. These results suggest carisoprodol interacts with distinct sites to allosterically modulate and directly gate the $\mathrm{GABA}_{\mathrm{A}} \mathrm{R}$, and subunit isoform influences these effects. As mentioned earlier, physical dependence is more prone to develop with drugs that interact with a broader collection of $\mathrm{GABA}_{\mathrm{A}} \mathrm{R}$ subtypes (Licata and Rowlett, 2008), the high efficacy of carisoprodol for both direct and allosteric effects on $\alpha 1$-containing receptors, coupled with its ability to interact with $\mathrm{GABA}_{\mathrm{A}} \mathrm{R}$ subtypes, is consistent with its high abuse potential (Rudolph and Knoflach, 2011).

After gaining information regarding carisoprodol's $\mathrm{GABA}_{\mathrm{A}} \mathrm{R}$ subunit selectivity, we identified the subunit amino acid domains involved in direct gating and allosteric modulation effects of carisoprodol (Chapter III). To gain insight into the molecular mechanism of action of carisoprodol and specific amino acid domains involved in the direct gating and allosteric modulatory effects of carisoprodol, we aligned the amino acid sequence 
of $\alpha$ subunit isoforms and took advantage of site directed mutagenesis. We identified several residues in TM4 of the $\alpha 3$ subunit that are unique compared to residues present in all other $\alpha$ subunits. We tested their involvement in the ability of carisoprodol to directly gate the $\mathrm{GABA}_{\mathrm{A}} \mathrm{R}$ by mutating these residues to those present in the $\alpha 1$ subunit, individually and in combination, and assessing effects on carisoprodol elicited gating. In single and combined mutations expressing the $\alpha 3(\mathrm{~V} 440 \mathrm{~L})$ residue mutation, carisoprodol gained significant capacity to directly gate the receptor compared to $\alpha 3$ WT receptors. In contrast, the V440L mutation did not affect carisoprodol's ability to allosterically modulate GABA-activated currents. These results demonstrate amino acid residues in TM4 of the $\mathrm{GABA}_{\mathrm{A}}$ receptor are critical in the direct gating, but not allosteric modulatory actions of carisoprodol

To confirm the involvement of TM4 residues in carisoprodol direct gating, we did corresponding reverse mutations in $\alpha 1$ subunit, individually and in combination, and tested to see if these mutations decrease carisoprodol sensitivity of $\alpha 1 \beta 2 \gamma 2$ receptors. In single and combined mutations that included the TM4 L415 residue, direct gating activity of carisoprodol was significantly reduced. Specifically carisoprodol direct gating efficacy reduced to $18 \%$ of $\alpha 1(\mathrm{~L} 415 \mathrm{~V}) \beta 2 \gamma 2$ receptors from $42 \%$ of WT $\alpha 1 \beta 2 \gamma 2$ receptors. To further investigate the role of the alpha1 TM4 415 region, we substituted the wild type leucine with eight different amino acids one by one based on size, volume, polarity, hydrophobicity and hydrophobicity to study the effect of physio-chemical properties of amino acid side chains on carisoprodol direct gating affinity and efficacy. Insertion of isoleucine, arginine, tyrosine and threonine at alpha1 415 position did not affect carisoprodol direct gating efficacy, 
however, insertion of cysteine, tryptophan, valine, glycine and serine significantly decreased the direct gating efficacy relative to wild type. Interestingly, substitution of leucine with serine decreased direct gating efficacy to $5.5 \%$ from $42 \%$ (WT) but insertion of threonine did not affect carisoprodol direct gating efficacy suggesting orientation of hydroxyl and isopropyl group at alpha1 415 position plays a critical role in carisoprodol direct gating efficacy. In physio-chemical analysis of substituted amino acid side chain properties with carisoprodol's direct gating efficacy, we concluded that the volume and polarity of amino acid side chain at 415 position of $\alpha 1$ subunit significant affect carisoprodol direct gating efficacy. To further confirm the involvement of $\alpha 1$ (415) domain only in direct gating action and not in allosteric modulatory effect, we tested $\alpha 1$ (L415S) mutant for allosteric modulatory effect of carisoprodol and found insertion of serine at $\alpha 1(415)$ position does not affect the allosteric modulatory effect of carisoprodol. The $\alpha 1$ (L415S) mutation also did not affect pentobarbital direct gating efficacy. Thus, $\alpha 1$ (L415) amino acid residue is solely involved in the direct gating effect of carisoprodol but not in the allosteric modulation. These data confirmed carisoprodol interacts with distinct sites to allosterically modulate and directly gate the $\mathrm{GABA}_{\mathrm{A}}$ receptors.

The central nervous system adapts to its ambience constantly and it is not surprising that prolonged exposure to drug molecules elicits compensatory changes at the receptor level. A single intoxicating dose of alcohol results in down regulation of $\alpha 4 \beta \delta$ receptors in hippocampal pyramidal neurons leading to generation of acute tolerance (Hemby et al., 2006; Shen et al., 2011). With a few more doses of alcohol, internalization of $\alpha 1$ subunit receptors 
at synapses occurs, leading to mobilization of $\alpha 4$ subunit receptors to the synapses from extrasynaptic region. Down regulation of $\alpha 4 \beta \delta$ receptors at extrasynaptic region is compensated by overexpression of $\alpha 4 \beta \gamma$ receptors to supplement tonic inhibition (Liang et al., 2007). This mobilization of receptors is reversible, however, during chronic consumption of alcohol it becomes irreversible resulting in alcohol dependence (Liang et al., 2007). With chronic opiate exposure and following withdrawal, $\mathrm{GABA}_{\mathrm{A}} \mathrm{Rs}$ signaling transition from inhibitory to excitatory in ventral tegmental area, contributing to opiate dependence (Laviolette et al., 2004). Carisoprodol abuse is also associated with dependence, tolerance, and withdrawal (Heacock and Bauer, 2004; Reeves et al., 2012; Reeves et al., 2007). We did not explore the changes associated with chronic carisoprodol administration, but it is likely that carisoprodol elicits fundamental changes in the GABAergic system. Moreover, chronic administration of drugs that target $\mathrm{GABA}_{\mathrm{A}} \mathrm{Rs}$ reorganize the GABAergic system transmission and may lead to tolerance; the extent of modification depends upon the dose and duration of drug exposure (Korpi et al., 2002; Wafford, 2005). This event may be due to uncoupling of allosteric sites (Ito et al., 1996), modifications in receptor turnover (Kumar et al., 2003; Pericic et al., 2003), or desensitization. Whether expression of a subunit is upregulated or down regulated in response to chronic use varies with its location in the brain (Wafford, 2005). In some studies, down regulation of the $\alpha 1$ subunit has been observed, which is generally accompanied by compensatory up regulation of other subunits (Ito et al., 1996; Wafford, 2005). We have shown carisoprodol is most efficacious on $\alpha 1$-containing receptors and less efficacious on other receptor configurations, displacing $\alpha 1$ subunits with 
other isoforms may diminish the physiological effects of carisoprodol. The shift towards $\mathrm{GABA}_{\mathrm{A}} \mathrm{R}$ configurations that are less sensitive to carisoprodol's effects may contribute to tolerance. Such compensatory mechanisms associated with chronic activation of the GABAergic system are analogous to inhibitory dysregulation. Thus, abrupt cessation of the drug is likely to precipitate withdrawal symptoms as the central nervous system attempts to restore normal inhibitory function.

While carisoprodol remains an efficacious choice for the treatment of acute low back pain, its abuse liability has become a major concern in recent years, and ready availability and low cost has made it a drug of choice among abusers. Scheduling of carisoprodol in Norway resulted in a rapid and significant decline in the detection of carisoprodol in autopsies and driving under the influence occurrences (Hoiseth et al., 2009). As carisoprodol is now controlled in the United States at the federal level, it is likely the incidence of abuse and fatalities will also decline here. Physician awareness regarding potential dangers associated with abuse of carisoprodol and its metabolite meprobamate should also improve with the recent scheduling. However, considering the fact that low back pain has been one of the top five reasons for physician visits in the United States for decades (Witenko et al., 2014), the need to develop a safe and efficacious agent for this substantial medical need is clear. Also, while the number of reports regarding carisoprodol abuse continues to increase, there has been little progress in the treatment of carisoprodol dependence and withdrawal. At present, treatment consists of brief courses with benzodiazepines or phenobarbital to combat anxiety and insomnia. Further, treatment of 
carisoprodol overdose is complicated as it is often characterized by agitation and seizures, and the administration of anticonvulsants and sedatives exacerbates CNS depression, leaving supportive therapy as a preferred course of action. The insights gained in our study of carisoprodol's molecular action should prove useful in better understanding how to treat misuse, and in development of improved muscle relaxants with reduced abuse liability. 


\section{FUTURE DIRECTIONS}

In the present study we concluded that distinct amino acids or binding sites are involved in direct gating and in the allosteric modulation action of carisoprodol. We identified the leucine 415 residue at TM4 of $\alpha 1$ subunit is critical in the direct gating action of carisoprodol. Docking of carisoprodol on a molecular model of $\mathrm{GABA}_{\mathrm{A}}$ receptors will provide further insights into the binding pocket amino acids of carisoprodol. However, it is still unclear whether L415 is involved in the binding pocket of carisoprodol of $\mathrm{GABA}_{\mathrm{A}}$ receptors or if it is involved in the conformational wave leading to channel gating called coupling. Ligand binding assays, single channel analysis, and substituted cysteine accessibility method (SCAM) experiments at mutant $\alpha 1(\mathrm{~L} 415 \mathrm{~S}) \beta 2 \gamma 2 \mathrm{GABA}_{\mathrm{A}}$ receptors would clarify the importance of this residue in carisoprodol's direct gating action. Single channel (open probability) analysis would also provide critical information on whether channel opening gated by carisoprodol is more like pentobarbital (long duration opening) or benzodiazepines (burst openings) (MacDonald et al., 1989; Steinbach and Akk, 2001; Thompson et al., 1999).

It cannot be denied that the allosteric modulatory effect of carisoprodol is highly important in physiological actions of carisoprodol and we have shown that carisoprodol is highly efficacious at potentiating GABA-gated currents. In the present study, that we did not identify the molecular domains involved in the allosteric modulatory effect of carisoprodol. However, we demonstrated that carisoprodol is highly efficacious on $\alpha 1$ subunit containing receptors compared as to other isoforms of $\alpha$ subunit and the fact the $\alpha 1$ subunit $\mathrm{GABA}_{\mathrm{A}}$ 
receptors are involved in the addiction and sedative mechanisms of benzodiazepines (Ator, 2005; Tan et al., 2010). It is very critical to determine the molecular mechanism of allosteric modulation by carisoprodol. We have identified two amino acids in the pre-TM1 region (G200 and V202) and one amino acid at the N- terminal (F45) region of $\alpha 1$ subunit which are unique compared to the rest of the $\alpha$ subunit isoforms in the extracellular domains of $\mathrm{GABA}_{\mathrm{A}}$ receptor. Investigation of these amino acids may provide critical information about carisoprodol's allosteric modulation binding site.

Our study demonstrates that $\mathrm{GABA}_{\mathrm{A}}$ receptor subtype isoforms influence carisoprodol's action and the molecular sites where carisoprodol can interact to modulate $\mathrm{GABA}_{\mathrm{A}}$ receptor functions. Replication of our experiments in an in-vivo model would allow us get complete knowledge of carisoprodol's subunit-dependent physiological effects. Therefore, it is critically important to investigate which of the $\mathrm{GABA}_{\mathrm{A}} \mathrm{R}$ subunit isoforms account for specific behavioral actions of carisoprodol. The extensively used techniques to study specific $\mathrm{GABA}_{A} \mathrm{R}$ subunit isoform with behavior are genetic deletion of a subunit isoform in a knockout mouse and viral delivery of inhibitory RNAs or other RNAs to generate knockdown in specific brain regions. The knockout model of specific $\mathrm{GABA}_{\mathrm{A}}$ receptor subunits have been studied for alcohol research (Blednov et al., 2012). The $\alpha 1$ and $\alpha 2$ subunit knockin mice showed $\alpha 1 \mathrm{GABA}_{\mathrm{A}}$ receptors are involved in alcohol tolerance and physical dependence while $\alpha 2 \mathrm{GABA}_{\mathrm{A}}$ receptors with taste aversion, alcohol consumption, and motor stimulation (Hemby et al., 2006; Liang et al., 2007; Shen et al., 2011). Knockdown of $\alpha 4$ subunit together with $\delta$ subunit in the nucleus accumbens region 
of the mice brain have been shown to reduce the alcohol intake, suggesting a critical of role extrasynaptic $\alpha 4 \beta \delta \mathrm{GABA}_{\mathrm{A}}$ receptors in alcohol intake reinforcement (Nie et al., 2011). As mentioned earlier, behavioral effects of benzodiazepines have also been studied in mutant mice, where diazepam was made insensitive on specific $\mathrm{GABA}_{\mathrm{A}}$ subunit isoforms by mutating arginine to histidine at its conserved site of action on $\alpha 1, \alpha 2, \alpha 3$ and $\alpha 5$ subunit containing receptors (Rudolph et al., 1999). Diazepam's sedative, amnesic and anticonvulsant effects were absent in $\alpha 1(\mathrm{H} 101 \mathrm{R})$ mutant mice. Mutant mice containing $\alpha 2(\mathrm{H} 101 \mathrm{R})$ receptors showed absence of anxiolytic, motor-impairing and partly myorelaxant effects while retaining sedative effects of diazepam. Also, it's been shown that development of tolerance to the sedative effects of diazepam in mice requires $\alpha 5 \mathrm{GABA}_{\mathrm{A}}$ subunit receptors (van Rijnsoever et al., 2004). Further, $\alpha 1$ subunit containing GABA receptors have been shown to be involved in addictive properties of benzodiazepines (Tan et al., 2010). GABA A receptor $\alpha$ subunit isoforms knockout mice would provide importance of each $\alpha \mathrm{GABA}_{\mathrm{A}} \mathrm{R}$ subunit isoform in carisoprodol's pharmacological effects. Also, $\alpha 1$ (L415S) knock in mutant mice will give insights into the role of the direct gating action of carisoprodol.

The ultimate goal of our study is to get critical information which will help in the development of a better muscle relaxant with reduced or no abuse potential. GABAA receptor subunit-selective compounds have been developed and studied widely. Zolpidem (brand name Ambein) is a frequently prescribed sedative for sleep disorder that is selective for $\alpha 1$ $\mathrm{GABA}_{\mathrm{A}}$ receptors (Rowlett et al., 2005). L-838417, a partial agonist at $\alpha 2, \alpha 3$ and $\alpha 5$ and antagonist at $\alpha 1 \mathrm{GABA}_{\mathrm{A}}$ was developed as an analog of benzodiazepines as a non-sedative 
anxiolytic (Rowlett et al., 2005). However, pharmacokinetic properties of this compound were not promising (Scott-Stevens et al., 2005). As mentioned previously, a drug selective primarily for $\alpha 2$-expressing $\mathrm{GABA}_{\mathrm{A}}$ receptors would likely have less abuse potential and fewer sedative effects (Rudolph and Knoflach, 2011). SL651498 is a selective agonist of $\alpha 2$ and $\alpha 3 \mathrm{GABA}_{\mathrm{A}}$ receptors and partial agonist at $\alpha 1$ and $\alpha 5 \mathrm{GABA}_{\mathrm{A}}$ receptors, which is under development as non-sedative anxiolytic and muscle relaxant (Griebel et al., 2003; Whiting, 2006). As mentioned earlier, carisoprodol was developed as an analog of meprobamte (replacing isopropyl group on one of the carbamyl nitrogens) suggesting lower abuse liabilities and better muscle relaxation properties (Nebhinani et al., 2013) but recent evidence confirms carisoprodol high abuse potential (Reeves et al., 2012). However, subunitdependence data has shown carisoprodol is more efficacious than meprobamate on $\mathrm{GABA}_{\mathrm{A}}$ receptors (Kumar et al., 2012). These finding suggest carisoprodol would be a good candidate to investigate its structure-activity relationship on $\mathrm{GABA}_{\mathrm{A}}$ receptor subunit isoforms. 


\section{REFERENCES}

Ator NA (2005) Contributions of GABAA receptor subtype selectivity to abuse liability and dependence potential of pharmacological treatments for anxiety and sleep disorders. CNS spectrums 10(1): 31-39.

Blednov YA, Mayfield RD, Belknap J and Harris RA (2012) Behavioral actions of alcohol: phenotypic relations from multivariate analysis of mutant mouse data. Genes, brain, and behavior 11(4): 424-435.

Bormann J (2000) The 'ABC' of GABA receptors. Trends in pharmacological sciences 21(1): 16-19.

Bramness JG, Skurtveit S and Morland J (2004) Impairment due to intake of carisoprodol. Drug and alcohol dependence 74(3): 311-318.

Bramness JG, Skurtveit S, Morland J and Engeland A (2007) The risk of traffic accidents after prescriptions of carisoprodol. Accident; analysis and prevention 39(5): 10501055.

DEA (2011) Schedule of controlled substances: placement of carisoprodol into Schedule IV, in 76 (Administration DE ed) pp 77330-77360, Federal Register.

Elder NC (1991) Abuse of skeletal muscle relaxants. American family physician 44(4): 1223-1226.

Gonzalez LA, Gatch MB, Taylor CM, Bell-Horner CL, Forster MJ and Dillon GH (2009) Carisoprodol-mediated modulation of GABAA receptors: in vitro and in vivo 
studies. The Journal of pharmacology and experimental therapeutics 329(2): 827837.

Griebel G, Perrault G, Simiand J, Cohen C, Granger P, Depoortere H, Francon D, Avenet P, Schoemaker H, Evanno Y, Sevrin M, George P and Scatton B (2003) SL651498, a GABAA receptor agonist with subtype-selective efficacy, as a potential treatment for generalized anxiety disorder and muscle spasms. CNS drug reviews 9(1): 3-20.

Heacock C and Bauer MS (2004) Tolerance and dependence risk with the use of carisoprodol. Am Fam Physician 69(7): 1622-1623.

Hemby SE, O'Connor J A, Acosta G, Floyd D, Anderson N, McCool BA, Friedman D and Grant KA (2006) Ethanol-induced regulation of GABA-A subunit mRNAs in prefrontal fields of cynomolgus monkeys. Alcoholism, clinical and experimental research 30(12): 1978-1985.

Hoiseth G, Karinen R, Sorlid HK and Bramness JG (2009) The effect of scheduling and withdrawal of carisoprodol on prevalence of intoxications with the drug. Basic \& clinical pharmacology \& toxicology 105(5): 345-349.

Ito T, Suzuki T, Wellman SE and Ho IK (1996) Pharmacology of barbiturate tolerance/dependence: GABAA receptors and molecular aspects. Life sciences 59(3): 169-195.

Korpi ER, Grunder G and Luddens H (2002) Drug interactions at GABA(A) receptors. Progress in neurobiology 67(2): 113-159. 
Kumar M, Nguyen JD, Gatch MB, Forster MJ and Dillon GH (2012) A comparison of molecular mechanism of carisoprodol with its metabolite meprobomate on GABAA receptors and assessment of its action on NMDA receptors, in Society for neuroscience, New Orleans, Louisina.

Kumar S, Kralic JE, O'Buckley TK, Grobin AC and Morrow AL (2003) Chronic ethanol consumption enhances internalization of alpha1 subunit-containing GABAA receptors in cerebral cortex. J Neurochem 86(3): 700-708.

Laviolette SR, Gallegos RA, Henriksen SJ and van der Kooy D (2004) Opiate state controls bi-directional reward signaling via GABAA receptors in the ventral tegmental area. Nat Neurosci 7(2): 160-169.

Liang J, Suryanarayanan A, Abriam A, Snyder B, Olsen RW and Spigelman I (2007) Mechanisms of reversible GABAA receptor plasticity after ethanol intoxication. The Journal of neuroscience : the official journal of the Society for Neuroscience 27(45): 12367-12377.

Licata SC and Rowlett JK (2008) Abuse and dependence liability of benzodiazepine-type drugs: GABA(A) receptor modulation and beyond. Pharmacology, biochemistry, and behavior 90(1): 74-89.

MacDonald RL, Rogers CJ and Twyman RE (1989) Barbiturate regulation of kinetic properties of the GABAA receptor channel of mouse spinal neurones in culture. The Journal of physiology 417: 483-500. 
Nebhinani N, Aggarwal M, Mattoo SK and Basu D (2013) Carisoprodol: an underrecognized drug of abuse in north India. General hospital psychiatry 35(1): $89-92$.

Ni K, Cary M and Zarkowski P (2007) Carisoprodol withdrawal induced delirium: A case study. Neuropsychiatric disease and treatment 3(5): 679-682.

Nie H, Rewal M, Gill TM, Ron D and Janak PH (2011) Extrasynaptic delta-containing GABAA receptors in the nucleus accumbens dorsomedial shell contribute to alcohol intake. Proceedings of the National Academy of Sciences of the United States of America 108(11): 4459-4464.

Pericic D, Strac DS, Jembrek MJ and Rajcan I (2003) Prolonged exposure to gammaaminobutyric acid up-regulates stably expressed recombinant alpha 1 beta 2 gamma 2s GABAA receptors. Eur J Pharmacol 482(1-3): 117-125.

Reeves RR, Burke RS and Kose S (2012) Carisoprodol: update on abuse potential and legal status. Southern medical journal 105(11): 619-623.

Reeves RR, Hammer JS and Pendarvis RO (2007) Is the frequency of carisoprodol withdrawal syndrome increasing? Pharmacotherapy 27(10): 1462-1466.

Rowlett JK, Platt DM, Lelas S, Atack JR and Dawson GR (2005) Different GABAA receptor subtypes mediate the anxiolytic, abuse-related, and motor effects of benzodiazepine-like drugs in primates. Proceedings of the National Academy of Sciences of the United States of America 102(3): 915-920. 
Rudolph U, Crestani F, Benke D, Brunig I, Benson JA, Fritschy JM, Martin JR, Bluethmann H and Mohler H (1999) Benzodiazepine actions mediated by specific gamma-aminobutyric acid(A) receptor subtypes. Nature 401(6755): 796-800.

Rudolph U and Knoflach F (2011) Beyond classical benzodiazepines: novel therapeutic potential of GABAA receptor subtypes. Nature reviews Drug discovery 10(9): 685697.

Scott-Stevens P, Atack JR, Sohal B and Worboys P (2005) Rodent pharmacokinetics and receptor occupancy of the GABAA receptor subtype selective benzodiazepine site ligand L-838417. Biopharmaceutics \& drug disposition 26(1): 13-20.

Shen Y, Lindemeyer AK, Spigelman I, Sieghart W, Olsen RW and Liang J (2011) Plasticity of GABAA receptors after ethanol pre-exposure in cultured hippocampal neurons. Molecular pharmacology 79(3): 432-442.

Steinbach JH and Akk G (2001) Modulation of GABA(A) receptor channel gating by pentobarbital. The Journal of physiology 537(Pt 3): 715-733.

Tan KR, Brown M, Labouebe G, Yvon C, Creton C, Fritschy JM, Rudolph U and Luscher C (2010) Neural bases for addictive properties of benzodiazepines. Nature 463(7282): 769-774.

Thompson SA, Smith MZ, Wingrove PB, Whiting PJ and Wafford KA (1999) Mutation at the putative $\mathrm{GABA}(\mathrm{A})$ ion-channel gate reveals changes in allosteric modulation. British journal of pharmacology 127(6): 1349-1358. 
van Rijnsoever C, Tauber M, Choulli MK, Keist R, Rudolph U, Mohler H, Fritschy JM and Crestani F (2004) Requirement of alpha5-GABAA receptors for the development of tolerance to the sedative action of diazepam in mice. The Journal of neuroscience : the official journal of the Society for Neuroscience 24(30): 67856790.

Wafford KA (2005) GABAA receptor subtypes: any clues to the mechanism of benzodiazepine dependence? Current opinion in pharmacology 5(1): 47-52.

Whiting PJ (2006) GABA-A receptors: a viable target for novel anxiolytics? Current opinion in pharmacology 6(1): 24-29.

Witenko C, Moorman-Li R, Motycka C, Duane K, Hincapie-Castillo J, Leonard P and Valaer C (2014) Considerations for the appropriate use of skeletal muscle relaxants for the management of acute low back pain. $P \& T:$ a peer-reviewed journal for formulary management 39(6): 427-435. 